\title{
Comprehensive academic undergraduate advising services: One university's successful model
}

Heidi B. Samuels

Follow this and additional works at: https://researchrepository.wvu.edu/etd

\section{Recommended Citation}

Samuels, Heidi B., "Comprehensive academic undergraduate advising services: One university's successful model" (2016). Graduate Theses, Dissertations, and Problem Reports. 6562.

https://researchrepository.wvu.edu/etd/6562

This Dissertation is protected by copyright and/or related rights. It has been brought to you by the The Research Repository @ WVU with permission from the rights-holder(s). You are free to use this Dissertation in any way that is permitted by the copyright and related rights legislation that applies to your use. For other uses you must obtain permission from the rights-holder(s) directly, unless additional rights are indicated by a Creative Commons license in the record and/ or on the work itself. This Dissertation has been accepted for inclusion in WVU Graduate Theses, Dissertations, and Problem Reports collection by an authorized administrator of The Research Repository @ WVU.

For more information, please contact researchrepository@mail.wvu.edu. 


\title{
COMPREHENSIVE ACADEMIC UNDERGRADUATE ADVISING SERVICES: ONE UNIVERSITY'S SUCCESSFUL MODEL
}

\author{
Heidi B. Samuels \\ Dissertation submitted to the \\ College of Education and Human Services \\ at West Virginia University \\ In partial fulfillment of the requirements for the degree of
}

Doctor of Education

in

Educational Leadership Studies
Erin McHenry-Sorber, Ph.D., Chair
Nathan Sorber, Ph.D.
Amy Kuhn, Ed.D.
Patricia Haught, Ed.D
Neal Shambaugh, Ph.D.

Department of Curriculum and Instruction

\section{Morgantown, West Virginia}

2016

Keywords: Comprehensive academic advising, student retention, student success, culture, levels of culture 


\begin{abstract}
Comprehensive Academic Advising Services: One University's Successful Model
\end{abstract}

Heidi B. Samuels

This qualitative study examined the emerging field of comprehensive academic advising programs (CAAPs). The purpose of this study is to describe a successful CAAP in-depth at one public four-year higher education institution. The research specifically investigated strategies the CAAP uses with the aim of increasing retention rates, and level of CAAP embeddedness into institutional culture. Findings indicated that the CAAP was successful at embedding the CAAP in to the surface and middle layers of the culture. Good academic advising was recognized as an essential element of the effective CAAP across participant groups. Slightly divergent results concerning other CAAP elements indicated that a committed Dean, a decentralized advising model, departmental advising, professional and/or faculty advisors, collaboration, and providing resources and rewards for advising, were considered vital elements of a CAAP to certain participant groups. Specific strategies were identified as: using an advising hold, identifying atrisk students, connecting a student to a specific school or college, focusing on career development, embedding the CAAP in to the curriculum, parallel programs, and good course scheduling. The primary conclusions and recommendations included: a centralized advising center for undecided/exploratory students only, a decentralized advising model, more professional development for faculty advisors, rewarding advising and incorporating it in to the evaluation process, collaboration across the University, and making the CAAP more visible and valued.

Keywords: Comprehensive academic advising, student retention, student success, culture, levels of culture. 


\section{Acknowledgements}

My sincerest appreciation goes to Dr. Erin McHenry-Sorber for stepping in as my committee chair. They say the third time is a charm and it certainly was when you assumed the duties as my chair. Your patience and guidance throughout the dissertation process helped make its completion possible. I would like to thank Dr. Amy Kuhn, committee member, for periodically checking in on my progress and offering her kind words of encouragement and motivation. I am grateful to Dr. Patricia Haught, Dr. Nathan Sorber, and Dr. Neal Shambaugh for persevering as my committee members throughout the process.

I would never have made it this far had it not been for my sister Barb. The two-hundred dollars you loaned me to pay my rent many years ago, during my undergraduate degree, kept me in school. Had it not been for that, my life would have taken a very different route. There are absolutely no words that can express my deepest and sincerest gratitude for that, and everything else, and there have been many things, that you have done to help me throughout my entire life!

I am grateful to my partner for her support and empathy over the years. She has tolerated my complaining and has encouraged me along the journey. 


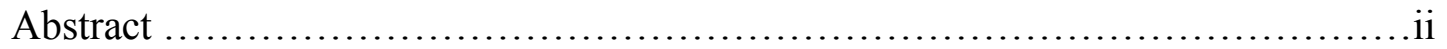

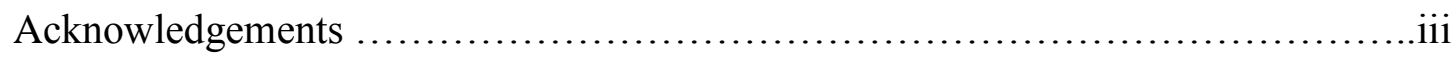

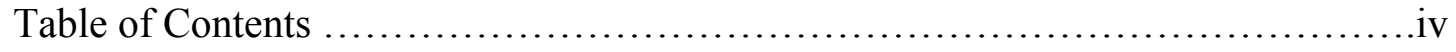

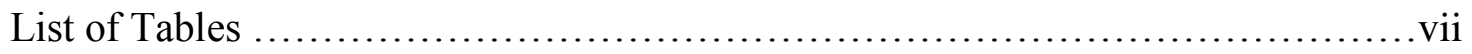

List of Figures........................................................ viii

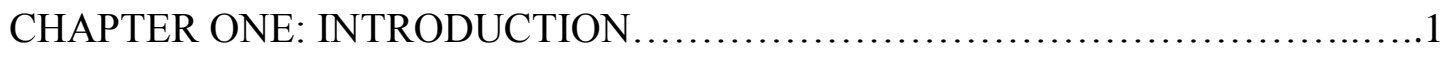

Academic Advising Models and Definitions..............................6

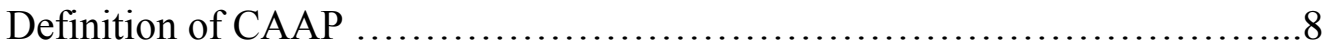

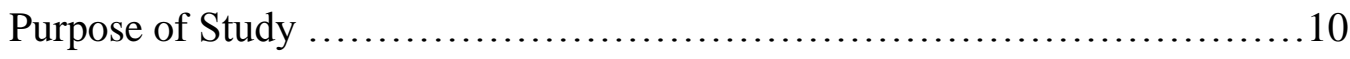

Theoretical Framework: Schein's (2010) Theory of Organizational Culture

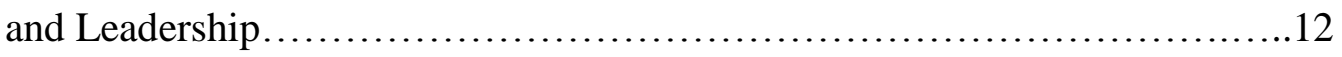

Study Significance................................................ 13

Definition of Terms.................................................... 20

CHAPTER TWO: REVIEW OF RELATED LITERATURE: ACADEMIC

ADVISING.............................................21

Academic Advising and Student Retention and Persistence.................22

Academic Advising.................................................27

Prescriptive Academic Advising...................................28

Developmental Academic Advising.............................28

Intrusive Academic Advising...................................31

Comprehensive Academic Advising Programs (CAAPs).....................33

Review of Related Literature: Organizational Culture .....................36 
Organizational Culture as the Framework for the Study........................36

Chapter Summary...............................................43

CHAPTER THREE: METHODOLOGY ....................................44

Qualitative Methodology..........................................44

Research Design.................................................46

Research Site................................................44

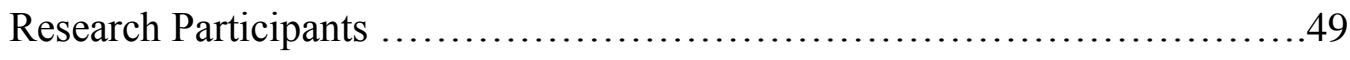

Data Collection....................................................54

Interviews....................................................54

Observation....................................................... 55

Document Analysis...............................................5 57

Data Analysis ................................................... 58

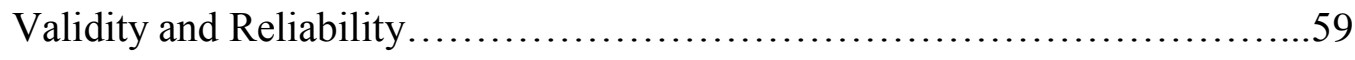

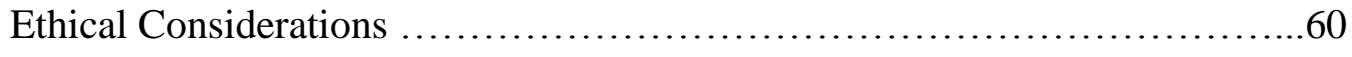

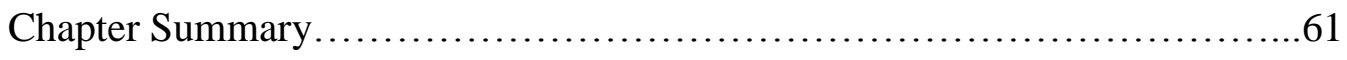

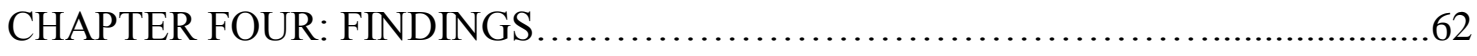

Academic Advising Organizational Structure..........................6 62

CAAP Characteristics that Influence Retention.........................64

The Benefits of Good Advising.....................................64

Other Elements of an Effective CAAP................................85

Specific Strategies Aimed at Retention.................................100

CAAP Characteristics Embedded in the Institution's Culture................124

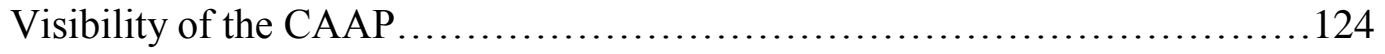


Value of the CAAP.

Summary.

CHAPTER FIVE: DISCUSSION, IMPLICATIONS, AND RECOMMENDATIONS.......143

Strategies the CAAP Uses to Increase Retention........................... 144

CAAP Embeddedness.................................................. 151

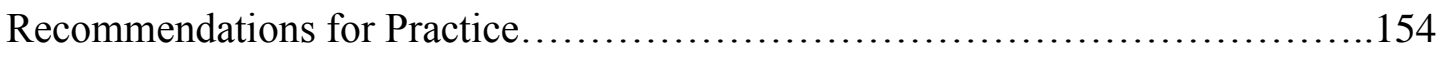

Recommendations for Future Research..................................158

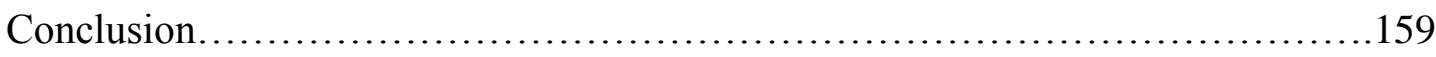

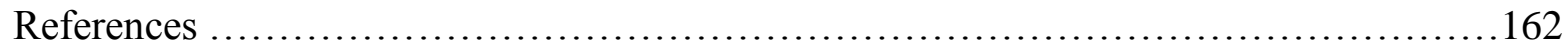

Appendix A: Interview Questions for Students for First Research Question...............179

Appendix B: Interview Questions for Students for First Research Question...............180

Appendix C: Interview Questions for Academic Advisors (professional, faculty, and

administrators) for First Research Question.................................... 181

Appendix D: Interview Questions for Academic Advisors (professional, faculty, and

administrators) for Second Research Question.................................... 182

Appendix E: Observation Protocol............................................. 183

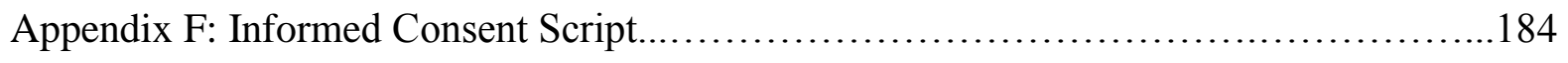

Appendix G: Informed Consent Statement of Understanding for Administrator............185

Appendix H: Informed Consent Statement of Understanding for Student..................186

Appendix I: Informed Consent Statement of Understanding for Faculty Advisor...........187

Appendix J: Informed Consent Statement of Understanding for Professional Advisor......188

Appendix K: Interview Cover Letter ........................................ 189 


\section{List of Tables}

Table Title Page

1 Participants, Academic and Professional Standing, and School Affiliation ............53

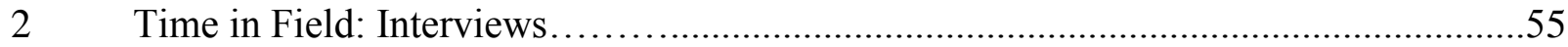

3 Time in Field: Observations............................................ 57 


\section{List of Figures}

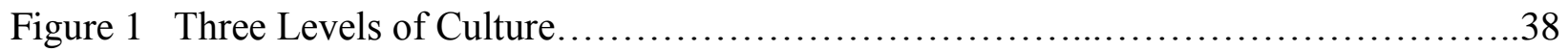

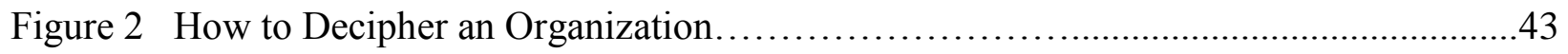

Figure 3 Fall to Fall Retention Rates 2009-2015 Research Institution......................49 


\section{Chapter One}

The importance of academic advising on student college experiences and retention has been accepted knowledge for decades. In the 1990s, Pascarella \& Terenzini (1991) and Tinto (1993) asserted that academic advising was important for student academic success and persistence. Ten years later, Light (2001) argued, "good advising may be the single most underestimated characteristic of a successful college experience" (p. 81). Pascarella \& Terenzini (2005) affirmed that "institution of all sizes and types" want to improve the quality and effectiveness of their academic advising programs (p. 403). And again, they assert that academic advising is influential for student persistence to graduation (Pascarella \& Terenzini, 2005, p. 404). In a recent study, students at four-year institutions ranked academic advising as "the most important aspect of their educational experience" (Noel-Levitz, 2009). Drake (2011) emphasized advising as the vital link in student retention, and that strong academic advising programs are indicative of an institution's commitment to student success (pp. $9 \& 12$ ). In a recent study, Braxton et al. (2014) found academic advising as a significant force for student persistence to graduation.

According to the American College Testing Program (ACT) National Collegiate Retention and Persistence to Degree Rates for 2005-2014, the average retention rate for first to second year BA/BS students at public institutions is $66.7 \%$, and research indicates that there is a correlation between quality academic advising and retention (Bahr, 2008; Braxton et al., 2014; Cuseo, 2011; Drake 2011; Fowler \& Boylan 2010; McArthur 2005; Robbins et al., 2009; Smith 2007). Drake (2011) asserts that there are three elements that are critical to student retention: connecting students to the institution through learning support systems, first-year programming, and solid academic-advising (p.9). Tinto (2006) identified five factors that contribute to retention 
that include: high expectations, advising, support, involvement, and learning (pp. 2-3). Braxton, Sullivan, and Johnson (1997), Identified 13 testable propositions in Tinto's original 1975 Interactionalist Theory of Student Departure, a sociological perspective on student persistence. An empirical analysis of Tinto's theory led Braxton et al. (2014) to develop a revised version of Tinto's theory for residential colleges, and to develop a different theory of student persistence in commuter colleges and universities. There are six factors that form the core of the revised theory of college student persistence for residential colleges and universities that include: commitment of the institution to student welfare, communal potential, institutional integrity, proactive social adjustment, psychosocial engagement, and ability to pay (Braxton et al., 2014, pp. 84-89). Braxton, Sullivan, and Johnson (1997) concluded that Tinto's 1975 theory lacked explanatory power of student persistence in commuter colleges and universities, and Braxton, Hirschy, and McClendon (2004) developed a new theory of student persistence in commuter colleges and universities. Braxton et al. (2014) identified six components to this theory of student departure in commuter institutions that include: student entry characteristics, the external environment, the campus environment, student academic and intellectual development, subsequent institutional commitment, and student persistence in the college and university (p.110). There are 11 propositions in Braxton's et al. (2014) new theory of student persistence in commuter colleges and universities, and propositions six, ten, and eleven are related to academic advising (pp. 189193).

Proposition 6: The more a student perceives that their college or university is committed to the welfare of its students, the greater the student's degree of academic and intellectual development. 
Proposition 10: The greater the degree of academic and intellectual development perceived by the student, the greater the student's degree of subsequent commitment to the commuter college or university.

$>$ Proposition 11: the greater the student's degree of subsequent institutional commitment, the greater the likelihood of the student's persistence to the commuter college or university (Braxton et al., 2014, pp. 119-120).

Student satisfaction is an integral component of academic advising and student success because it contributes to academic, personal, and professional achievement (Corts, Lounsbury, Saudargas \& Tatum, 2000, p.1) while increasing retention (Kuh et al., 2010; McArthur, 2005, p. 1). An increased amount of quality faculty-student interaction enhances students' satisfaction with their overall college experience (McArthur, 2005; Tontodonato, 2006). Contact between student and faculty through a variety of advising models ties the student to the culture of the institution and cements his or her commitment to the program, thereby increasing retention (McArthur, 2005; Smith, 2007; Tinto, 1993), and Kimball and Campbell (2013) stated that "advisors can help create the conditions necessary for students to achieve success" (p. 3). Pascarella and Terenzini (2005) found that "research consistently indicates that academic advising can play a role in students' decision to persist and in their chances of graduating" ( $p$. 404), and faculty advisors have been the main source of academic advising at institutions of higher education for many years (Beatty, 1991/2009; Brubacher \& Rudy, 1997; Cohen, 1998; Cook, 2009; Crookston, 1972; Lucas, 2006; Thelin \& Hirschy, 2009).

Faculty advisors continue to be a source of academic advising at many institutions of higher education (Gordon, Habley, Grites \& Associates, 2008; Self, 2013), but presently, academia additionally uses advising centers, also known as a centralized academic advising. 
According to the ACT's Sixth Survey of Academic Advising, the use of centralized advising increased from 14\% of reporting institutions in 1979, to 73\% in 2003 (Habley, 2004). Currently, there are three type of advising systems used by institutions of higher education that include: centralized, decentralized, and shared (King, 2005; Pardee, 2004). The 2011 NACADA National Survey of Academic Advising found that faculty advisors and full-time professional advisors are used most often for counseling services, but more than half of the surveyed institutions indicated the use of the shared advising. In the shared advising model, faculty are advisors for all students, and the advising center is used by students (King, 2005).

Whether it be advising centers, or faculty advising, the approaches to, and styles of, advising vary and include: the developmental model, the counseling liaison model and the engagement model which are basically derived from the developmental model, intrusive academic advising, the prescriptive model, appreciative academic advising, the educativeadvising model, and the learning partnerships model (Drake, Jordon \& Miller, 2013). The advising structure, and advising models, have a crucial role in determining the effectiveness of academic advising for impacting student persistence (Braxton et al., 2014; Cuseo, 2011; Gordon et al., 2008; O'Keeffe, 2013; Pascarella and Terenzini, 2005), and academic advising programs subsequently became a component of retention programs, first-year programs, and at-risk student programs (Braxton, Hirschy, \& McClendon, 2004; Sams, Brown, Hussey, \& Leonard, 2003; Chiteng Kot, 2014; Cuseo, 2011; Wirth \& Padilla, 2008; Trotter \& Roberts, 2006; Turner \& Thompson, 2014).

So, there are many academic advising models or styles, the structure of academic advising varies according to institution, and academic advising is used for many student retention initiatives. There is evidence of the value of academic advising for student retention, and every 
institution of higher education uses some type of academic advising. (Pascarella \& Terenzini, 2005). Based on the above referenced extensive use of academic advising, and the value of academic advising for student persistence, it appears there is a need to address comprehensive academic advising programs. A comprehensive academic advising program (CAAP) addresses academic advising models or styles, the structure of academic advising as it varies according to institution, and the use and purpose of academic advising for individual institutions.

The institution in this single case study has instituted a CAAP that uses a decentralized advising structure wherein each college or school uses professional advisors, faculty advisors, or a hybrid structure which used both professional and faculty advisors. The advising models employed by advisors vary according to the needs of the student, but professional and faculty advisors espouse the predominant use of the developmental advising model. The reality is that the prescriptive model of academic advising is extensively used. Students were not dissatisfied with the prescriptive approach, in fact, they were more satisfied when their advisor was knowledgeable about degree requirements and available courses, and were able to advise them to ensure a timely graduation. However, students in this case study were more satisfied with the advising they received from their degree conferring school or college which most often used faculty advisors.

The professional and faculty advisors have a somewhat divergent experience for providing academic advising and other CAAP services. The faculty advisors are in a much better position to use the developmental model. Due to advising caseloads and time constraints, the professional advisors are hindered in their goal to use the developmental model of academic advising. Professional advisors that are assigned to the undecided and provisionally admitted students. They are taxed with the responsibility of knowing the admission requirements and 
curriculums for multiple majors, and their caseloads tend to be much higher than the caseloads of faculty advisors. Faculty advisors are advising in their major which affords them an advantage of being experts in advising for their curriculum, graduation requirements, and professional career opportunities.

\section{Academic Advising Models and Definitions}

There are numerous models for academic advising. The most commonly used models are: developmental, intrusive, prescriptive, appreciative, engagement, counseling-liaison, educativeadvising, and learning partnerships. Each model is characterized by certain strengths, with some researchers preferencing the developmental style of advising (Drake, 2011; Hale, Graham, and Johnson, 2009; McArthur, 2005) while others suggest an integrated model of academic advising that incorporates multiple models (Cuseo 2011; Freeman, 2008; Harrison, 2009; Heisserer \& Parette, 2002; Johnson \& Morgan, 2005). Other researchers, however tend to prefer the developmental style of academic advising. Regardless of the advising model used, any definition of good advising "must be guided by a clear vision of what good or quality advising actually isbecause if we cannot define it, we cannot recognize it when we see it, nor can we assess it or improve it" (Cuseo, 2011, p.13).

Students define a quality advisor as one that serves as a mentor, and is available and accessible, knowledgeable and helpful, and personable and approachable (Cuseo, 2011; Harrison, 2009). These traits are elements in the developmental style of advising. A study conducted by McArthur (2005) found positive student satisfaction, and an improved retention rate, for students that were involved with a quality academic advising program that specifically utilized developmental advising techniques. The developmental style of advising involved a variety of roles and responsibilities for the advisor that include: open and active communication, 
promoting the values and benefits of higher education, coordinator of degree completion, being caring and concerned, and providing referrals (pp. 4-14). According to Hale, Graham, and Johnson (2009), students with developmental advisors, and a preference for developmental advising, had significantly higher satisfaction than students with prescriptive advisors and a preference for developmental advising. Jordan (2000) provides a thorough and succinct definition of developmental advising as " relating to students in a holistic way, integrating academic, career, and personal goals into advisement, rather than focus only on academic or career goals" (p. 4)

One definition of quality academic advising incorporates the student perspective and asserts that there are three key advisor roles or functions that include an advisor as: a humanizing agent, a counseling/mentoring agent, and as an educational/instructional agent. The humanizing agent function involves the building of a personal relationship with the student. The advisor will know details of the students' life such as interests and values. The counseling and mentoring agent functions requires that the advisor to: act as a guide in navigating institutional policies and procedures, act as a referral agent and direct the student to proper services and programs, act as a confidante, and act as a student advocate. The educational/instructional agent function involves equipping the student with specific strategies for success and promote experiential learning that takes place outside of the classroom (Cuseo, 2011, pp. 14-15).

Drake (2011) asserts that quality academic advising is about keeping students connected to the institution and building a relationship with them through out-of-class interactions and mentoring (p.8). “Good academic advising” helps students' value learning and the process of learning. It helps students develop decision-making skills, develop thinking and learning skills, 
evaluate events, and learn to make good choices (Drake, 2011, p. 10). The University of Wisconsin-Oshkosh defines good academic advising as:

The dynamic relationship between a student and adviser. At the center is a shared responsibility for a coherent education plan that incorporates personal, social, academic, and career considerations. Advising focuses on helping students identify life goals, acquire skills and attitudes that promote intellectual growth, and become academically successful. (Freeman, 2008)

\section{Definition of a Comprehensive Academic Advising Program}

Multiple Models and delivery methods of academic advising are used across higher education institutions. All provide some type of academic advising (Cook, 2009), and while extensive research has been published on academic advising in general (Drake, 2011; Freeman, 2008; Gordon et al., 2008; Johnson \& Morgan, 2005; Kuh,2008; Melander, 2005), the literature is limited regarding comprehensive academic advising programs (CAAPs), but comprehensive academic advising is an emerging field (Braxton et al., 2014; Chiteng Kot, 2014; Cuseo, 2011; Drake et al., 2013; Gordon et al., 2008; Tinto, 1993; Wallace, 2011).

A review of the research identifies at least six necessary elements to create a viable and effective CAAP. Common elements to a viable and effective CAAP include: a designated and recognized advising unit that receives administrative support in terms of finances and resources (Freeman, 2008; Robbins et al., 2009; Johnson \& Morgan, 2005), accessibility to all students (Trotter \& Roberts, 2006), training, leadership support, and professional development for advisers (Gordon et al., 2008; Cuseo, 2011; Kuh, 2008), assessment of the advising program (Corts et al., 2000; Freeman, 2008; Gordon et al., 2008, Light, 2001; Melander, 2005), incorporation of advising into the organizational culture (Braxton et al., 2014; Kuh et al., 2010; 
Ahren, Ryan, Niskode',-Dossett, 2009), use of several advising theories, models, and techniques (Gordon et al., 2008; Harrison, 2009), and a focus on the first academic year (Braxton et al., 2014; Kuh et al., 2010; Tinto, 1993; Trotter \& Roberts, 2006). Based on the previously referenced research, the definition on a CAAP is: A dedicated academic department, supported through leadership and resources, focused on providing an integrated array of effective advising services and resources, through a corroborated institution-wide effort, that assists the student in persistence to graduation. Research indicates that student retention can be improved through academic advising, and a CAAP is an effective method of providing the advising component of higher education (Bahr, 2008; Braxton et al., 2014; Cuseo, 2011; Drake, 2011; Gerdes \& Mallinckrodt, 1994; McArthur, 2005; Smith, 2007).

Much research is available that focuses on the individual elements of a CAAP, but very little research has focused on academic advising as a comprehensive program that includes all elements of a CAAP. The earliest reference to an institutional comprehensive academic advising program I found in the literature was a quantitative study conducted by Patrick, Furlow and Donovan (1988) that focused on first-year academically underprepared students. Eastern Michigan University implemented an institution-wide comprehensive academic advising program, but the quantitative research about that program was inconclusive (Erwin, 1997). Johnson and Morgan (2005) addressed comprehensive advising but referred to it as a "multifaceted" advising plan that focused on a specific program. Their quantitative study offered promising results for using a comprehensive academic advising program. Freeman (2008) identified, through a quantitative analysis, the successes and challenges of implementing a comprehensive academic advising program at the University of Wisconsin-Oshkosh. A comprehensive academic advising program was identified as one component of a comprehensive 
support program at CUNY in a quantitative study conducted by Kolenovic, Linderman, and Karp (2013) that yielded positive results associated with academic advising and student retention, if the intrusive advising model was used on a continuous basis to graduation. A mixed methods study was conducted by Sams, Brown, Hussey\& Leonard (2003) that focused on an academic advising program for first-year students. They identified the program as a systematic program as opposed to a comprehensive program, but elements of a CAAP were identified in that systematic program. The field of research is even more limited for qualitative studies on comprehensive academic advising programs. Qualitative studies that evaluate advising as a program component (Corts, Lounsbury, Saudargas, \& Tatum, 2000; Battin, 2014) or as a collateral assignment for librarians (Flatley, Weber, Czerny, \& Pham, 2013) exist, but are not directly related to comprehensive academic advising programs. This study adds to the emerging body of literature on CAAPs through an in-depth case study of one successful program as evidenced by relatively high retention rates at the institution and existence of all or most elements of effective CAAPs identified in the literature. It contributes to our understanding of the processes by which a successful CAAP operates within the context of its organizational/institutional culture

\section{Purpose of the Study}

The purpose of this study is to describe a successful CAAP in-depth at one public fouryear degree-granting higher education institution. A successful CAAP is one that can be identified as a contributing factor for improving student retention rates, or a contributing factor for maintaining an already established high level of student retention (Braxton et al., 2014; Bahr, 2008; Drake 2011; Cuseo, 2011; Fowler \& Boylan 2010; McArthur 2005; Robbins et al., 2009; Smith 2007). The national average retention rate for first to second year BA/BS students at public institutions from 2004 to 2014 is $66.7 \%$ (ACT, 2015), and for the purposes of this study, 
successful retention rates should be well above that national average. The National Center for Education Statistics (NCES) identified a 2012 range for BA/BS student retention at four-year public institutions as "61 percent at the least selective institutions (those with open admissions) to 95 percent at the most selective institutions (those where less than 25 percent of students are accepted)" (U.S. Department of Education, 2014). Therefore, successful or high retention rates are established at rates at or above $75 \%$ which depicts the mid-range point as established by NCES (U.S. Department of Education, 2014).

Specifically, this study answers the following questions:

1. What are the strategies the CAAP uses with the aim of increasing retention rates?

2. What are the ways in which the institution has embedded the CAAP into its institutional culture?

This study is warranted because research that has studied an exemplary CAAP in-depth is limited. The CAAP at the institution for this study is considered a viable and effective CAAP according to the definition, in that, the CAAP meets most of the identified CAAP criteria established as necessary according to the research (Cuseo, 2011; Freeman, 2008; Gordon et al., 2008; Harrison, 2009; Johnson \& Morgan, 2005; Kuh, 2008; Kuh et al., 2010; Robbins et al., 2009; Tinto, 1993; Trotter \& Roberts, 2006). The criteria this CAAP does meet is dedicated academic advising departments for colleges and schools that utilize the professional or hybrid model supported through leadership and resources (Freeman, 2008; Robbins et al., 2009; Johnson \& Morgan, 2005). The data indicates that this CAAP lacks leadership, support and resources for faculty advisors. The following criteria is also met by the institution under study: providing an array of advising services to all students, assisting students to graduation, using several advising models, and focusing on the first academic year. The data indicates that this 
CAAP moderately met several criteria of an exemplary CAAP according to the individual elements as determined in the research. First, assessment of the advising program (Corts et al., 2000; Freeman, 2008; Gordon et al., 2008, Light, 2001; Melander, 2005), was not effectively incorporated in to the CAAP. Secondly, this CAAP was only moderately embedded in the second level of the institution's culture, and did not meet the third and deepest level of the culture (Schein, 2010). Thirdly, an adequate reward system for advising and an evaluation system for faculty advisors were only moderately embedded in the CAAP (Braxton et al., 2014;

Brown, 2008; Cuseo, 2011; Drake et al., 2013; Gordon et al., 2008; King, 2008; O’Keeffe, 2013; Pascarella and Terenzini, 2005; Self, 2008).

This study contributes to the literature by: giving university leaders an informed view of how to effectively approach student retention and improve graduation rates; informing policy makers so that resources may be directed effectively; and assisting higher education researchers in understanding the phenomenon of a CAAP. A better understanding of a CAAP will inform higher education researchers about the positive impact a CAAP can have for institutions of higher education. The contributions to practice include: providing faculty and academic advisory personnel with relevant information to guide their interactions with students, thereby, enhancing the student advising experience and hopefully impacting student success in a positive manner; and informing students and student's families so they can make an informed decision when selecting and higher education institution.

\section{Theoretical Framework: Schein's (2010) Theory of Organizational Culture and Leadership}

Institutions that have been successful at integrating an effective CAAP to enhance retention efforts have focused on making advising an integral component of the institutional 
culture (Ahren, Ryan, Niskodé-Dossett, 2009; Kuh et al., 2010). One must first understand the institution's culture in order to integrate academic advising, and in order to understand the culture, one must first define it. Schein's (2010) theory of organizational culture and leadership states:

The culture of a group can now be defined as a pattern of shared basic assumptions learned by a group as it solved its problems of external adaption and internal integration, which has worked well enough to be considered valid and, therefore, to be taught to new members as the correct way to perceive, think, and feel in relation to those problems. (Schein, 2010, p. 18)

Schein (2010) views culture as the foundation of social order. It is through culture that we learn the rules for our actions. The leaders of institutions and organizations ultimately establish culture. Initiating change within an organization affects the culture and vice versa. Institutions that have effectively established a CAAP have affected the institution's culture and understanding the culture can affect a more efficient and expeditious change (pp. 3-9).

Nitecki (2011) asserts that "organizational theory is crucial to understanding the potential of the program to retain students" (p. 100). In response to shrinking student retention rates, institutions have begun to focus on academic advising as a feasible intervention for addressing the problem of student retention (Corts et al., 2000; Erwin, 1997; Freeman, 2008; Johnson \& Morgan, 2005; Kadar, 2001; McArthur, 2005; Trotter \& Roberts, 2006). Some of those institutions have embedded the value of academic advising in to their culture (Erwin, 1997; Johnson \& Morgan, 2005; Melander, 2005; Nutt, 2013). Embedding a value or focus in to the culture must be completed at three levels: artifacts, espoused beliefs and values, and basic underlying assumptions (Schein, 2010, p. 24). 


\section{Study Significance}

On February 24, 2009, President Barack Obama, in his Address to the Joint Session of Congress, stated that:

In a global economy where the most valuable skill you can sell is your knowledge, a good education is no longer just a pathway to opportunity - it is a pre-requisite. Right now, three-quarters of the fastest-growing occupations require more than a high school diploma. And yet, just over half of our citizens have that level of education. We have one of the highest high school dropout rates of any industrialized nation. And half of the students who begin college never finish. This is a prescription for economic decline, because we know the countries that out-teach us today will out-compete us tomorrow. President Obama (2009) established an education goal that "by 2020, America will once again have the highest proportion of college graduates in the world" (http://www.whitehouse.gov/the_press_office/Remarks-of-President-Barack-Obama-Address-toJoint-Session-of-Congress/) In response to meeting this goal, Martha Kanter, Under Secretary of Education, recognized several challenges to that college completion goal that include the following: "only half of all undergraduates complete a college degree in six years, $38 \%$ of all U.S. Students take a remedial course in their first or second more than $60 \%$ of jobs will require a postsecondary education, and the U.S. is $9^{\text {th }}$ in the world in college attainment" (Kanter, Ochoa, Nassif, \& Chong, 2011, p. 9). A major goal for meeting President Obama’s 2020 college completion goal is to increase college degree attainment rates from $40 \%$ to $60 \%$ (Kanter et al., 2011, p. 12). Providing more access to college appears to be one of this administration's solutions for improving degree completion rates. Ochoa (2011) did address retention rates in 
meeting President Obama's 2020 college completion goal but did not specifically address academic advising (Kanter et al., 2011).

A failure to prioritize academic advising in higher education and a general lack of understanding of the significance of a comprehensive academic advising program contribute to the problem of low student retention rates (Cuseo, 2011; Kuh, Kinzie, Schuh, Whitt, and associates, 2010; McArthur, 2005; Robbins et al., 2009). Yet, the literature indicates that there is a connection between effective academic advising and student retention completion (Cuseo, 2011; Freeman, 2008; Kuh, 2008; McArthur, 2005; Robbins et al., 2007; Smith, 2007; Tinto, 2006).

Higher education institutions need to develop strategic plans to address student retention (Braxton, 2008; Cuseo, 2011; Fowler \& Boylan, 2010; Tinto, 2006). Braxton (2008) Suggests that institutions need to develop " a scholarship of practice that embraces two purposes: the improvement of administrative practice in higher education and the development of a knowledge base befitting of administrative work" (p. 101). Institutions should use replicative and applicatory knowledge in professional practice. Replicative knowledge is used to guide routines of professional practice, and applicatory knowledge involves the use of technical knowledge to guide institutional action (Braxton, 2008, p. 101). Recommendations for institutional policy and practice to increase student retention should be designed from research findings (Braxton, 2008; Tinto 2006, p. 110). Cuseo (2011) identified several reasons why higher education institutions should focus on retention: economic implications, to promote learning and development, and student retention is an assessment outcome. Economic implications address the fiscal solvency of institutions, the financial solvency of graduates, and the ability of the U.S to compete in a global market. 
University leaders need an informed view of how to effectively approach student retention and improve graduation rates (Braxton, 2008; Cuseo, 2011; Elkins, Braxton, \& James, 2000; Erwin, 1997; Johnson \& Morgan, 2005; Kuh et al., 2010; McArthur, 2005; Tinto, 1993:2006). According to the ACT (2015) National Collegiate Retention and Persistence to Degree Rates for 2005-2014, the average retention rate for first to second year BA/BS students at public institutions is $66.7 \%$, and that indicates that four-year public institutions are losing, on average, 33 out of 100 students from the first to second year of college. That loss equates to serious financial repercussions for the institution. In the data from the National Association for College Admission Counseling, the average expenditure for recruiting a student was around $\$ 714$ which is over $\$ 2$ million each year for institutions with approximately 2800 students (Heldman, 2008, p.6). This information indicates the importance of retaining students, and research asserts that academic advising has an important role in retention efforts. Evidence supports a positive relationship between academic advising, student support services, and retention (Cuseo; \& Gansemer-Topf \& Schuh, 2006; Drake, 2011; Robbins et al., 2009; Smith, 2007; Tinto, 1993 \&2006;). This literature informs institutional leaders about fiscal repercussions of low student retention rates, and other literature informs institutional leaders about the components and areas of focus to improve student retention (Braxton et al., 2004; Braxton \& Lee, 2005; Braxton et al., 2014; Kuh et al., 2010; Pascarella \& Terenzini, 2005; Tinto, 1993). This study will address the missing dimension of specific comprehensive academic advising strategies employed by a specific institution that contribute to high retention rates, which are retention rates above 75\% (ACT 2015; U.S. Department of Education, 2014).

Policy makers will be informed about the relationship between academic advising and student retention. An informed policy maker will be more competent in allocating resources and 
assessing student outcomes (Wirth \& Padilla, 2008). Harney (2008) stated that "many colleges are also under ever-increasing scrutiny by politicians, legislators, and the community to become more accountable in achieving successful outcomes" (as cited in Gordon et al., p. 426). Retention has a crucial role in achieving those student outcomes. All stakeholders have the overarching objective to ensure that students get a quality education and achieve the educational goal of degree completion (Vowell, 2008 in Gordon et al., p. 426). One of the most pressing policies regarding higher education is apparent in President Obama's 2020 strategic vision and goals for higher education. This initiative calls for an increase of college graduates from the expected two million to 10 million (Kanter et al., 2011). Students must be retained in order to accomplish that goal. Four methods have been proposed by the U.S. Department of Education to improve retention and graduation rates: shorter time to degree, program consolidation, streamlined business operations, and greater economies of scale for business functions. (Kanter et al., 2011). For policy makers, this study addresses the missing dimension of using the specific strategies employed by a successful CAAPs to improve student retention thereby, contributing to the initiative of increasing graduation rates.

Higher education researchers will be informed about the relationship between a CAAP and student retention. Much research is available concerning the vital components of a CAAP based on an examination of the individual elements (Ahren, Ryan, Niskode',-Dossett, 2009; Brown, 2008 in Gordon et al.; Cuseo in Gordon et al.; Erwin, 1997; Freeman, 2008; Hagen \& Jordan, 2008 in Gordon et al.; Harrison, 2009; Johnson \& Morgan, 2005; Kuh 2005; Kuh et al., 2010; Robbins et al., 2009; Tinto, 1993; Trotter \& Roberts, 2006). Researchers are beginning to examine the elements of effective academic advising programs (Erwin, 1997; Freeman, 2008; Johnson \& Morgan, 2005; Trotter \& Roberts, 2006). Providing additional research into the 
comprehensive academic advising program concept and practice will bring those individual elements together to enhance advising practices and impact student retention.

Many Institutions of higher education use a faculty advising system, have an advising center or program, or use a combination of both (Gordon et al., 2008, pp. 243-248). Regardless of the system, faculty and advisory personnel have an important role in advising students, fulfilling the mission of the institution, and retaining students to improve graduation rates (Cuseo, 2011; Drake, 2011; Gordon et al., 2008; McArthur, 2005). For these reasons, it is imperative to apprise faculty and academic advisory personnel with relevant information to guide their interactions with students, thereby, enhancing the student advising experience and hopefully impacting student success in a positive manner. Research indicates that academic advising impacts student retention (Cuseo, 2011; Drake, 2011; Gordon et al., 2008; McArthur, 2005; Smith, 2007), but many faculty members know little about advising practices or theories prior to arriving on their respective campuses (Brown \& Ward, 2007).

Higher education is an expensive investment. The costs of attending four-year public institution continue to rise on a yearly basis. In 2011-12, public four-year colleges experienced an $8.3 \%$ increase for tuition and fees for in-state students and a 5.7\% increase for out-of-state students (College Board Advocacy \& Policy Center, 2011). The average yearly costs for tuition and fees for in-state students at four-year public schools average approximately $\$ 17,000$ which equates to $\$ 68,000$ if the student completes his or her degree in four years (College Board Advocacy \& Policy Center, 2011). Students and parents are concerned about paying for college, and the debt accrued as a result of attending college (Pryor, Hurtado, DeAngelo, Palucki-Blake, \&Tran, 2011; Youngmi \& Sherraden, 2014). This study will provide information about retention, and the academic advising program aspect of student services. This study will specifically 
identify the impact that academic advising has on student retention. Braxton et al. (2014) stated that "academic advising fosters the academic and intellectual development of students given its emphasis on the realization of the academic potential of the students" (p. 189). In a new theory of student persistence in commuter colleges and universities, Braxton et al. (2014) identified academic advising as a relevant source of influence for academic and intellectual development. In the Braxton et al. revision of Tinto's theory for residential colleges and universities, academic advising was again identified as an antecedent contributing to student persistence. Specifically, academic advising is associated with propositions two, seven, and eight of the revision to Tinto's theory. Those propositions state the following:

2: the more a student perceives that the institution is committed to the welfare of its students, the greater the student's level of social integration 7: the greater the student's degree of social integration, the greater their level of subsequent commitment to the college or university 8: the greater the level of subsequent commitment to the institution, the more likely the student persists in college.

Academic advising performed well communicates to students that their college or university values them and has an abiding concern for their growth and development. Accordingly, satisfaction with academic advising may positively affect the student perceptions of the commitment of their college or university to the welfare of its students. (Braxton et al., 2014, p. 102). This study will expand on specific areas in propositions in the Braxton's et al. new theory and revised theory of student persistence as it relates to academic advising, thereby, assisting students and student's families in making a decision of where to attend college. Despite the costs 
of higher education, students and student's families realize the benefits of higher education (Abel \& Deitz, 2014). It not simply a costly burden to attend college, it is an investment in future earnings, and a necessity in obtaining viable employment (Abel \& Deitz, 2014; Baum, Ma \& Payea, 2010).

\section{Definition of Terms}

Comprehensive academic advising: A dedicated academic department, supported through leadership and resources, focused on providing an integrated array of effective advising services and resources, through a corroborated institution-wide effort, that assists the student in persistence to graduation.

Student retention: Continuous Fall-to-Fall enrollment by a student at any institution.

Student success: Progress toward graduation or actually graduating college (Wirth \& Padilla, 2008, p. 688).

$>$ Culture: The culture of a group can now be defined as a pattern of shared basic assumptions learned by a group as it solved its problems of external adaption and internal integration, which has worked well enough to be considered valid and, therefore, to be taught to new members as the correct way to perceive, think, and feel in relation to those problems (Schein, 2010, p. 18).

Levels of culture: The levels as explained in Schein's theory of organizational culture and leadership: artifacts, espoused beliefs and values, and basic underlying assumptions (Schein, 2010, p. 24). 


\section{Chapter Two}

\section{Review of Related Literature: Academic Advising}

Chapter two provides a comprehensive review of existing literature related to relevant elements of a CAAP. It begins with an examination of the role of academic advising with student retention and persistence to graduation (Braxton, Hirschy, \& McClendon, 2004; Brown, Hussey, \& Leonard, 2003; Chiteng Kot, 2014; Cuseo, 2011; Sams, Wirth \& Padilla, 2008; Trotter \& Roberts, 2006; Turner \& Thompson, 2014). The types and frequency of advisor and student interactions through specific academic advising models are discussed as avenues for promoting student satisfaction which may lead to student retention and persistence (Kuh et al., 2010; MacArthur, 2005; Pascarella and Terenzini, 1991:2005; Tinto, 1987). Specific advising models that are discussed include: prescriptive, developmental, and intrusive/proactive (Crookston, 1972; Glennen, 1975; Heisserer \& Parette, 2002; Varney, 2007). Three derivative academic advising models that emerged from the developmental model are examined: the engagement model (Yarbrough, 2002), the counseling liaison model (Drake et al., 2013; Kadar, 2001), and the advising-as-educating model (Drake 2013; Melander, 2005). The appreciative advising model, which is closely associated with the intrusive model for advising, is also discussed. Studies from Eastern Michigan University (EMU), The University of Wisconsin (UW)-Oshkosh, and a single case study by Nitecki (2011) conducted at Fairview Community College is reviewed. Lastly, Schein's (2010) theory of organizational culture and leadership is presented as the theoretical framework for the study. 


\section{Academic Advising and Student Retention and Persistence}

Historically, academic ability was considered the primary predicator for student retention (Fowler and Boylan, 2010; Kuh et al., 2010; Pascarella and Terenzini, 1991: 2005; Smith, 2007) but, Gerdes and Mallinckrodt (1994) expanded predictors of student retention to include institutional commitment, social adjustment, personal or emotional problems, and pre-enrollment expectations about anticipated adjustment. Informal, quality faculty contact was identified as an integral component of the social adjustment of students and was identified as a factor for student retention (p.281). Pascarella and Terenzini (2005) identified more frequent and meaningful interaction between faculty members and students as having a statistically positive relationship with student persistence (p.403). O'Keeffe (2013) found that the development of a positive student and faculty relationship creates a sense of belonging to the institution, and that sense of belonging is recognized as a "critical factor for determining student retention" (p.605). Braxton, Doyle, Hartley, Hirschy, Jones, McLendon, (2014) recognized the importance of faculty and student involvement for student persistence. Turner and Thompson's (2014) qualitative research on student retention found support for an association between social integration, academic advising and student retention, which would serve to support Braxton's empirical research concerning the relationship between social integration contributing to institutional commitment, in turn, improving student persistence. Turner and Thompson assert (2014) that "the instructorstudent relationship was a critical component to the social and academic integration process," and that good academic advising involves a collaborative relationship between student and advisor (p. 101). Academic advising connects the student to the institution and that connection contributes to student success and persistence (Turner and Thompson, p. 101). 
Faculty academic advising can be a source of that informal and formal contact for students. Specifically, the intrusive advising model provides a suggested format for increasing informal student and faculty contact (Fowler and Boylan, 2010; Smith, 2007). This is relevant because the majority of students use faculty advisors (Miville \& Sedlacek, 1995, p.23). Of particular importance for examining a successful CAAP, is examining the positive effect the use of advising approaches has on retention rates (Gordon et al., 2008; Cuseo, 2011). Pascarella and Terenzini (2005) stated that "research consistently indicates that academic advising can play a role in students' decisions to persist and in their chances of graduating” (p. 404).

Although the faculty academic advisor's first priority is directed toward teaching, he or she is in a unique position to increase contact with advisees and exhibit a personal interest in their success (Kuh et al., 2010; McArthur, 2005; Pascarella and Terenzini, 1991; 2005). An increase in student-faculty interaction appeared to increase student satisfaction, and deepen the students' social integration in the higher education institution (Kuh et al., 2010; MacArthur, 2005; Pascarella and Terenzini, 1991:2005; Tinto, 1987). Both student satisfaction and social integration in the institution have been linked to student persistence (Bahr, 2008; Braxton et al., 2014; Fowler and Boylan, 2010; Harrison, 2009; Johnson \& Morgan, 2005; Kadar, 2001; Kuh et al., 2010; Melander, 2005; Pascarella and Terenzini, 1991: 2005; Pizzolato, 2008; Smith, 2007; Tinto, 1987; Titley \& Titley, 1982; Truschel, 2008). The results of a study completed by Tontodonato (2006) found that students are more satisfied with their academic experience when they have met with a department advisor (p. 169). Student-faculty interaction extends beyond the classroom or formal advising position. Student-faculty interaction includes simply talking to an instructor outside of class, assisting faculty with class preparation or a research project, and being a guest in the instructor's home (Tontodonato, 2006, p. 166). 
Braxton et al. (2014) further expand, beyond academic ability, the predictors of college persistence, and they differentiated between student persistence in residential colleges and universities, and student persistence in commuter colleges and universities. This differentiation was a result of an empirical assessment of the validity of Tinto's Interactionalist theory of student departure (Braxton, Sullivan, \& Johnson, 1997; Braxton, Hirschy, \& McClendon, 2004; Braxton \& Lee, 2005; Braxton et al., 2014). Braxton, Sullivan, and Johnson (1997) identified 13 testable propositions in Tinto's theory. The research results regarding the empirical internal validity of Tinto's paradigmatic theory indicated partial support for Tinto's theory for residential colleges and universities and that Tinto's theory "lacks explanatory power in commuter institutional settings" (Braxton et al., 2014). The results of the empirical assessment led to a revision of Tinto's paradigmatic theory of college student persistence in residential institutions, and a new theory of student persistence in commuter colleges and universities (Braxton et al. 2004:2014; Braxton \& Lee, 2005).

In regard to college student persistence in residential institutions, Tinto's propositions nine and 13 were empirically supported, and were used as the foundation for the revised theory of college student persistence for residential college and universities (Braxton et al., 2004). Tinto's propositions nine and 13, as identified by Braxton et al. (2014), are as follows:

9: The greater the degree of social integration, the greater the level of commitment to the institution

13: the greater the commitment to institution, the greater the likelihood of persistence

"Social integration plays a pivotal role in the formulations of this revised theory" (Braxton et al. 2014). The revised theory for student persistence in residential colleges and universities focuses 
on six factors that impact social integration. The six antecedents include: commitment of the institution to student welfare, communal potential, institutional integrity, proactive social adjustment, psychosocial engagement, and ability to pay (Braxton et al., 2014, pp. 85-92). These six antecedents led to the eight propositions of the revised theory for student persistence in residential colleges and universities. Three of the eight propositions, two, seven, and eight, directly relate to academic advising and are identified as follows:

$>$ 2: the more a student perceives that the institution is committed to the welfare of its students, the greater the student's level of social integration

$>$ 7: the greater the student's degree of social integration, the greater their level of subsequent commitment to the college or university

$>$ 8: the greater the level of subsequent commitment to the institution, the more likely the student persists in college (Braxton et al., 2014, p. 95).

In regard to student persistence in commuter colleges and universities, Braxton, Hirschy, and McClendon (2004) developed a new theory that applies to two-year and four-year commuter institutions. There are six components to the new theory of student departure in commuter institutions that include: student entry characteristics, the external environment, the campus environment, student academic and intellectual development, subsequent institutional commitment, and student persistence in the college and university (Braxton et al., 2014, p.110). These components guided the development of the 11 propositions for the new theory of student departure in commuter institutions, and four of those propositions; six, eight, ten, and 11, are linked to academic advising and are identified as follows: 
Proposition 6: The more a student perceives that their college or university is committed to the welfare of its students, the greater the student's degree of academic and intellectual development.

$>$ Proposition 8: the more a student perceives that their college or university is committed to the welfare of its students, the greater the student's degree of subsequent commitment to their college or university"

Proposition 10: The greater the degree of academic and intellectual development perceived by the student, the greater the student's degree of subsequent commitment to the commuter college or university.

Proposition 11: the greater the student's degree of subsequent institutional commitment, the greater the likelihood of the student's persistence in a commuter college or university (Braxton et al. 2014, pp. 119-120).

Academic advising is identified as a force that may influence the propositions in the revised theory and new theory of student persistence as developed by Braxton et al. (2004: 2014). Specifically, through a logical progression of Braxton's revised theory of student persistence in residential higher education institutions, one can posit that academic advising positively affects student persistence (Braxton et al., 1997, 2004, 2005, \& 2014).

Academic advising performed well communicates to students that their college or university values them and has an abiding concern for their growth and development. Accordingly, satisfaction with academic advising may positively affect the student perceptions of the commitment of their college or university to the welfare of its students. (Braxton et al., 2014, p. 102). 
The more a student perceives this commitment to their welfare, the greater the social integration, in turn, the greater commitment to the institution, and lastly the more likely the student will persist to graduation (Braxton et al., 2014, p. 95).

Additionally, academic advising has a role in student persistence in Braxton's new theory of college student persistence in commuter colleges. The greater the emphasis on academic advising as a strong component of the academic environment, the greater the student perception that the institution is committed to the welfare of students (Braxton et al., 2014, p.193). Academic advising is also a source of influence on academic and intellectual development, which is a significant component of Braxton's new theory of student persistence in commuter institutions of higher education (Braxton et al., 2004: 2014). Braxton et al. (2014) stated that “... academic advising fosters the academic and intellectual development of students given its emphasis on the realization of the academic potential of students" (p.189). Propositions six and ten are linked to academic and intellectual development which are, in turn, linked to proposition 11 which is related to student commitment to the institution and persistence. Specifically, through a logical progression of Braxton's new theory of student persistence in commuter higher education institutions, one can posit that academic advising positively affects student persistence because academic advising positively affects the students' perception that their college or university is committed to the welfare. The greater this perception, the greater the student's degree of academic and intellectual development and subsequent commitment to their college or university, in turn, leading to a greater likelihood of the student's persistence to graduation.

\section{Academic advising}

A vast amount of literature is available for review in developing a plan for academic advising. Many advising frameworks have been developed and should be addressed when 
deriving a plan to develop, assess, and manage a CAAP (Drake, Jordan \& Miller, 2013; Gordon et al., 2008; Grites and Gordon, 2000; Hale et al., 2009). Primarily, there are three essential models of academic advising that include the prescriptive model (Crookston, 1972), the developmental model (Crookston, 1972; Grites, 2013), and the intrusive/proactive model (Earl, 1988; Glennen, 1975; Varney, 2007, 2012 \& 2013). The following sections will provide an explanation of some of the various models of academic advising currently used in higher education.

Prescriptive academic advising. Prior to the mid-1970s, prescriptive advising was the most widely used model (Crookston 1972) and continues to be widely used among faculty advisors (Creamer \& Scott, 2000; Robbins, 2012). This model of academic advising is characterized by an authoritarian relationship between student and advisor. The student asks for advice and the advisor provides a solution to the problem/issue. Advising sessions are structured and are primarily concerned with course selection and degree completion (Crookston 1972, pp. 1-2). Many faculty view advising as peripheral to teaching as the central mission; it is an added burden, an extracurricular, nonteaching activity (Crookston, 1972, p.5). Crookston (1972) reported negative aspects of this advising model, particularly the lack of student involvement in the decision-making process. However, many students have reaped the advantages of prescriptive advising such as degree completion planning, and knowledge of institutional processes, and may have no further need for any other type of advising (Heisserer \& Parette, 2002).

Developmental academic advising. Burns B. Crookston could be considered the father of the developmental academic advising model. Crookston (1972) stated that "developmental counseling or advising is concerned not only with a specific personal or vocational decision but 
also with facilitating the student's rational processes, environmental and interpersonal interactions, behavioral awareness, and problem-solving, decision-making, and evaluation skills" (p.1). A survey conducted by Hale, Graham, and Johnson (2009), found that students were more satisfied with academic advising when their advisor used a developmental style of advising (p.315). "Developmental advising is based on a personal relationship between the student and advisor, and integrates academic, career, and personal goals ... rather than having a sole focus on academic goals" (Hale, et al., 2009, p.315). Faculty should get to know the student. Involvement with the student can assist the faculty member in identifying any issues or problems the student may be experiencing and develop intervention action items to remedy the problem (Trotter and Roberts, 2006, p.382).

Developmental academic advising recognizes the importance of interactions between the student and the campus environment; it focuses on the whole person; and, it works with the student at that person's own life stage of development (Hale et al., 2009; King, 2005). Developmental advising is premised on the idea that the student and advisor work together in a collaborative effort to resolve issues and develop goals and plans (Drake et al., 2013; Grites and Gordon, 2000). Three derivative models of academic advising that emerged from developmental advising include the engagement model (Yarbrough, 2002), the counseling liaison model (Drake et al., 2013; Kadar, 2001), and the advising-as-educating model (Drake 2013; Melander, 2005).

Yarbrough (2002) found that the engagement model is an effective method used in academic advising. "The engagement model approach to academic advising allows both students and advisers to develop a heightened personal investment in the success of the individual academic program, the supporting academic unit, and the overall university" (p. 61). 
The counseling liaison model of academic advising is used interchangeably with developmental academic advising. This process is geared toward guiding the student. The advisor assists the student with taking ownership of their decisions and behavior. It uses a goalcentered approach to advising (Kadar, 2001). Kadar (2001) asserts that advising using the counseling liaison model "encompasses more than academic issues; it also includes assessing the students' personal concerns and their adjustment and integration into campus life" (p.175). This holistic view of academic advising is also present in the advising-as-educating model.

According to Drake (2013) Crookston (1972) coined the metaphor of advising-asteaching. The National Academic Advising Association (NACADA) supports the reconceptualization of advising as teaching (Ryan, 1992). Advising-as-educating is a framework suggested by Melander (2005). This framework defines advising as the personalized interface between the institution and the student with the goal of helping the students with his/her educational options while helping him/her to navigate the educational environment (Melander, 2005, pp. 85-86). Melander furthers his argument in favor of educative-advising by offering seven guiding principles for developing an advising system. Those principles include: guidance and support for the student, reflection of the institution's mission and goals, developing the student toward self-advising and self-direction, providing access to knowledge content, the advisor should act as a teacher; the student is the learner and educational planner, and quality control (pp. 88-89). Hurt (2007) went as far to say that "In every way that matters, advising is a form of teaching" (p. 36). Just as the developmental model utilizes a holistic approach to advising (Crookston, 1972), Drake (2013) posits that good teachers and advisors should take a holistic view of the learning process (p. 21). The developmental model of academic advising has served as the impetus for the development of the engagement model, the counseling liaison 
model, and the advising -as-educating model. The major tenet of the developmental model is a relationship with the student that addresses the student's overall needs (Crookston, 1972), which has also been used as a major tenet for the development of the intrusive model of academic advising (Earl, 1988; Glennan, 1975; Varney, 2013).

Intrusive academic advising. Intrusive academic advising is defined by the work of Robert Glennen (1975) and according to Varney (2013), intrusive advising is now known as proactive advising due to the "somewhat negative connotation associated with the word intrusive" (p. 139). The name change was a result of the efforts of NACADA (Varney, 2012). According to Earl (1988), the intrusive academic advising model is defined as:

A deliberate, structured student intervention at the first indication of academic difficulty in order to motivate a student to seek help. By this definition, intrusive advising utilizes the systematic skills of prescriptive advising while helping to solve the major problem of developmental advising, which is a student's reluctance to self-refer (p.1).

Intrusive advising involves intentional contact with students with the goal of developing a caring and beneficial relationship that leads to increased academic motivation and persistence (Varney, 2013).

Research literature on student retention suggests that contact with a significant person within an institution of higher education is a crucial factor in a student's decision to remain in college (Heisserer \& Parette, 2002). Heisserer and Parette (2002) contend that that "the only variable that has a direct effect on student persistence is the quality of a relationship with a significant member of the college community" (p. 72). A second goal of intrusive academic advising is to enhance student motivation and responsible decision making through the use of intervention techniques. Intrusive advising is proactive and utilizes programs that incorporate 
intervention strategies such as mandating advising contacts. Other strategies include: proactively monitoring grades, implementing an early warning system for students that includes grades, attendance, and classroom behavior. Varney (2007) suggests taking any and all opportunities to connect with students e.g., in hallways, on campus, or at Wal-Mart@ (p.1). She posits that involvement in student activities is an excellent way to bond with students, as is having lunch or taking breaks where students typically "hang out". Finally, Varney suggests that faculty, staff, and students should be encouraged to network with each other (Varney, 2007). An academic advising framework that can be closely associated with the intrusive/proactive academic advising model is appreciative advising.

Appreciative advising is a "positive and action-oriented" approach to academic advising (Truschel, 2008, p. 9). Like intrusive advising, appreciative advising involves structured student intervention to motivate students and assist with developing problem-solving skills to achieve the goal of student persistence (Bloom, Hutson, \& He, 2013; Truschel, 2013). Bloom, Hutson, \& Ye He (2008) stated that "it entails the intentional and collaborative practice of asking positive, open-ended questions that help students optimize their educational experiences and achieve their dreams, goals, and potentials" (as cited in Bloom et al., 2013). There is a significant amount of commitment on the part of both student and academic advisor. In Truschel's study (2008), the participants and advisors met three times during the first five weeks of the semester, and the majority of the at-risk student participants provided positive feedback regarding the intensity and intrusiveness of the appreciative advising approach (Truschel, 2008).

There are six phases involved with implementing the appreciative advising framework that include: disarm, discover, dream, design, deliver, and don't settle. The phases do not necessarily have to be completed in sequential order, nor do they all have to be completed in one 
advising session (Bloom et al., 2013). The discover, dream, design, and deliver phases are based on the 4-D cycle of organizational development theory. The 4-D model was initially researched for its impact on at-risk students but, this is an advising approach that could be adapted to any student issue that arose in academic advising (Truschel, 2008, pp.7-8).

I have addressed seven distinct models for academic advising that include: the prescriptive model; the developmental model; the engagement model, the counseling liaison model, and the educative-advising model which are basically derived from the developmental model; intrusive academic advising, and the appreciative advising model which is closely related to the intrusive model. "While the ideal model or theory may not exist... models and theories serve to promote and facilitate an effective advising program” (Harrison, 2009, p. 230). Still, other academicians agree that the advisor-advisee relationship is the key element for effective academic advising (Bahr, 2008; Harrison, 2009; Johnson \& Morgan, 2005; Melander, 2005; Pizzolato, 2008; Tinto, 1987; and Truschel, 2008). Perhaps, more importantly, than the relationship in and of itself, is the type of relationship between the advisor-advisee. For academic advising to be effective, the advisor needs to connect to the student and build a rapport that influences and empowers the decision making ability of the student (Kadar, 2001; Pizzolato, 2008; Titley \& Titley, 1982). There are numerous models for academic advising, and academic advising is the foundation for a comprehensive academic advising program.

\section{Comprehensive academic advising programs (CAAPs)}

There are a few studies that investigate comprehensive program approaches to academic advising. Programs currently researched in existing literature include those located at Eastern Michigan University, University of Wisconsin-Oshkosh, and Fairview Community College. Eastern Michigan University (EMU) began using a comprehensive advising and career planning 
system that incorporated an intrusive advising approach to improve student retention, created a university wide retention council, and incorporated new intervention programs, but did not build an assessment component to their new plan (Erwin, 1997, pp. 89-92 \&95). The impact of EMUs program on retention has yet to be ascertained. The University of Wisconsin (UW)-Oshkosh, in 2002, established an advising center, hired a director, created an Advisory Council for Comprehensive Academic Advising, established a mission and goals, and expanded academic advising staff. The developmental advising model is the approach used by The University of Wisconsin-Oshkosh and an assessment component was incorporated into their new plan. As a result of the new advising initiative, student satisfaction has improved over the past five years (Freeman, 2008, pp. 1-4). Although improved student retention was not addressed as a goal of UW-Oshkosh's new advising initiative, student satisfaction did increase and student satisfaction is linked to student persistence (Braxton et al., 2014; Cuseo, 2011; Fowler \& Boylan, 2010; Kuh et al., 2010; Pascarella \& Terenzini, 2005; Tinto, 1993). The psychology department at the University of Wisconsin overhauled their advising program by designating an advising coordinator, initiating a freshman outreach program to initiate student contact with advisors and form relationships, made administrative changes, and began using mass advising. Assessment results indicated a 70\% satisfaction rate of good or high quality with academic advising within that department (Johnson \& Morgan, 2005, pp. 15-16).

A practical example of improving student retention and success is exemplified in a case study conducted by Nitecki (2011) that addresses the impact culture has for improving an academic program and subsequently increasing student success, through a comprehensive approach. Nitecki conducted a single case study at Fairview Community College and used a systems-based organizational theory, Bronfenbrenner's bio-ecological model, to explore the 
impact that sub-organizations, that develop their own practices, values, norms, and social relationships, have on increasing student retention (Nitecki, 2011, p.100). The focus was on the mezzo-level as identified in Bronfenbrenner's bio-ecological theory, and in this case, it was the academic program. The institution was identified as the macro level, and the individual was identified as the micro level (Nitecki, 2011, p.101).

Two academic programs at the institution were identified as having higher-than-average student success based on graduation and transfer rates. These two programs were succeeding at an institution that had the lowest success in that state. What made these programs unique was the fact that they assumed the duties that were usually undertaken at the macro level such as academic advising and activities programming (Nitecki, 2011, p.102). Nitecki found that for one of the two successful programs "advisement duties were vital for maintaining student retention" (Nitecki, 2011, p.109). The underlying success of the second successful program was attributed to creating a program identity and culture, and specifically building a culture of family. That program also assumed the academic advising duties (Nitecki, 2011, p.113). Overall, findings indicated that in these two successful programs the common elements for their success was caring faculty, students with strengths, conducting their own advising, individual faculty working with students, faculty involvement on college-wide committees, internships, job readiness experiences, and a unique program culture (Nitecki, 2011, p.114). "Although they worked in very different cultures, students and faculty members in both programs reported that the culture of the program was the factor that kept students involved" (Nitecki, 2011, p.114).

Common elements across these programs include: a dedicated academic department, supported through leadership and resources, focused on providing an integrated array of effective advising services and resources, through a corroborated institution-wide effort, that assists the 
student in persistence to graduation (Braxton et al., 2004:2014; Cuseo, 2011; Drake, 2011; Drake et al., 2013; Gordon et al., 2008; Johnson \& Morgan, 2005; Kuh et al., 2010; Pascarella \& Terenzini, 2005; Tinto, 1975:1995; Turner \& Thompson, 2014). The success of a CAAP is essentially determined by how effectively the program is embedded in the culture of the institution (Erwin, 1997; Freeman, 2008).

\section{Review of Related Literature: Organizational Culture}

This section provides synthesis and analysis of Schein's theory of organizational culture and leadership to provide a deeper understanding of the role culture plays in establishing an effective comprehensive academic advising program. Schein's theory is used as the framework for incorporating a successful CAAP into an institution. (Schein, 2010).

\section{Organizational Culture as the Framework for the Study}

Edgar H. Schein provides the theoretical framework for this study. His theory on organizational culture and leadership provides the foundation I use to examine how culture affects a successful CAAP. Research indicates that institutions that have been successful in instituting a successful CAAP have embedded the CAAP into their culture (Erwin, 1997; Freeman, 2008).

Schein (2010) defines culture as:

a pattern of shared basic assumptions learned by a group as it solves its problems of external adaptation and internal integration, which has worked well enough to be considered valid and, therefore, to be taught to new members as the correct way to perceive, think, and feel in relation to those problems" (p. 18).

Culture is deep, pervasive, complex, patterned, and morally neutral (Schein, 2010, p. 53). In essence, culture is about learning. The content of learning is broken down by two sets of 
problems: survival, growth, and adaptation to the environment; and internal integration that permits daily functioning and the ability to adapt and learn (Schein, 2010, p. 18). These issues directly relate to the student retention problems currently being experienced in higher education (Corts, Lounsbury, Saudargas, \& Tatum, 2000; Cuseo, 2011; Elkins, Braxton, \& James, 2000; Erwin, 1997; Johnson \& Morgan, 2005; Kuh et al., 2010). Institutions are plagued by low student retention rates and degree completion rates, (ACT, 2015). Researchers suggest that institutions of higher education adapt its focus of success by expanding its efforts on enrollment to include student retention in order for the institution to survive and experience growth (Braxton, 2008; Cuseo, 2011; Elkins, Braxton, \& James, 2000; Erwin, 1997; Johnson \& Morgan, 2005; Kuh et al., 2010; McArthur, 2005; Tinto, 1993; Tinto, 2006). The learning experienced in the institution's culture can been accomplished at the three cultural levels identified by Schein (2010, pp. 23-32).

Schein examines organization culture through three levels. A level is "the degree to which the cultural phenomenon is visible to the observer" (Schein, 2010, p. 23). Levels range from "very tangible" to the "deeply embedded." The very tangible level includes everything one can see and feel at the institution. The deeply embedded level includes the unconscious and basic assumptions, made by the people within the institutions, which guide their behavior (Schein, 2010, pp. $23 \& 28)$. These basic assumptions are taken for granted by the group and are nonnegotiable. In between levels are espoused values, beliefs, norms, and rules of behavior. There are three levels of organizational culture that include artifacts, espoused beliefs and values, and basic underlying assumptions (Schein, 2010, p. 23-32).

Figure 1

Three Levels of Culture 


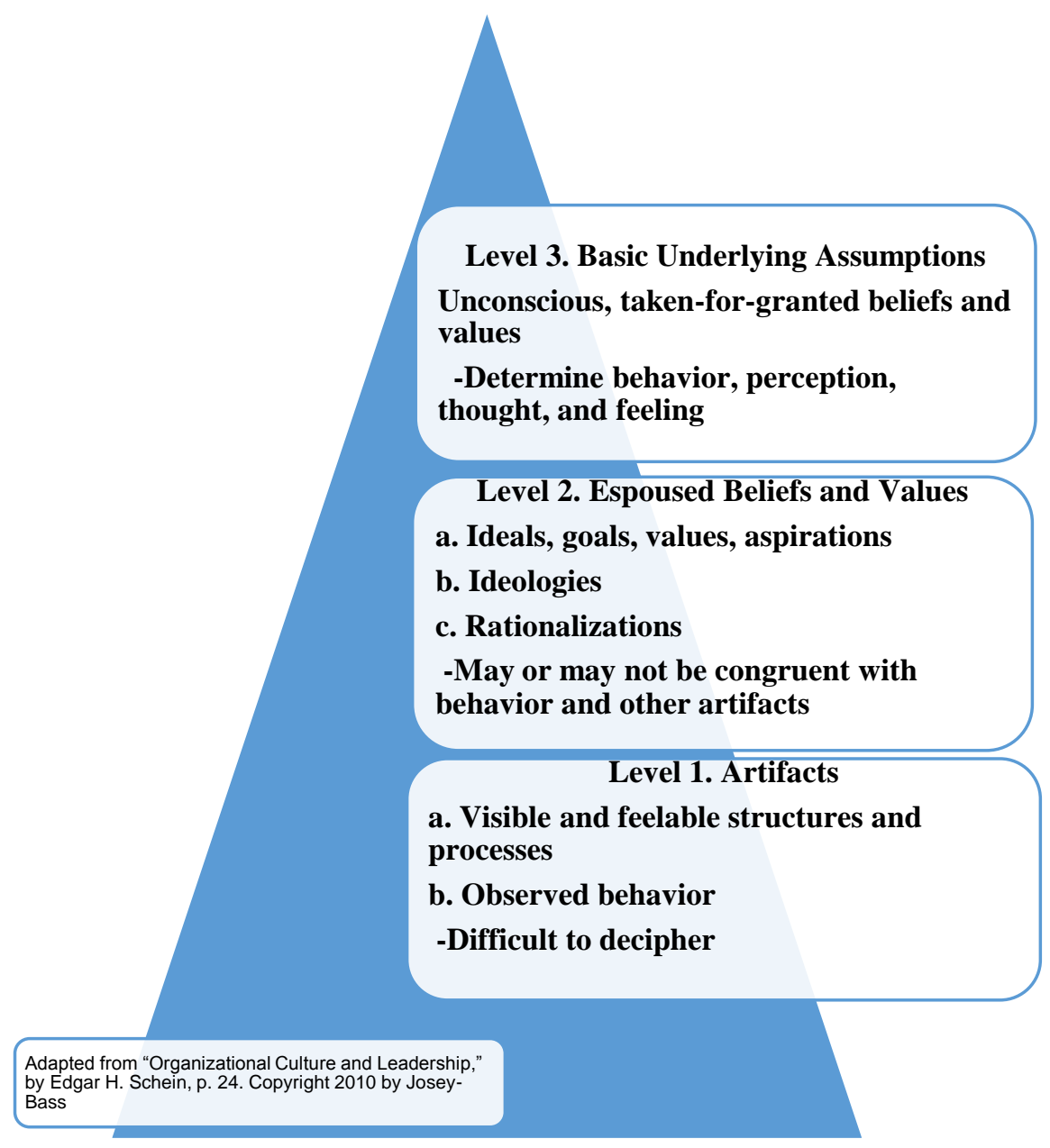

Artifacts appear on the surface of the organization and are the first level of the organizational culture. They include all the phenomena that you would see, hear, and feel. They are easy to observe, very difficult to decipher, and include the visible products of the group. The meanings of artifacts come to light through talking to insiders, and that is the best way to learn the espoused values, norms, and rules of an organization (Schein, 2010, pp. 23-25). People's reactions are artifacts of the culture (Schein, 2010, p. 45).

Espoused beliefs and values comprise the second level of organizational culture, including the ideas, goals, values, aspirations, and ideologies of the organization. They are found in slogans, parables, and assumptions (Schein, 2010, p. 38). Asking about observed behavior or 
artifacts will elicit espoused beliefs and values. Espoused beliefs and values explain the rationalizations of the culture. These rationalizations may or may not be congruent with behavior and other artifacts. Rationalizations work in a distinct and succinct manner (Schein, 2010, p. 48), for example, if the leader convinces the group to act on his or her behalf, the solution works, and the group has a shared perception of that success, then the perceived value gradually becomes transformed: first into a shared value or belief and ultimately into a shared assumption. The solution, however, must continue to work reliably to become a shared assumption (Schein, 2010, p. 49). Beliefs and values must reach a consensus through social validation to be transformed into a shared assumption. Social validation indicates that certain beliefs and values are confirmed only by the shared social experience of the group (Schein, 2010, p. 26). The second level, espoused beliefs and values, can be analyzed by discriminating carefully among the beliefs and values that are:

1. Congruent with the underlying assumptions that guide performance.

2. Part of the ideology or philosophy of the organization.

3. Rationalizations or only aspirations of the future.

Espoused beliefs and values often leave large areas of behavior unexplained which is why basic underlying assumptions must be examined more fully (Schein, 2010, pp. 23-32).

Basic underlying assumptions are the third level of organizational culture and are unconscious, taken-for-granted beliefs and values that determine behavior, perception, thought and feeling (Schein, 2010, p. 24). Basic assumptions have a high degree of group consensus due to the repeated success of solutions to problems, issues, or situations. This notion was previously described. Basic assumptions are non-confrontable, non-debatable, and difficult to change (Schein, 2010, p. 28). Basic assumptions are the mechanisms by which behavior is guided. They 
dictate, to the organization's members, how to think, feel, and act (Schein, 2010, p. 28). Herein lies the importance of culture in truly embedding a CAAP into an organization. Schein's theory supports the idea that all members of the organization perceive the CAAP as important and relevant enough to guide how they think and feel about academic advising and, in turn, change their behavior to incorporate academic advising into their daily activities. This process entails a new level of learning. (Schein, 2010, pp. 29-32). Learning can create a sense of anxiety because basic assumptions have to be challenged. That challenge will release anxiety and defensiveness (Schein, 2010, p. 29). "The essence of culture lies in the basic underlying assumptions, and after you understand those, you can easily understand the other more surface levels and deal appropriately with them" (Schein, 2010, p. 32). Understanding culture can be furthered through an examination of macrocultures, subcultures, and microcultures.

Subcultures share many of the assumptions of the organization, and assumptions beyond the institution. Shared assumptions that create subcultures most often form around the functional units of the organization. They are derived from common origins, common educational backgrounds, occupational requirements, and shared contact (Schein, 2010, p. 57). There are three generic subcultures that occur in every organization. They must be identified and managed to minimize destructive conflict like political interdepartmental fights, power maneuvers, or personality conflicts. Many problems can be attributed to a lack of alignment between these subcultures (Schein, 2010, p. 57).

The first subculture is the operator subculture. It is based on human interaction. Members learn that high levels of communication, trust, and teamwork are essential to getting the work done. The cultural assumptions that evolve around how work is actually done are often the most important parts of organizational culture (Schein, 2010, p. 58-59). To fully understand how 
things work in a total organization you observe the informal culture, which is the interplay of the various operator subcultures (Schein, 2010, p. 60).

The second subculture is the engineering/design subculture. The basic assumptions within the engineering/design subculture are derived from their occupational community and education. They have knowledge of how technology is to be used. A key theme is that they try to design humans out of the system (Schein, 2010, p. 60-61).

The third subculture is the executive subculture. Top managers share a similar environment with similar concerns. Their worldview is built around the necessity to maintain the financial health of the organization. Members are fed by preoccupations of boards, investors, and the capital market. People become seen as "human resources", and relationships are viewed as a means to an end of efficiency and productivity (Schein, 2010, pp. 59-65). These subcultures are highlighted because many organizational problems are a result of the misalignment of the subcultures (Schein, 2010, p. 65).

All groups face two types of archetypical problems: survival in and adaptation to the external environment; and integration of the internal processes to ensure the capacity to continue to survive and adapt (Schein, 2010, p. 18). Group culture determines how the group will address these problems. "The shared patterns of thought, belief, feelings, and values that result from shared experience and common learning-results in the pattern of shared assumptions that is referred to as the "culture" of the group (Schein, 2010, p. 73). "The shared assumptions about "who we are' become an important element of the organization's culture and limits the strategic options" (Schein, 2010, p. 77). Achieving goals is an element of group dynamics, and how a group achieves those goals is influenced by the organizational culture. Common language and shared assumptions are cultural elements that influence group dynamics (Schein, 2010, p. 78). 
"Only as consensus is reached on matters leading to solutions that work repeatedly, can we begin to think of the goals of an organization as potential cultural elements" (Schein, 2010, p. 80). Schein (2010) stated that "culture is a multidimensional, multifaceted phenomenon, not easily reduced to a few major dimensions" (p. 91). Because culture is multidimensional, using typologies help build an understanding of how culture works in the organization.

Typologies tend to group different phenomena. It should be noted that typologies are abstract and should not be solely relied upon to evaluate the culture in an organization (Schein, 2020, p. 157). Typologies can be used to form a basic understanding of culture. They can shed light on peer relationships and authority. "They simplify thinking and provide useful categories for sorting out the complexities we must deal with when we confront organizational realities" (Schein, 2010, p. 175). Numerous organizational culture typologies exist. Some typologies rely on grouping specific dimensions of the organization while others group organizations by types (Schein, 2010, pp. 163-174). The examination of cultural typologies is only one of several reasons why culture is examined and evaluated, and Schein identifies four specific reasons to decipher organizational culture.

The first reason to decipher organizational culture is based on pure academic research. The second reason is to assess the culture to determine if that is an appropriate place for employment. Third, understanding the culture can lead to organizational improvement, and fourth, to facilitate changes or begin a new program (Schein, 2010, pp. 177-178). The purpose for deciphering culture for the purposes of this research is a combination of academic research and to provide the impetus whereby organizations can use this information to change and improve existing academic advising programs, subsequently resulting in improved student retention rates. The cultural audit should begin at the artifact level and precede through the 
espoused beliefs and values, and basic underlying assumptions levels (Schein, 2010, pp. 178179). Figure 2 depicts the recommended steps for analyzing organizational culture. In essence, the organization should be observed and followed by inquiry. There is no standardized method for conducting a cultural audit but the suggestions by Schein are a good start.

Figure 2

How to Decipher an Organization from the Outside

1. Visit and observe.

2. Identify artifacts and processes that puzzle you.

3. Ask insiders why things are done that way.

4. Identify espoused values that appeal to you, and ask how they are implemented in the Organization.

5. Look for inconsistencies, and ask about them.

6. Figure out from all you have heard what deeper assumptions actually determine the behavior you observe.

Adapted from "Organizational Culture and Leadership," by Edgar H. Schein, p. 178. Copyright 2010 by Josey-Bass

\section{Chapter Summary}

In this chapter, research related to academic advising and student retention, and organizational culture was reviewed and related to instituting a CAAP or revising an existing 
academic advising program. A void in the research was discovered as related to the depth of various cultural manifestations. In fact, Martin (2002) stated that "most cultural researchers do not address the issue of depth when they define culture..." (p. 60). Schein is one of those rare researchers that addresses the issue of depth and does so through addressing the three levels of organizational culture that include artifacts, espoused beliefs and values, and basic underlying assumptions. Nitecki's research, is an excellent illustration of the impact academic advising and organizational culture has on an institution. Nitecki's research was based on a single case study and the research used in this literature review used case studies to illustrate certain theoretical assumptions, therefore, I believe that using a single case study for my research is an appropriate methodology. The next chapter will discuss the methodology I will use for the case study. 


\section{Chapter Three}

\section{Methodology}

\section{Qualitative Methodology}

The purpose of this study is to describe a successful CAAP in-depth at one public fouryear degree-granting higher education institution. A successful CAAP is one that can be identified as a contributing factor for improving student retention rates, or a contributing factor for maintaining an already established high level of student retention (Braxton et al., 2014; Bahr, 2008; Drake 2011; Cuseo, 2011; Fowler \& Boylan 2010; McArthur 2005; Robbins et al., 2009; Smith 2007). Specifically, this study answers the following questions:

1. What are the strategies the CAAP uses with the aim of increasing retention rates?

2. What are the ways in which the institution has embedded the CAAP into its institutional culture?

A qualitative research design best enabled me to answer the research questions. Stake (2010) posits that qualitative methods are used to "study how human things work in particular situations” (p. 14). Qualitative research focuses understanding through inquiry of "people's words, actions, and records" (Maykut \& Morehouse, 1994, p.17). It is characterized by rich description within a "complex" context (Stake, 2010, p. 31). Merriam (2009) suggests the foci of qualitative research are meaning and understanding through an inductive and comparative process in a flexible design. Further, she notes the utility of a purposeful sample in answering qualitative research questions, as well as the importance of time spent in the field.

Yin (2016) identifies five features of qualitative research that serve as the basic tenets of qualitative research. Yin's (2016) first tenet is “studying the meaning of people's lives, under real-word conditions" (p. 9). Observing actions and interactions in a real-world setting allows 
people to say what they want to say, and act how they want to act, with minimal intrusions from artificial research procedures (Yin, 2016, p. 9). My research focuses on the real-world condition of academic advising situations and activities. The second tenet involves "representing the views and perspectives of the people (participants)" (Yin, 2016, p. 9). The themes that emerge, as a result of qualitative research, are free from the researcher's values or preconceptions (Yin, 2016, p. 9). My research includes a diverse array of participants that include faculty advisers, general advisers, students, parents, and administrators. This participant diversity allows for a wide range of views and perspectives. The third tenet indicates that qualitative research involves "covering the contextual conditions within which people live" (Yin, 2016, p. 9). In the case of my research, the contextual condition involves work and school. According to the fourth tenet, qualitative research contributes "insights into existing or emerging concepts that may help to explain human social behavior" (Yin, 2016, p. 9). New concepts may emerge that can attempt to explain social processes (Yin, 2016), and my research explains the strategies the CAAP uses with the aim of increasing retention rates, and the ways in which the institution has embedded the CAAP into its institutional culture. The fifth and final tenet involves the use of "multiple sources of evidence rather than relying on a single source alone" (Yin, 2016, p. 9). This tenet is suited for my study because I include observations, interviews, and the review of documents.

\section{Research Design}

This research employs a single case design. According to Merriam (2009), "a case study is an in-depth description and analysis of a bounded system" (p. 40). The bounded system is a "single entity," in fact, "the single most defining characteristic of case study research lies in delimiting the object of the study" (Merriam, 2009, p. 40). The object of study is the "case," and 
the case is the unit of analysis. This research is focused on the CAAP within the bounds of one university.

A case study is particularistic, descriptive, and heuristic (Merriam, 2009). A case study design is appropriate when the investigator has "little control over the events, and when the focus of the research is on a contemporary phenomenon within a real-life context" (Yin, 2014, pp. 2). This study focuses on the phenomenon of a CAAP within the context of the institutional organization which is a public, four year or above, university with very high research activity. The ways in which the institution has embedded the CAAP into its institutional culture are examined through the lens of Schein's theory, the theoretical framework of the study, which identifies three levels of organizational culture that include artifacts, espoused beliefs and values, and basic underlying assumptions which relate specifically to people's words, actions, and records (Schein, 2010). As the CAAP and university are inextricably connected, a case study provides the most appropriate research design.

This is a representative, or a typical case design, as identified by Yin (2014). In my study, the institution of higher education, represents the "typical case" of a university with successful or relatively high student retention rates. Successful or high retention rates were previously identified as rates at or above $75 \%$ which depicts the mid-range point for BA/BS student retention at four-year public institutions as established by NCES (U.S. Department of Education, 2014).

\section{Research Site}

The University has a Carnegie classification as a public land-grant, four year or above, university with the highest research activity (http://classifications.carnegiefoundation.org/lookup). This University was established in the 
mid-1800s. It has several regional campuses and one main campus, which is the focus of this research. The main campus has approximately 15 colleges and schools and over 300 majors, about one-third of which are undergraduate majors. The most popular majors are business, management, marketing, engineering, multi/interdisciplinary studies, and social sciences. The institution offers undergraduate, graduate, doctoral, and professional degrees. In 2015, there were almost 30,000 students enrolled at the main campus, with slightly more females than males, and about half of its population was comprised of state residents. There were just under 2000 fulltime instructional faculty and approximately two-thirds of classes were taught by these full-time faculty. This institution is considered to be a "selective" school and accepts approximately $85 \%$ of applicants. There are a variety of student services and activities offered that include student organizations, recreational facilities, and a renowned athletic program. The location offers students access to many cultural activities.

Academic advising is provided through the degree conferring schools or colleges, and through the University College which houses the centralized advising unit that provides advising to undecided or provisionally admitted students. Students that are directly admitted to a degree program are assigned an advisor at that school or college. The institution uses a decentralized organization model for advising; thus, each school or college uses one of three distinct academic advising models: faculty advisors, professional advisors, or a hybrid model which uses faculty and professional models. The school or college to which a student is admitted determines the type of advisor to which he or she is assigned.

This institution is currently ranked with the highest retention rate for a public institution in its state. It has ranked above the national average for retention for the last seven years. Retention rates range from just over $80 \%$ in 2009 to just under 80\% in 2015 (NCES, 2016). This 
rate is based on Fall to Fall enrollment at the same institution. Figure 3.1 provides a graphic depiction of retention rates.

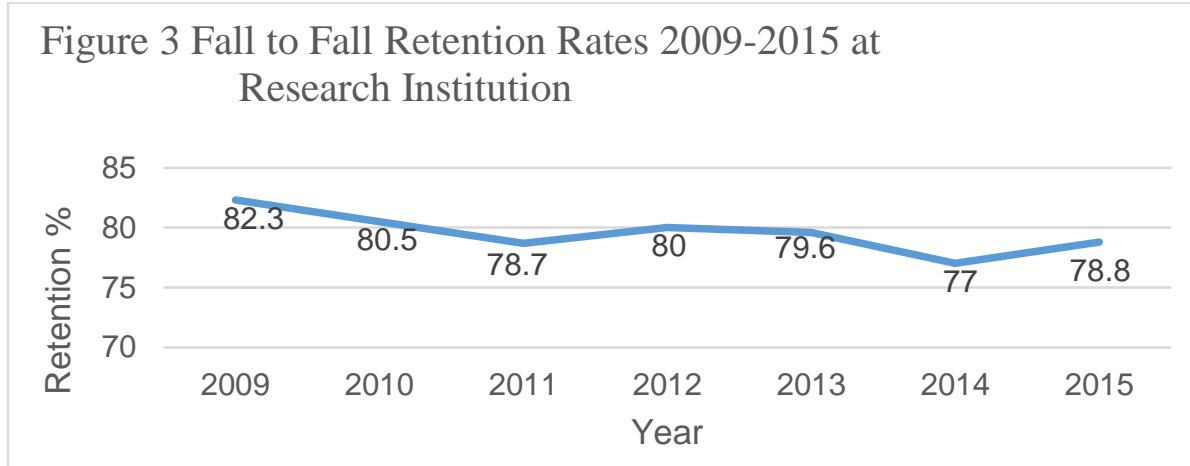

Adapted from http://nces.ed.gov/

\section{Research Participants}

Participants were selected using purposive sampling. "Purposive sampling increases the likelihood that variability common in any social phenomenon will be represented in the data" (Maykut \& Morehouse, 1994, p. 45). I interviewed four groups of participants: faculty advisors, professional academic advising personnel, administrators, and students. Each participant had direct experience with CAAP services, either through receiving or providing services. Faculty advisors, academic advising personnel, and administrators provided information regarding the styles of advising utilized, frequency of advising, student engagement techniques utilized during advising, cultural elements of the CAAP, and location of advising. Students provided information regarding their satisfaction with the advising they received, and what variables they used to determine their satisfaction with advising and the impact advising had on their decision to persist to graduation. Information about the perceived impact of advising for student persistence was garnered from students. 
Administrators were selected for interviews based on their direct involvement with the CAAP on campus. They had to be willing to provide at least an hour for each interview. Administrators were interviewed to provide an in-depth description regarding their expectations for an effective CAAP since they provide evaluations on advising performance, allocate resources to the CAAP, conduct searches for CAAP personnel, and promulgate and develop policies and procedures for CAAPs (Braxton et al., 2014; Cuseo, 2011; Gordon et al., 2008; Kimball and Campbell, 2013; O’Keeffe, 2013; Pascarella and Terenzini, 2005).

The professional advising personnel were asked to participate by an administrator. To eliminate any possibility of perceived coercion to participate, in addition to the informed consent form, they were verbally given the option of opting out prior to the start of the interview. They agreed and participated in 30 to 60 minute interviews. The group advising sessions conducted by professional academic advisors were also observed. The professional advisors were selected based on their years of experience and the quality of their job performance. The administrator that selected them assured the researcher that they had over five years' experience as a professional advisor and were deemed high performing. Professional advisors were asked to participate due to research that indicates the trend in higher education is an increased use of professional advising personnel (Habley, 2004; Pardee, 2004; Self, 2008).

Students were selected based on their years of experience with receiving CAAP services. Only undergraduate students were selected to participate as the focus of the study was on the undergraduate experience. Students with minimal experience, freshman, to multiple years' experience, senior, with CAAP services were selected. The researcher chose students from each academic class standing which provided a rich description of their CAAP experiences at various years throughout the students' educational experience at the University. Students were selected 
as participants based on their willingness to provide a detailed description of their CAAP experience, and their perspective of visibility and value of the CAAP. Research indicates that data derived directly from students is an excellent indicator of what motivates them to persist to graduation (Braxton, Hirschy, \& McClendon, 2004; Sams, Brown, Hussey, \& Leonard, 2003; Chiteng Kot, 2014; Cuseo, 2011; Wirth \& Padilla, 2008; Trotter \& Roberts, 2006; Turner \& Thompson, 2014).

Faculty academic advisors with over five years of advising experience were selected to participate. The five years experienced provided the faculty advisors with the knowledge necessary to assess the CAAP. Faculty advisors were selected due in part to research that indicated the historical relevance of the role of faculty in advising. They were chosen primarily because faculty have been the main source of academic advising (Beatty, 1991/2009; Brubacher \& Rudy, 1997; Cohen, 1998; Gordon et al., 2008; Self, 2013; Lucas, 2006; Thelin \& Hirschy, 2009). Faculty were deemed an excellent source for providing data regarding the relevance of advising for degree completion which is an important factor in student persistence (Drake, 2011; Tinto, 1993; McArthur, 2005; Smith, 2007Tontodonato, 2006). Finally, faculty advisors were selected based on the research that specifically identified a link between student satisfaction and advising conducted by a departmental faculty advisor (Bahr, 2008; Braxton et al., 2014; Fowler and Boylan, 2010; Harrison, 2009; Johnson \& Morgan, 2005; Kadar, 2001; Kuh et al., 2010; Melander, 2005; Pascarella and Terenzini, 1991; 2005; Pizzolato, 2008; Smith, 2007; Tinto, 1987; Titley \& Titley, 1982; Truschel, 2008; and Pizzolato, 2008). The participants were identified based on their respective positions at the various schools that utilized the faculty advisor or hybrid model for advising. The research compiled a good representation of the various 
schools within the university, and the participants had to be willing to succumb to a 60 minute interview.

The specific number of each type of participant varied because, "in an emergent research design the composition of the sample itself evolves over the course of the study" (Maykut \& Morehouse, 1994, p. 45). I began with the goal of five participants from each category. These participants provided the rich narrative and, descriptive data, required for a case study. The information provided by the participants presents an opportunity to understand the strategies a CAAP uses with the aim of increasing retention rates, and the ways in which the institution has embedded the CAAP into its institutional culture. These participants are a necessary component to understanding the organizational culture within the context of Schein's three levels of culture. The institution used for this case study has a total of 14 colleges and schools, one University College, and several regional campuses. The regional campuses and professional schools were excluded. That left a total of eight viable colleges and the University College to use to select advisor and student interview participants. Three of the eight colleges were further excluded because they only used a professional advising structure which left five colleges and the University College. The University College was specifically selected to represent the colleges that only use a professional advising structure and the three professional academic advisors that were interviewed were housed there. Subsequently, the researcher interviewed six faculty advisors from four of the five remaining viable colleges within the University, and six students from three of the five viable colleges and the University College, thus providing a good representation of the institution. All in all, there were a total of 20 participants interviewed for this study. An overview of participants is provided in Table 1. 
Table 1

Participants, Academic and Professional Standing, and School Affiliation Sub-categories

\begin{tabular}{|c|c|c|}
\hline Students & Protocol & Characteristic \\
\hline Student 1 & Freshman & $\begin{array}{l}\text { Undecided Major: } \\
\text { Professional Advisor }\end{array}$ \\
\hline Student 2 & Sophomore & Engineering: Faculty Advisor \\
\hline Student 3 & Sophomore & $\begin{array}{l}\text { Agriculture Business: Faculty } \\
\text { Advisor }\end{array}$ \\
\hline Student 4 & Junior & $\begin{array}{l}\text { Biology \& Psychology: } \\
\text { Professional Advisor }\end{array}$ \\
\hline Student 5 & Junior & $\begin{array}{l}\text { Animal \& Nutritional } \\
\text { Sciences: Professional } \\
\text { Advisor }\end{array}$ \\
\hline Student 6 & Junior & $\begin{array}{l}\text { History and Philosophy: } \\
\text { Faculty advisor }\end{array}$ \\
\hline Faculty & & \\
\hline Faculty Academic Advisor 1 & College of Engineering & Engineering \\
\hline Faculty Academic Advisor 2 & Sports Sciences College & Physical Education \\
\hline Faculty Academic Advisor 3 & $\begin{array}{l}\text { School of Agricultural } \\
\text { Studies }\end{array}$ & Agriculture \\
\hline Faculty Academic Advisor 4 & $\begin{array}{l}\text { School of Agricultural } \\
\text { Studies }\end{array}$ & Agriculture \\
\hline Faculty Academic Advisor 5 & College of Arts \& Sciences & Communication \\
\hline Faculty Academic Advisor 6 & College of Arts \& Sciences & Communication \\
\hline \multicolumn{3}{|l|}{ Administrators } \\
\hline Administrator 1 & $\begin{array}{l}\text { Gatekeeper \& Associate } \\
\text { Provost }\end{array}$ & $\begin{array}{l}\text { Undergraduate Academic } \\
\text { Affairs }\end{array}$ \\
\hline Administrator 2 & Associate Dean & University College \\
\hline Administrator 3 & Executive Director & Academic Success Initiatives \\
\hline Administrator 4 & Executive Director & $\begin{array}{l}\text { Academic Advising and } \\
\text { Student Success }\end{array}$ \\
\hline Administrator 5 & Registrar \& Chair & Academic Advising Council \\
\hline \multicolumn{3}{|l|}{ Professional Advisors } \\
\hline Professional Advisor 1 & Professional Advising Staff & University College \\
\hline Professional Advisor 2 & Professional Advising Staff & University College \\
\hline Professional Advisor 3 & Professional Advising Staff & University College \\
\hline
\end{tabular}




\section{Data Collection}

Data collection included interviewing, observing, and collecting and examining documents. The interviews were loosely structured, conversational interview modality, with open-ended questions. Observations focused on advising style such as prescriptive, developmental, or intrusive, and the general interactions between advisor and advisee. Other materials for this study include a document analysis of retention rate data, policy and procedure, and institutional academic advising protocols.

Interviews. The purpose of the interview questions was to obtain specific information from academic advising personnel, faculty academic advisors, and students, regarding the strategies they used to assist the student with persistence to graduation, and how academic advising is embedded in the institution's culture. The questions addressed how all participants felt about the quality and style of advising at their institution, whether or not they believed advising has a role in improving student retention, and how they knew advising was an integral component of their institutional culture. I used an open-ended interview format to guide the interview process (Yin, 2016, p. 142). The open-ended question format allowed the participants the opportunity to elaborate on their answers and afforded me the opportunity to identify trends, contextual conditions, and themes. I used a conversational mode of interviewing to allow for two-way interaction and a social relationship of sorts. That mode lends itself to eliciting follow-up questions (Yin, 2016, p. 143). Specific interview questions are located in the appendices A-D. I conducted 17 hours and 15 minutes of interviews in total. I audio recorded all interviews. I transcribed the interviews. An overview of time spent in the field for interviews and observations is provided in Table 2 . 
Table 2

Time in Field: Interviews

\begin{tabular}{|c|c|c|}
\hline Students & Data Collection Protocol & Time \\
\hline Student 1 & Interview & 1 hour \\
\hline Student 2 & Interview & 30 minutes \\
\hline Student 3 & Interview & 30 minutes \\
\hline Student 4 & Interview & 30 minutes \\
\hline Student 5 & Interview & 30 minutes \\
\hline Student 6 & Interview & 15 minutes \\
\hline \multicolumn{3}{|l|}{ Faculty } \\
\hline Faculty Academic Advisor 1 & Interview & 1 hour \\
\hline Faculty Academic Advisor 2 & Interview & 30 minutes \\
\hline Faculty Academic Advisor 3 & Interview & 1 hour \\
\hline Faculty Academic Advisor 4 & Interview & 1 hour \\
\hline Faculty Academic Advisor 5 & Interview & 1 hour \\
\hline Faculty Academic Advisor 6 & Interview & 1 hour 15 minutes \\
\hline $\begin{array}{l}\text { University Academic } \\
\text { Advising Council }\end{array}$ & Interview & 30 minutes \\
\hline \multicolumn{3}{|l|}{ Administrators } \\
\hline Administrator 1 & Interview & 1 hour \\
\hline Administrator 2 & Interview & 1 hour \\
\hline Administrator 3 & Interview & 1 hour \\
\hline Administrator 4 & Interview & 1 hour 15 minutes \\
\hline Administrator 5 & Interview & 1 hour \\
\hline \multicolumn{3}{|l|}{ Professional Advisors } \\
\hline Professional Advisor 1 & Interview & 30 minutes \\
\hline Professional Advisor 1 & Follow-up interview & 30 minutes \\
\hline Professional Advisor 2 & Interview & 30 minutes \\
\hline Professional Advisor 3 & Interview & 30 minutes \\
\hline Professional Advising Staff & interview & 30 minutes \\
\hline Professional Advising Staff & interview & 15 minutes \\
\hline
\end{tabular}

Observations. The second data collection method I utilized was observation. I conducted three hours and 45 minutes of observation. Table 3 provides an overview of the observations that were completed. The specific observation protocol is available in the Appendix E. I incorporated observation into my data collection with the goal of strengthening the internal validity of the study through data triangulation (Merriam, 2009; Patton, 2015; Yin, 2014). I gained access to 
observations as a result of obtaining information about relevant observation opportunities during interviews. Additionally, future observation opportunities were presented during observations I was currently attending. As an example, when I was interviewing an administrator, he informed me of an upcoming University Academic Advising Council meeting. I asked him to assist me with obtaining permission to observe the meeting, and the observation ultimately came to fruition.

My method of data collection was detailed field notes of observations. Merriam (2009) posits that "observational data represent a firsthand encounter with the phenomenon of interest rather than a secondhand account of the world obtained in an interview" (p. 117). Observing produces rich data related to gestures, social interactions, actions, and the physical environment (Yin, 2016, p. 139). My observation protocol intertwines components from Yin (2014) and Patton (2015). Yin (2014) suggests that the researcher must decide when, where and what to observe. Yin's (2016) protocol dictates recording the following: observation times and locations, participant information, the field setting, and a summary of the event or non-event. Observations were made at multiple times to reduce bias (p. 152). Patton's (2015) protocol dictates recording the following: a description of the setting, the activities, people that participated in the activities, and describe the meanings of what was observed from the perspectives of those observed. Specified formal observation occasions included planned advising sessions. Informal observations were those casual observations made throughout my fieldwork (Patton, 2015; Yin, 2014). In this study, informal observations included interaction between advising personnel, administrators, faculty advisors, and students. I sought approval from the appropriate administrator of academic advising prior to making the observations. The majority of the observation time was devoted to formal, planned activities (Patton, 2015; Yin, 2014) such as 
academic advising sessions, or meetings between academic advising personnel and administrators.

\section{Table 3}

Time in Field: Observations

\begin{tabular}{|l|l|l|}
\hline \multicolumn{1}{|c|}{ Participants } & \multicolumn{1}{|c|}{ Data Collection Protocol } & \multicolumn{1}{c|}{ Time } \\
\hline $\begin{array}{l}\text { University Academic } \\
\text { Advising Council }\end{array}$ & Observation: advising council & 1 hour \\
\hline $\begin{array}{l}\text { Professional Advisor \& } \\
\text { students }\end{array}$ & Observation: group advising & 45 minutes \\
\hline Professional Advising Staff & Observation & 1 hour \\
\hline Professional Advising Staff & Observation & 1 hour \\
\hline
\end{tabular}

Document analysis. The third data collection method I employed was document analysis. Yin (2016) states that "collecting refers to the compiling or accumulating of objects (documents, artifacts, and archival records) related to your study topic" (p. 154). I examined program records to gain a behind-the-scenes look at program processes and how they came into being (Patton, 2015 , p. 377). I conducted a document analysis of retention rates for the University prior to the institution using a CAAP, and after the CAAP was implemented to triangulate perceived influence on retention rates.

The documents were analyzed pursuant to Merriam's (2009) process of analysis. Information in the documents were initially coded with identifiers related to the research questions, for example: $\mathrm{R}$ for retention data, and $\mathrm{C}$ for data related to the culture of the institution. Using the research questions as a guide, the retention information was further coded in to the expansive categories of CAAP elements and CAAP strategies for retention. These categories were incorporated with the tentative categories developed from interview data and observation data and subjected to the subsequent final phase of analysis in which the final categories were designated. 


\section{Data Analysis}

I used the constant comparative method to analyze my data. Merriam (2009) stated "Collection and analysis should be a simultaneous process in qualitative research" (p. 169). Merriam's (2009) data analysis protocol was used for the data analysis for this research.

Step one according to Merriam (2009), is rudimentary analysis. First, I documented my thoughts, hunches, and speculations, and after each interview, observation, and document was collected, I reviewed each for tentative themes and ideas to pursue in the next data collection. Merriam refers to this process as organizing and refining. (p. 171). I transcribed my own data to generate insight and hunches (Merriam, 2009, p. 174). In step two, I used open/initial coding which was guided by the research questions. Coding is the "process of making notations next to bits of data that strike you as potentially relevant for answering your research questions" (Merriam, 2009, p. 178). The coding is how I began to construct the categories. Step three entailed axial coding in which I grouped the open codes. The patterns and regularities that became evident through axial coding formed the tentative categories (Meriam, 2009). Categories were then refined according to the rule of inclusion or exclusion. Rules for inclusion involved examining the properties under each category. The construction of the categories was highly inductive at first, i.e. grouping segments of data, and then there was a subtle shift to a deductive mode of thought wherein subsequent data was analyzed to verify co-existing categories (Merriam, 2009, p. 183).

I constructed the categories in step four using the following process as outlined by Merriam (2009). First, the categories were responsive to the purpose of the research, in that, they were essentially answers to the research questions (Merriam, 2009, p. 185). The fewest possible categories were developed (Creswell, 204, p. 199). Second, they were exhaustive. All the 
important or relevant data was placed in a category or subcategory. Third, I verified that the categories were mutually exclusive. Each particular unit of data fit into only one category (Merriam, 2009, p. 185). Fourth, the categories were developed according to the sensitizing in which they were developed to be as specific as possible, thereby making it easy to understand the meaning of the phenomena. The categories were then designed around conceptual congruence, in which, the meanings from each category were connected and referred to as outcome propositions. Finally, the results are presented in narrative form (Maykut and Morehouse, 1994, p. 139).

\section{Validity and Reliability}

Interview data may be limited by personal bias or recall error (Patton, 2015; Yin, 2011). These potential limitations are related to construct validity and reliability (Yin, 2016). I addressed these potential limitations by using triangulation to compare data derived from the three data collection methods used in this research study, and intensive long-term field involvement. Triangulating is an essential part of qualitative data collection and strengthens the validity of the data (Patton, 2015; Stake, 2010; Yin, 2016). Intensive long-term field involvement is the second method I used to address the potential limitations related to construct validity and reliability. Becker and Geer (1957) claim that "long term participant observation provides more complete data about specific situations and events than any other method" (as cited in Maxwell, 2009). Over a three month period of time, I conducted 17 hours and 15 minutes of interviews, and three hours and 45 minutes of observations. I was physically at the research site for fourteen days, for approximately two to three hours a day. Time spent at the University that was not directed at official interviews and observations was used to establish contacts to schedule interviews and observation, and to collect and review some retention documents and advising 
policies and procedures. The data was analyzed pursuant to Merriams (2009) procedure. Interview transcripts, observation notes and documents were first categorized according to participant group. Secondly, the data was coded in reference to each question, and further coded according to each interview question. The coded information was grouped for potential categories. The categories included: qualities of a good advisor, student and advisor relationship, good academic advisor attributes, overall opinion of advising or the advising program, advising between colleges, faculty advisor v. professional advisor, advising Model most often used, advising services, retention strategies, culture by Schein's (2010) theory, and suggestions for improvement. Tentative themes were derived from these categories, and subsequently the final themes were developed.

After analyzing the data collected from the each visit, I returned to follow-up on any themes that needed further development, and to clarify information. In addition to triangulation across data types and time spent in the field, I utilized peer review to help minimize potential bias. My committee chair was the primary source of the peer review process. We discussed the study's process, emerging findings, and tentative interpretations (Merriam, 2009). Based on those discussions, and the chair's review of the draft document, numerous iterations were completed for each section in every chapter prior to submitting the final draft to the committee for review and comments. Based on those comments, the study was again revised and refined.

\section{Ethical Considerations}

It is imperative to maintain high ethical standards. Yin (2016) asserts, "throughout your entire career as a researcher, much less in conducting any single research study, you will need to uphold one critical personal trait: You will need to bring a strong sense of ethics to your research" (p. 41). I completed the Institutional Review Board for Protection of Human Research 
Subjects (IRB) training prior to conducting my research and received IRB approval. I have taken measures to ensure the anonymity of all subjects in my study. The rights, dignity, welfare and privacy of all research participants are protected in my study. My research relies heavily on interviews and observations and, to a much lesser extent, document analysis. Intrusion and privacy are ethical issues involved with qualitative research that uses observation and interviewing data collection methods. Ensuring anonymity alone is insufficient for protecting privacy. My research involved collecting and analyzing data related to student retention rates. This information is widely published by many institutions and readily available on their respective web sites. The fact that this information is public information decreases the ethical issues related to privacy. Documents also reduce the issue and challenges of reflexivity that may introduce a degree of bias into the research (Yin, 2016, p. 157).

\section{Chapter Summary}

Chapter three explained the qualitative methodology used to complete the study. The use of a case study was justified, and the use of a single case study was justified as the research method used for this study (Merriam, 2009; Patton, 2015; Yin, 2014). The research site was discussed, and the selection of that institution was justified due to the relatively high student retention rate. Data collection methods were presented and included interviewing, observing, and collecting and examining. The chapter described the procedures for selecting participants and, the protocol used for interviews and observations. The use of document analysis was presented and its usefulness for this study was explained. Procedures were presented for collecting and storing data. The use of the constant comparative for data analysis was discussed. The methods used to address construct validity, bias, and reliability concerns were presented, and chapter three concluded with an explanation regarding ethical issues. 


\section{Chapter Four}

\section{Findings}

The purpose of conducting this study was to describe a successful CAAP in-depth at one public four-year degree-granting higher education institution. A successful CAAP is one that can be identified as a contributing factor for improving student retention rates, or a contributing factor for maintaining an already established high level of student retention. This study used two research questions to guide the collection of data that was used to develop the description of a successful CAAP. The research questions are as follows: what are the strategies the CAAP uses with the aim of increasing retention rates and what are the ways in which the institution has embedded the CAAP into its institutional culture?

This chapter begins with a brief discussion of the advising organizational structure at the institution used in this study. Through the analysis of data compiled from interviews, observations, and documentation, major themes emerged. The themes around each research question are discussed as follows: first, themes common across participant groups with analysis are presented; second, divergent themes between participant groups with analysis are presented with a discussion regarding reasons for the differences. This discussion format is repeated for the second research question. This chapter ends with a brief summary of the research findings.

\section{Academic Advising Organizational Structure}

There are three distinct academic advising models utilized throughout the University. First, academic advising programs may use a professional advisor model only. A professional advisor is employed as a full-time advisor with the sole purpose of providing academic advising. Second, faculty academic advisors provide advising in addition to their teaching load, service obligations, and research activities. Third, a hybrid model was identified in which a school may 
use both professional and faculty academic advisors. Every college or school within the University is permitted to use whichever model they deem appropriate.

The University identified several distinct populations of students and matched them to a specific academic advising model. The first student population is the direct admission students. These students met the requirements necessary to be directly admitted to a program of study. They are assigned to a specific school or college within the University and receive academic advising there or at a designated department within that school or college. The advising model for direct admission students is determined by the college or school to which they were admitted and could be professional or faculty advising, or a hybrid model. The second distinct population of students are identified as provisionally admitted. This population has been admitted to the University but they have not been admitted to the school or college for which they applied because they did not meet the admission requirements for a specific program. These provisionally admitted students receive academic advising through the professional advising model, at the advising center. The third population of students is the exploratory student. They are classified as general studies students. These students have been fully admitted to the University but have not declared a specific major, and as a result, have not been assigned to a specific department within a college. This population receives academic advising through the professional advising model, at the advising center.

The CAAP organizational structure of the institution is highly decentralized. As one administrator explained it:

When I first came here two years ago, one of the things that people kept telling me from all sides was, [this institution] is very decentralized. Whenever I asked a question, I always got: well it depends on, and depending on what the question was, it depends on 
various things. It depends on what college you're from, whether you're a direct admit from high school, maybe on which side of town you live on, but it always depends on something, and the answer is always, it depends. [This institution] does very few things in a monolithic way. So when you ask a question like: what's the CAAP like at [this institution], It depends on, in this case, which college or school you are in as to what your advising experience is like, what the organizational structure is within which advising is housed, and what the advisors specifically might tell an individual.

Each of the 15 total colleges and schools and two regional campuses select their own specific advising model. It is not unusual for departments within schools and colleges to further decentralize the approach to academic advising by using a different advising model than that of the college or school.

\section{CAAP Characteristics that Influence Retention}

Two sub-themes have been identified in the data as CAAP characteristics that influence retention: the benefits of good advising; and other elements of a good CAAP. All four categories of participants, including students, faculty, administrators, and professional advisors identified knowledge and rapport as relevant for good advising and are thus identified as overlapping themes evident under benefits of good advising. There were some divergent ideas concerning the attributes for knowledge and rapport which will be addressed. The second sub-theme, other elements of a good CAAP, presented divergent ideas across all participant categories.

The benefits of good advising. All four categories of participants identified good advising as an integral component of an effective CAAP. Two pillars of a good advisor overlapped among all participants and included: knowledge and rapport. 
Knowledge. The first pillar of a good advising, according to all data, was being knowledgeable. A major commonality apparent in the data was knowledge related to degree completion. The common thread through all participant data was related to providing accurate information to ensure graduating in a timely manner. An agriculture business major, Student Two, provided a positive experience with receiving accurate information from her advisor. The student described the importance of advisor accessibility to obtain information. "I usually go to my advisor a lot... Usually, I like to talk to him about internships and what classes I should be taking, and if I'm on track to graduate on time; if there's any new classes." The student went on to discuss specific guidance sought from her advisor regarding upcoming classes and advice about life. "He told me about a class that was going to be taught spring and that I should probably take it just to get some other classes. I just talk to him about everything, my future." These findings support research by McArthur (2005) and Cuseo (2011) who identified being knowledgeable and personable as traits of a quality advisor. Student Four, a biology major, stated "They've saved me a couple grand by graduating on time I guess, and um the whole scheduling, changing my classes, is going to help me raise my GPA." Students tended to seek advisor degree completion input even when computer generated scheduling programs were available, as related by this student:

Degree works [a computer generated scheduling program] can be kind of confusing. I've used other school's programs, and it just says what you need. An advisor can tell you the courses you want in the program, like [advisor name], he's in the [college of science] so he knows like this comparative class or when something is really hard, like when you're already taking bio chemistry and this teacher you're taking is hard, so maybe push that back to next semester, it's gonna be offered next semester. 
Faculty Advisor Two, a communications professor, identified knowledge about degree requirements and completion as being number one on his list of describing a good advisor: Number one, a person should be knowledgeable about the types of obligations that the student has to fulfill so that the advisor can help the student meet those obligations. A student needs to know for instance: what are the requirements of the university, the college, and of the department that he or she is a part of, so that's one, knowledgeability. The advisors essential function is to keep the student aware of what is required of him or her so that she's not in the dark about her or his requirements. I think in that respect, we do a good job.

Faculty Advisor Four differentiated academic advising into two specific types: official registration advising and drop in advising. Official registration advising was related to advisor approval of course scheduling to have the advising hold released. She exemplified how she uses official registration advising to empower students by promoting student responsibility and ownership over graduation.

In terms of official registration academic advising, that usually takes place for about a month. We have a scheduling system and students come in for appointments of about 20 minutes each time. We do try to prepare our students before they come in for their official registration advising appointment, in that we try to talk to them about expectations that we want them to be ultimately responsibility for their own graduation. We are there to guide them and answer questions, help them navigate the system, but ultimately it is their responsibility to make the right choices because we're not holding their hands when they're registering for classes. We want them to have ownership of their registration process and the courses they take. 
Faculty Advisor Four, an agriculture, natural resource, and design professor, further explained that assisting the student with course selection is an important part of ensuring timely degree completion, "I try to convince the students to plan ahead in terms of their academic course work... We have a plan of study form... so they have a pretty good idea of what courses they need."

Knowledge of degree completion was the principal quality professional advisors acknowledged as being the most important quality of a good advisor. Professional advisors housed in the advising center must have a vast array of degree completion knowledge due to the categories of clientele they advise. Professional Advisor One stated: "We advise three types of students: one it's the exploratory students that are really trying to figure out what they're doing. Secondly, we advise pre-professional programs." He further explained that students that have not met the qualifications to apply to a professional program, for example; pharmacy school, would fall into this category. He added, "Third, we advise students that do not meet the requirements to go over to their major of choice." They must be knowledgeable about every facet of the University that ties to degree completion, as stated by Professional Advisor Two, "As an advisor, every policy that anybody makes, no matter what office it is, whether it's admissions, or registrar, or for a specific college that the faculty changes the curriculum, it affects advising." Administrators viewed knowledge of degree completion requirements as essential for aligning academic aptitude with curriculum. They acknowledged the importance of that alignment for student persistence as exemplified here: "I've seen students in the past, before the [advising center], before the academic advising council, before folks were really ramping up advising on this campus ... with schedules that were really appalling, just schedules that a student should never have." She further provided a specific example of a student's schedule that 
had five courses with a heavy reading requirement in every course, but the student had a reading disability. Additionally, this administrator acknowledged the relationship between course scheduling through academic advising and retention and stated, "If you have students that are misadvised or ill-advised or not advised at all or wind up with poor schedules for whatever set of reasons, the system is not working properly." She further noted "If the student starts off with a poor schedule, that student is going to be much less likely to be retained." Thus, the administrators' concern with matching the student with an appropriate major, through advising, was related to the overarching goal of student retention.

Students want their advisor to be knowledgeable about degree completion, schedule their course load with difficulty in mind, and make sure they are "on track" for graduation. Faculty and professional advisors recognize the importance of proper course scheduling that aligns with degree completion requirements, and administrators concur with those perspectives. This perspective aligns with the prescriptive model of advising pursuant to Crookston (1972), and according to Heisserer \& Parette (2002), students benefit from the prescriptive approach because they may have no additional needs from advising. Research conducted by Christian \& Sprinkle (2012) found that some students only wanted to meet with their advisors about course selection to ensure graduation in a timely manner.

Rapport. The second pillar of good advising, according to all data, was having positive rapport between the advisor and the student in which those involved communicate with each other and understand each other's goals and ideas. While the theme of rapport was common among all participant groups, the elements for rapport were divergent in some respects. Two common elements of rapport among students, faculty advisors, and administrators were care and concern. Students believed that their advisor cared and was concerned about them when the 
advisor identified alternative career goals that their degree could be used for. Students believed the advisors presented the appearance of caring about them when the advisors addressed issues outside of course scheduling, such as internships, and social engagement. Care and concern were expressed by the advisor, according to students, when there were face-to-face meetings with ample time allotted to discuss issues other than course selection. This finding is consistent with the literature. Melander (2005) identified a personalized interface between student and advisor as a major tenet in the advising as teaching advising framework, which is considered a method of developmental advising (Crookston, 1972; Drake, 2013; Hurt, 2007; Melander, 2005; Ryan, 1992). As one student explained, In the undergraduate studies program, it [advising] was done over the phone. I didn't actually go in, in person and meet her. I never even know what she looked like and I talked to her up to 10 or 12 times. But here in [school of science], there's less kids so like I had to go in face to face and meet him [advisor] which is no problem for me. It was very personable and while it was like only a half hour time slot, I was offered more time another part of the day like when he didn't have advising sessions and stuff.

Students that were prompted to take an active role in the advising process, such as coming in with a list of questions not related to scheduling courses, were more satisfied with advising and viewed the experience as "personalized." This personalized advising led the student to believe that the advisor cared about them. Student Six stated "They'll [advisors] give you a basic outline about what classes you should take to complete your degree but that doesn't really personalize you exactly. You have to be able to communicate with them. That makes the whole experience better." Student Four explained that communicating meant having a list of questions for the 
advisor that were not related to course scheduling. The questions could have been if reference to internships or campus activities, but anything other than courses.

Advisor accessibility was identified as an element of care and concern. The more accessible an advisor was, the more the students viewed their advising as personalized, and in turn, they felt the advisor legitimately cared and was concerned for their success. When advisors were inaccessible, students described the process negatively. Student Four described her experience with professional advising outside her degree program: "In the undergraduate program [general studies], it was not very well organized. It was very much a mess. I had to call and email many times. It was not structured and it needs re-structured. I almost didn't want to deal with it at times." She further explained that she was required to "deal with it" in order to have her advising hold removed to schedule courses. Student One expressed his negative experience with professional advising from the advising center as follows:

When I first came here during orientation, it's sort of like a cattle line because like all the students coming in have an advisor to pick out what classes to take and then signing up for them and leaving. So that wasn't like that great or helpful.

Students looked for concern related to a post-graduation plan and a back-up plan relevant to their degree as depicted by Student Three,

I've had conversations with him [advisor] about what kind of jobs I could get with my major. I was trying to decide if I should go to veterinary school or not and if I didn't go, what other things I could do and he helped me out to find other options.

Student Four had a highly favorable experience with her advisor once she started receiving advising in her degree granting school. She expressed that those advisors expressed care and concern for her academic success and her career success, and stated: "They [advisors] want to 
know like: okay what's your plan after graduation, okay what if that doesn't work out, what's your back-up plan." She further explained that advisors expressed concern for applying the students" degree to their alternative career plan and stated "The [school of science] makes sure that if your first plan doesn't work, is your degree still gonna be good for your back-up plan. Are the classes you're gonna take still gonna be applicable to your back-up plan."

In summary, students were able to build a rapport with their advisor when they felt care and concern from the advisor. Care and concern was expressed when the advisor provided encouragement to participate in university sponsored activities. The rapport was established when students viewed advising as being personalized. Personalized advising was viewed as exhibiting care and concern. Advising was viewed as personalized when the advisor was readily accessible and when students were encouraged to take an active role in their course scheduling. An active role entailed having additional questions outside course scheduling to communicate to the advisor.

These findings support the literature regarding the engagement model and counseling liaison models which are derivative models of the developmental model, in that, the more the advisor and student interact, the more invested the relationship becomes. And, the student is guided to take ownership of their decisions and behaviors (Drake et al., 2013; King, 2005; Trotter \& Roberts. 2006; Yarbrough, 2002). The findings are further substantiated by the support of research conducted by Braxton and associates, whose findings indicted that when student perceived that the institution cared and were concerned about their welfare, they were more likely to persist and be retained (Braxton et al., 2004: 2014; Turner \& Thompson, 2014).

Faculty advisors incorporated being compassionate and empathetic in to expressing care and concern, and focused on student persistence and success in relation to academics and the 
"whole person." When discussing compassion, Faculty Advisor Two stated "The advisor should want to relate with the student. Should want to help the student. I would say without being corny, I think an advisor should be compassionate." He further explained that an advisor should want to help the student with any problem they may encounter, and that included personal issues, and other issues outside the realm of academics. "Various problems arise in a student's career. Some of which may seem to be unrelated to the very academic issues.... The more compassionate an advisor is, the more the student will feel safe to express his or her difficulties." Faculty Advisor Five added to the compassion aspect of building rapport with students and broached the feature of expressing concern for the student,

I think a big part of it is, the student's perspective that their academic advisor is concerned for them, not only from the standpoint of they are a student in the seat in the classroom, and they're getting the grades they need to get to stay in the classes, but concerned for their development as people and professionals. That sounds kind of warm and fuzzy but I think that kind of interpersonal relationship is important.

All advisors stated something specific about helping a student beyond mere course selection, which expressed their care and concern. One advisor referenced a specific case in which he helped a student: "I guided the student with 'making the case' in dealing with policy. The student needed to deal with balancing life, school, and future employment opportunities, and was guided through advising but persuaded to be independent." A specific case that exemplified care and concern for Faculty Advisor Five was related to a financial aid issue and stated "One of things that I, that always stands out because I know the least about it has been the financial aid problems that crop up. Especially early in the semester, I will have students come to me with problems accessing their financial aid." He expressed how he was concerned that students were 
withdrawing from courses due to failure to pay tuition as a result of late financial aid disbursements, "We have a number of cases, almost every year, where a student comes in, and they have been dropped from all classes because they haven't paid their tuition, because their financial aid hasn't arrived yet. I think that's a serious problem." He further described what he did to help students with that issue. "I don't really know a lot about that, or how to do that but wherever there's a chance I will make phone calls, write memos, send emails, or direct them to see other people, try to help those students with their financial aid." He described what he viewed as a disconnect between administrative offices, "The financial aid office and registrar's office need to learn to work together so those problems don't happen. That's not a student centered approach in my opinion."

According to Faculty Advisor Three, career planning and advising was a method that expressed care and concern for student persistence and beyond academics. She believed it empowered the student to take an active role in making life decisions, and it promoted independence. She offered the following scenario:

"I talk a lot about the chaos theory of careers. Sometimes it's that a student isn't enjoying their communication courses, or maybe this major isn't a good fit for them, or maybe they've had such a variety of classes that an MDS or Regents degree might be a better fit for them. I was talking to a student the other day that said: I think I need to be a communications major. We started talking and after talking to him a little while, I was like, you don't want to be a communications major, you want to be a history major, so I had to send him away. It was in the best interest of the student. One of the issues was that he thought communications would better prepare him for a career than a history major. I had to tell him that that is absolutely not the case. If you're enjoying your history classes 
and you're passionate about what you are learning in history, than that is what you should be getting your degree in. You can set yourself up for any career with just about any degree. It's about your work experience, how you sell yourself, the research you do on those careers. You have to think about what you're doing and being successful in your classes. Your passion will translate to an employer. Employers don't care what you majored in, yea they want you to have good communications skills, but they want you to be able to think critically, they want you to have the degree. Just getting through to our students that it's not about the major. It's about enjoying what you're doing and translating that to the workforce."

The encouragement, and care and concern, traits of a good advisor align with the developmental model of academic advising (Crookston, 1972; Drake, 2013; Kadar, 2001; Melander, 2005; Pascarella \& Terenzini, 2005). Thus, students and faculty preferred an integrated model of advising which combines elements from the prescriptive model and the developmental model. Hale, et al., (2009) postulated that developmental advising focuses on more than academic goals, and integrates career and personal goals in to the focus of advising. Advising should focus on the "whole" person (Drake, 2013; Hale, et al., 2009; Hurt, 2007; Kadar, 2001; Melander, 2005; Yarbrough, 2002). Findings support this postulation.

Care and concern demonstrates compassion for the individual human being, according to administrators. Administrator one explained care and concern as: "It's a combination of interpersonal skills and a choice to make time to interact with the individual student." Administrator Three described care and concern as looking out for the "welfare" of the student, and explained that: 
You must be interested in the success of the student. If ultimately you don't care if the student succeeds, you can just dole out advising and it may be good advice... but if doesn't connect with helping a student succeed, then in my opinion it's not good advising.

He offered details of a specific advising case based on his experience:

A particular student was having test anxiety issues that weren't just for tests but were for anxiety as a whole. He literally could not take a test. He would go to a classroom on the day of the exam and could not go through the door and he would just leave. So if he knew he had an exam, he wouldn't even go. So I helped connect him to the [Counseling] Center and some of the other resources. That helped him to alleviate the pressure and anxiety that he saw. We were able to help him get over that text anxiety which ultimately spilled over into other types of anxieties, and helped improve his affect for working with faculty members, seeing them outside of the classroom, going to office hours, all of the other things that he never did that traditional students would do. Ultimately he was successful academically. He had a 4.0 one semester. He ended up graduating.

He took that case from his term as an advisor and felt that it exemplified good advising in the perspective of welfare.

The second commonality identified as an element of rapport was connecting the students to resources. This element was identified by administrators, and professional and faculty advisors. All administrators determined that advisors must use their knowledge, about the resources that are available on campus and in the community, to address an array of student needs. Those needs may be academic or psychosocial, but the main point is that the advisor provides appropriate referrals to services that promote student persistence, as stated by 
Administrator Three, "The way in which it [a CAAP] contributes to student retention is helping connect students with resources on campus. If they struggle academically, personally, emotionally, psycho-social...they can have a person to whom they can go and get advice" $\mathrm{He}$ further added that the advisor facilitates a solution to many issues through advice about “...how to remedy any of those situations that they may encounter. It also helps a student be able to navigate the complexities of a large university, the bureaucracy of knowing who to go to." Administrator One concurred with this idea. "An advisor is a human single point of contact ... who will help humanize [the University] for them, point them in the right direction, and connect them to the resources they are going to need to do well here." He further proffered that the advisor's role is not to solve problems, but to facilitate and empower the student to solve their own problems and to take responsibility for their academic success, and that will have a positive impact on student retention. "The advisor can't solve problems for them but... help them find the resources to solve the problem. And if you do that, students... are more likely to stick around... If they stick around... the retention rate goes up." Connecting students to resources can also lead to creating a connection to the institution, in that, the student receives referrals for services and resources from the advisor, and in turn, an advisor and student connection or relationship begins to form. This process was detailed by Administrator Three as follows:

It [a CAAP] also creates a connection that a student has on campus. If they know there is a person concerned about their welfare, concerned about their progress, then having that connected individual that can help support them via positive figure can help reinforce any values or any other identities that that person can have. For all of those reasons and of course a host of others, I think advising is one of the key factors in whether or not the university can retain a student. 
Administrator One stated, "An advisor is a human single point of contact for this new and coming freshman who will help humanize [the University] for them and point them in the right direction, and connect them to their resources." Administrators expected advisors to have the ability to assist the student in all aspects of student success and that also entailed the knowledge of resources for personal development such as: counseling services, housing issues, financial aid, employment, and internships, to name a few.

Campus resources were referenced in relation to both academic and personal issues. A good advisor, according to all professional advisors that were interviewed, is one that has a vast array of knowledge related to all the available academic and psychosocial resources throughout the university. According to Professional Advisor Three, "the role of the advisor is to refer them [students] to the different resources that are out there either available at the university or elsewhere." Professional Advisor Two stated,

I might not know everything, but if I know you're struggling, I know that we have a counseling center, I know that we have a tutoring center, I know things about financial aid and financial aid appeals. It's about being a resource of knowledge.

Faculty acknowledged that in order for a student to successfully persist to graduation, the advisor needed to provide services related to more than course selection, and they identified providing referrals to resources for academic and psychosocial success as a crucial element of rapport. Faculty advisors provided wide range of advising services above and beyond course selection, including embedding a career focus into academic advising meetings with students. Faculty Advisor Six stated:

Over the past couple of years, we've actually moved towards group advising because the students move through their program in a lock-step fashion. Once they are admitted into 
the program they really don't have a lot of decisions to make in terms of courses. The other things we spend time on in advising, we'll talk quite a bit about transitional issues. As they prepare to move out to student teaching and transition into the school environment, we advise on the licensure process, applying for teaching positions and employment opportunities, and we talk about graduate education opportunities. A lot of the states will require a master's degree within three years after they have a position. Most of our students are from out of state and won't stay here for jobs.

Faculty advisors provided referrals to services provided by included: helping the student understand the layout of the university, encouraging them to do internships, addressing study habits, extra-curricular activities, scholarships, professional development in terms of internships and summer jobs. They provided referrals to services related to helping the student develop academically and professionally such as: resume building, study abroad, professional field experience courses, and networking with alumni. The focus on career preparation, according to Faculty Advisor Three, should begin immediately upon admission to the program. "We start working with them at the beginning of their college career through their senior year when they take the capstone course and they turn their portfolio into an employment portfolio. This is all tied into the academic part." Career planning is threaded throughout the curriculum, and she stated, "We want them to start thinking: these courses, projects, assignments, writings, or even the things I've done through my leadership or extracurricular activities, work experience, study abroad, how these will look for potential employer." She addressed the integration of the career focus, "All of that ties together and we work with that through advising as well, so it all is integrated." 
Divergent elements of rapport were apparent in the data. Student and faculty advisor data indicated that encouragement was a vital element for rapport. Students consider encouragement to get involved socially at the institution, and to pursue graduate school, or a career as beneficial for building rapport. Student One stated, “I wouldn’t even look at it as staying in school, but my advisors have pushed me to go to grad school so now I'm going to grad school. He viewed this interaction as having an impact on his personal persistence to graduation and further stated "I mean, I guess it is technically retention but they are pushing me to go on to better things." Student Four used a story about her friends to illustrate the importance of the advisor providing encouragement:

My one friend, she's also going to med school. She graduated in three years instead of four and she already took her MCAT a couple of times. Just that example. They [advisors] can help you with whatever your plans are. They can help expedite them. My one friend got an internship in Florida this past summer for engineering. He got it through his advising, so it's [advising] good for things.

Students appreciated it when advisors encouraged them to be engaged with university activities as depicted by Student Two, "My advisor suggested I get into stone works [student club] so I could get out and meet new people, and socialize a little more, so that's why I joined." For Student Three, being encouraged to engage in campus activities was very important, and stated "I know my freshman year there's a lot of things I didn't know about. I feel like if I had talked to my advisor more then, I would have been more involved in school and stuff." She described her advisor as "a nice guy" for encouraging her with activities outside the academic realm. Most students said it was common for them to receive encouragement from their advisor to get involved socially at the University. 
Encouragement, according to faculty advisor data, was related to encouraging students to achieve their academic goals, plan their career, become more involved with extra-curricular activities, do service projects, and to join student organizations. One faculty advisor described it like this: "Thinking about it [advising] in terms of teaching and building rapport with the students. Making them feel like we're not there to do the work for them, but we are there to guide them and help them." It was the contention of faculty that the more they assisted the student with focusing on their goal of graduating and beginning a career, and becoming engaged with the department, school, and University, the more likely it was that the student would be retained. Faculty Advisor Three explained that building a rapport and connection with the student involved encouraging and empowering them to make decisions:

"I think there's a little bit of pseudo parent thing going on in some cases but not a helicopter parent. A parent to help them make some hard decisions and choices and kind of force them to be independent in some ways, but know that they have a net to help them out."

The frequent and personalized interface between student and advisor presents the opportunity for the advisor to provide the encouragement that students deem important for good advising. Findings related to encouragement expand on the existing literature related to good advising. Most literature concerning developmental advising does not specifically address the issue of encouragement, but it does address behaviors related to encouragement such as setting goals, and assisting the student with taking ownership of decisions (Drake et al., 2013; Hale, et al., 2009; Kadar, 2001; King 2005; Melander, 2005; Yarbrough, 2002). Findings from this research specifically found that students and faculty believed good advising provided encouragement for 
both academic pursuits and psychosocial development, thus the findings are consistent with the literature.

A second divergent element of rapport, frequent and meaningful contacts, was identified in faculty data. Rapport is perpetuated through frequent and meaningful contacts, and according to faculty Advisor One, the intensity of that advisor and student contact is an important aspect of connecting the student to the institution thereby, contributing to student persistence: "If a person saw one person their freshman year and a different person... and finally got an advisor in their academic discipline, well if they're not an outgoing personality, it may take time to warm up to somebody." He added that it takes time and several visits before a student finally feels comfortable enough to discuss issues that may hinder their retention. "I see a lot of students that I never really find out about until they've seen me for the fourth or fifth time. Then they're more likely to sit there and not have one foot out the door." He further added that building that rapport is an important contribution to student retention, "I think it does lead to retention to have somebody that remembers their name and remembers where they're from." He believed that having a small advising load contributes to his ability to foster that rapport, and stated "we're sort of blessed that we are relatively a small program... Many of them don't have that luxury. They have too many students, and each faculty member has an enormous advising load.” Faculty Advisor Six stated:

What has been a little challenging for us is, at my previous position, I would advise a student from the time they were a freshman to a senior. That was a chance to work with the student all four years. I would get to know them very well, and they would get to know me very well. As I mentioned previously, for a couple years they're advised in the advising office here [in that college] and then when they come into or program, one 
faculty advised them in the first semester, another in the second semester, and another in the third semester. The advantage to that is they get to work with each faculty member. So they hear different perspectives and that's a good thing. The unintended consequence is you work with them for one semester and they move on. I haven't made up my mind if that is a good or bad thing. It's probably not good and bad, a better way to describe it is pros and cons, benefits and limitations.

The advisors recognized that meeting students more frequently, and in multiple ways, supported them with building a relationship with the student. Faculty Advisor Six stated "Often advising is reduced to the one time students are required to come see you. It really doesn't lend itself to the development of a relationship." He further offered insight into his past experiences of creating frequent and meaningful contact with students that included: "a weekly advising newsletter that talked about professional organizations, and professional conferences, and gave important reminders." He concluded by stating "I think that frequency of contact is important in establishing a relationship." Faculty advisors created more opportunities to meet with students by sponsoring student club organizations, being involved with study abroad programs, speed networking events where alumni meet with students, and by organizing group advising sessions. A third divergent element for rapport, building trust, was identified in professional advisor data. Building a relationship with the student was recognized as a necessary part of gaining the trust of the student to assist with persistence to graduation. Professional Advisor Three stated, “without trust they won't share their personal information, and without personal information, you can't help them.” Once you have a student's trust, they are more likely to seek assistance. Once the student seeks help, the professional advisors were zealous about providing whatever assistance was necessary to retain the student. 
They referred to rapport as "relatability" which was recognized as an important attribute for forming a relationship with the student through building trust. Professional Advisor One stated:

Relatability to the student in terms of forming a relationship and building trust with that student is important. They're gonna be more likely to come to you asking you questions. If they are struggling in any particular area, not necessarily academics at the university, that trust that's built, potentially in that first appointment hopefully, is going to give them a support system they can come and talk to somebody about what they are struggling with.

Professional Advisors One and Three recognized that the use of the appreciative advising model was successful when they were trying to build trust with the student, and professional advisor one stated, "One of the things [relationship building techniques] is appreciative advising. I think that's very, very beneficial in building that trust with the student, especially during that first appointment, and appreciative advising is going to help build that trust." He further stated that "From the student perspective, it helps to have somebody to go to for a resource." Additionally, the trust that forms through those meetings encourages the student to return for additional assistance: “It's going to keep them coming back. I don't want them to view their appointments as something they have to do but something that is a resource to them." Professional Advisor Three expressed that a good advisor "builds trust with students, has to have a passion to help the student, and has motivation to help the student" and further elaborated by proudly stating "my students share with me. I am here to help them make decisions and [help them] solve their problems." The advisor continued, "The appreciative advising is good because you have to bring 
the best out of the students. So, you use appreciative with them and they trust you because it's good advising: you have to build trust with the students."

A fourth divergent element of rapport was interpersonal skills. This element was identified in administrator data. Administrators considered Interpersonal skills as being paramount for building rapport with students. Interpersonal skills are related to the advisor's ability to communicate and exhibit care and concern for the students' success and persistence. Communication encompassed the features of a good attitude, being a good listener, and the art of persuasion. Administrator One recognized that a good attitude was a necessity for rapport and interpersonal skills: “A grumpy person that doesn't like life and is upset with the world is not likely to be a person to provide good advising. They need to be interested in people, the person, and the well-being of the student." Listening to the students' goals and expectations, and understanding their academic abilities to achieve those goals were identified as important attributes of good communication. Administrator Three explained that an important aspect of interpersonal skills is the ability to relate to the student. This obviously makes sense, in that, being able to relate to a student enhances the relationship between advisor and student thereby, creating a situation conducive to persuading change. This administrator stated "The advisor also needs to be people that are personable. You don't have to like each student but you have to like working with students." He was conveying the message that an advisor and student relationship can be formed out of respect, additionally, he stated “... I've seen a trap advisors fall into. They think they need to be well liked by the students. While I think if a student likes you, that may help you be able to help you have a connection." He further explained that an advisor should strive to have students' respect and value their advice, and stated, “... they need to respect you and value the advice that you are giving, and that means liking working with student but not 
necessarily liking every individual student which again I think is a trap that some advisors fall into."

These findings related to building an advisor and student relationship are supported in the literature. Cuseo (2011) posited that a quality advisor is accessible, personable and approachable, and the findings from all four participant categories support that research. There is a vast agreement among academicians and researchers that a student and advisor relationship is necessary for effective advising (Bahr, 2008; Harrison, 2009; Johnson \& Morgan, 2005; Melander, 2005; Pizzolato, 2008; Tinto, 1987; and Truschel, 2008). And, effective advising is linked to student retention (Pascarella \& Terenzini, 2005). The type of relationship is also important and should seek to build a rapport that empowers the student build their decision making skills (Kadar, 2001; Titley \& Titley, 1982; and Pizzolato, 2008). This relationship serves as a catalyst for student retention, in that the students decipher the care and concern their advisor exhibits for them from this relationship, and as previously stated, students value exhibited care and concern from their advisor. The advisor is in an excellent position to exhibit a personal interest in the student's success during advising sessions (Kuh et al., 2010; McArthur, 2005; Pascarella and Terenzini, 1991; 2005).

Other elements of an effective CAAP. Faculty and professional advisors, and administrator categories of participants identified six other elements of an effective CAAP that had a positive influence on student retention. The student data offered no findings suited for this sub-theme. Data indicated one common element, adequate resources and rewards, threaded across the participant categories of professional and faculty advisors, and administrators. All other elements were divergent across the faculty, professional advisor, and administrator categories of participants. Other elements included: a committed Dean, a decentralized approach, advising 
conducted in the degree conferring school or college, collaboration, and using professional advisors. Due to the divergent nature of the other elements sub-theme, an explanation for the divergent findings is presented followed by each element presented separately.

The divergent findings are attributed to the decentralized approach utilized by the University. Each department within each school or college within the institution has the option of choosing their own advising model. Historically, the University has not utilized any type of overarching administration of the CAAP, until recently with the inception of the University wide academic advising council. The council is in a position to offer assistance and guidance, regarding best practices, to advising programs throughout the University. Until recently, there was no Executive Director of Academic Advising and Degree Completion. That was a new position which was recently appointed in fall 2015. That position will provide the necessary leadership to foster an effective CAAP (King, 2008; Self, 2008; Brown, 2008).

Adequate resources and rewards. Adequate resources and rewards were a widely acknowledged element of a good CAAP. Resources included adequate staffing, money for professional development, and money for memberships in professional advising organizations. A main issue surrounded rewarding good advising through the evaluation process, as indicated by Administrator Four, "The problem is that academic advising does not weigh heavily in the promotion and tenure process. For faculty members to really take it seriously, there's very little weight in that process." The following statement by Administrator Two supports that perspective, “... you have to have capacity in the system. Our advisors in some colleges have very high ratios while other colleges have more reasonable ratios." She was referring to the advising case load when she mentioned capacity, and further stated 
And the system has to value advising. If you are going to use faculty advisors, but you're not going to consider advising in their tenure and promotion, or you're not going to give them credit for advising, maybe reduce their course load, something, then what incentive are you giving them to be good advisors. You have to count on them being altruists. And many of us are altruists and some of us are not altruists.

Administrator Three concurred with the resources and reward requirements for a good CAAP and proffered the benefits of recognition awards. He emphasized the point that the University only has one award for good advising, and a good CAAP must reward good advising in some shape or form. "I think we have to build an organization that really has a responsibility to, and rewards, academic advising [CAAP].We don't have that quite yet. We have great advisors but often times are not recognized, not rewarded for good work." Administrator Four stated:

If you reward advisors for good work, you definitely improve advising [the CAAP]. I don't want to tie that to money, but there are other ways to reward good performance and some of it is extrinsic meaning money, some is intrinsic. Just telling somebody you did a great job goes a long way. We need to recognize advising just like we do teaching. Then it becomes more prominent in what we do.

All administrators agreed that resources and rewards were a viable part of any good CAAP. The sentiment of Administrator Three best sums up the overall perspective of administrators:

We need to invest far more resources then we have currently. Moving to that professional advisor model required devoting more resources to do that. Devote resources to recruiting and retaining good advisors. Currently we have one award that helps to recognize good advising. But we have not built a culture around here that rewards good advising. We expect people to provide advising, if they provide good advising-ok great, if they don't- it 
doesn't matter. We need to really build structures around rewarding good advisors. Then we need to create an expectation that every advisor will provide good advising. If they don't, they shouldn't be an advisor.

Administrators favored the use of professional advisors and providing adequate resources and rewards for advising as other elements for an effective CAAP. Professional advisors were favored because they are adequately trained in advising best practices. Professional advisors are members in NACADA, the nationally recognized professional advisor organization, and they receive up-to-date training. Using professional advisors would give faculty more time to focus on mentoring students. Adequate resources should be provided for training, conferences, and professional organization memberships. Rewards could come in financial form, course releases, but the key issue with rewards is that advising, for faculty, should be tied to the promotion and tenure process.

These findings are supported by the literature. According to the sixth Survey of Academic Advising conducted by ACT, the use of professional advisors has increased. This University has followed that advising trend in higher education and has increased its use of professional advisers in a centralized approach. The University used an overall decentralized model for its CAAP, but allows each school or college to select its own model. Some schools and colleges are currently using a centralized professional advising model, while others are leaning toward that approach. Cuseo (2011) identified three key roles for advisors: humanizing agent, counseling and mentoring, and an educational/instructor agent, wherein the advisor promotes experiential learning outside the classroom. Two of the three roles are consistent with the administrators' perspective that the use of professional advisors would allow more time for faculty mentoring and educational activities outside classroom. "Freeing up" faculty from 
advising duties to assimilate to the role of mentor corroborates with the major tenets behind the advising-as-educating framework (Crookston, 1972; Drake, 2013; Melander, 2005). The goal of the advising-as-educating model is to help the student develop educational options, navigate the educational environment, and provide access to knowledge (Crookston, 1972; Drake, 2013; Earl, 1988; Glennan, 1975; Hurt, 2007; Melander, 2005). Self’s (2008) research supported the administrator's perspective that professional advisors are able to focus all their professional development towards advising activities.

The literature supports the administrator's contention that proper resources should be allocated to the CAAP (Freeman, 2008; Robbins et al., 2009; Johnson \& Morgan, 2005). The Council for the Advancement of Standards in Higher Education Standards and Guidelines for Academic Advising recommended that adequate funding be provided for any CAAP to accomplish its mission and goals, and that "special consideration should be given to providing funding for the professional development of advisors" (as cited in Gordon et al., 2008, p. 540). Data expand upon the existing literature that advising should be closely linked to the promotion and tenure process, and a proper reward system should be in place. In the few available studies that investigated CAAPs, none of them specifically identified a reward system, or identified the link between advising and promotion and tenure (Erwin, 1997; Johnson \& Morgan, 2005; Nitecki, 2011).

Committed Dean. The faculty advisors interviewed represented four of the viable schools within the University for this Study, and faculty advisors from all four schools stated that they had a Dean that was committed to a good academic advising program. A committed Dean was denoted as one that provides resources for the advising program such as additional staff, support to attend conferences, and includes advising in the evaluation plan. Faculty Advisor One 
expressed his opinion of his Dean as follows: "It's [advising is] very valued, especially in the office of the Dean. I would say that the associate Dean's primary responsibility is advising. So her functions have been to provide all kinds of workshops to improve advising." Faculty Advisor Three explained how her dean has improved her College's advising program:

We have an advising council in our college in addition to the university council. I think they called it the undergraduate advisory committee. We meet with the Dean once a month to talk about what's going on at the university in terms of advising, or recruiting events coming up, probation, and protocol and procedure for financial aid appeals, and all those things that tie in to advising. The council gives advisors a voice in the Deans office. So that's important and our Dean is really is really accessible.

The findings related to a committed Dean add to the body of literature. Kimball and Campbell (2013) found that "advisors can help create the conditions necessary for students to achieve success." The advisors would not be able to create those conditions were it not for the cooperation of the Dean. Research by Campbell (2008) found that advising must be integrated in to the vision and mission of the institution. Ultimately, the Dean is responsible on one level, for assuring his or her college or school complies with the vision and mission as it relates to the CAAP. King (2008) and the Council for the Advancement of Standards in Higher Education Standards and Guidelines for Academic Advising (CAS) (as cited in Gordon et al., 2008) identified the necessity of a strong leader as a key component of an effective advising program.

Decentralized approach. Faculty academic advisors had strong opinions about the organizational structure of advising. They preferred the organizational structure currently used by the University which consists of a decentralized approach to providing services wherein each College or School within the University is responsible for devising their own academic advising 
program. Faculty Advisor Three depicted how the decentralized approach allowed their faculty to work more closely with the students:

I think the decentralized system definitely has positives. I think it's so great that we are able to advise our students within our department because the careers our students go into are so varied, our curriculum can be pretty nuanced. I love that we are able to work with our students. At this point we are now, I had a meeting this morning and we are going to be able to take on even more of our students and have less students be met at the [advising center].

The following comment by this faculty advisor asserts that the decentralized approach was conducive to providing accurate degree completion information to students because the faculty in specific programs have more knowledge about the degree requirements than professional advisors do. Moreover, the faculty advisors have more knowledge about professional licensure and certifications than professional advisors. "I think it is important that it is decentralized. The faculty in those programs, know those programs the best. It's very difficult to conceive how a centralized advising system would work because each academic program is different. Faculty Advisor One agreed, "I think that in a university of this size that decentralized advising is almost a necessity. Given the uniqueness of a number of majors and their career paths that the student elects ... I think that the decentralized approach works." Faculty Advisor Five also favored a decentralized delivery modality for advising and stated, "Within the college, I think we do a pretty good job. The centralized advising that's done downtown, sometimes I think is kind of suspect." He further offered that he believed the professional advisors responsible for undecided and provisionally admitted students were not knowledgeable enough about specific degree programs and their curriculums. He stated, "I think that maybe because they're graduate students 
and maybe are not as familiar with all of the colleges on campus so they don't always know how to direct students to the appropriate majors they might be interested in.” Additionally, he expressed his approval of advising completed at his school and said, "Within the college though, I think we do a pretty good job at advising."

The findings regarding the faculty preference for a decentralized approach to providing a advising and other CAAP services are supported by the literature. The use of centralized advising has increased (King, 2008; Pardee, 2000), but a shared model is the most frequently model for advising (King, 2008). The advising model is important for an effective CAAP (Braxton et al., 2014; Cuseo, 2011; Gordon et al., 2008; O'Keeffe, 2013; Pascarella and Terenzini, 2005) but the literature does not support the faculty preference for a decentralized approach to advising (Drake, Jordan \& Miller, 2013).

School/college specific advising. Faculty advisors acknowledged school or college specific advising as the best structure for providing advising. There was a common belief among faculty advisors that providing advising within the department, by a faculty member, allowed for a more knowledgeable and individualized approach to facilitating student persistence and retention. Knowledgeable in the sense of degree requirements as previously noted, and more individualized as depicted by the assignment of a student to a specific advisor. Faculty Advisor Six explained how his program has a specific advising office and may be moving to a professional advisor model. He was disconcerted and stated:

Our program is pretty atypical compared to a number of others on campus. So if a student is identified as a pre major within our program, they are advised within our college. So faculty don't advise pre majors. Now there's some conversation that all academic advising within our college will be done in that advising office. That conflicts with the 
notion of increasing retention and student recruitment. I think that that faculty to student interaction is pretty important from a retention stand point.

Departmental advising was credited with the ability to individualize advising which, in turn, promotes the perception of students that the advisors care and are concerned for their success. The findings of this study indicated that student perception of care and concern was a major factor for persistence and retention. Faculty Advisor One offered the following explanation of the benefit of using a departmental model of advising with faculty advisors, "In the [division] we ...will typically have a few dozen to $40-50$ students in a major. That gives us the opportunity to do a lot of individualized advising with our students." He further explained the benefits of faculty and departmental advising, "I think that has been a strength for some of the smaller programs ... some of the larger programs will have a single advising session where all 300 majors in that department come in at one time." Faculty Advisor Four suggested connections made with faculty in the classrooms led to increased advising opportunities. "Many of our classes tend to be smaller 15-20-30 so the students do get to know their teachers much more on an individualized personal basis-one on one.” That relationship, he explained, promoted the student to take advantage of assistance, "They are usually pretty comfortable just walking in and talking about a classroom issue or something else that's coming up." This particular faculty advisor also stated, "I feel sorry for undergraduates that have to go to the downtown advising center. I don't think they do a very good job of what I think their job should be ... help those young people find an academic home." All faculty interviewed recognized the need to place students in the school or college for their chosen academic degree, even if those students did not yet meet the admission requirements of that college or school. The consensus was that the 
students would benefit from the faculty advising offered in that degree granting school or college.

All faculty advisor participants were proponents of using faculty advising as opposed to professional advisors. They believed faculty advising was necessary for forming a relationship with the student to further the students' engagement with the program, school, and the University. Faculty Advisor Four offered the following statement which connected faculty advising with a role in retention:

"I think that the sooner you can get students connected with a particular college and with the faculty and staff within that college, I think that helps from a retention stand point as opposed to just kind of floating around in terms of general academic advising."

Faculty generally like doing advising, and as previously referenced, a good advisor is necessary for good advising. People that generally like what they do are more likely to be good at it (Oswald, Proto \& Sgroi, 2014, p. 12). Faculty Advisor Four offered his perspective on faculty advisors,

Certainly there are good advisors, and some that are not so good. I like to think I am one of those good ones, at least students keep telling me that. Personally, I really enjoy getting to know the students and talking with them. That has been one of the more satisfying things I do even if it is kind of a black hole of time that eats up large chunks of the semester. I believe it is helpful for the student, and rewarding for me personally. There is a least an acknowledgement at the administrative level that it is something we need to do a good job with.

These findings related to faculty providing advising within the students' degree granting program are consistent with and are supported by the literature. Tontodonato's (2006) research 
specifically found that student satisfaction increased when advising was conducted by a departmental faculty advisor. Research indicates that student satisfaction is linked to retention (Bahr, 2008; Braxton et al., 2014; Fowler and Boylan, 2010; Harrison, 2009; Johnson \& Morgan, 2005; Kadar, 2001; Kuh et al., 2010; Melander, 2005; Pascarella and Terenzini, 1991; 2005; Pizzolato, 2008; Smith, 2007; Tinto, 1987; Titley \& Titley, 1982; Truschel, 2008; and Pizzolato, 2008). Faculty and student interaction through advising has a positive influence on the students' commitment to the program (Drake, 2011; Tinto, 1993; McArthur, 2005; Smith, 2007) which increases student retention (Kuh et al., 2010; McArthur, 2005; Pascarella \& Terenzini, 2005). The more faculty are involved with students, the more the students are satisfied with their experiences at the institution (Braxton et al., 2014; McArthur, 2005; Tontodonato, 2006). According to Cuseo (2011), one definition of good advising, and therefore a good CAAP element, is the educational/instructional element of advising. The findings that faculty prefer to provide advising is consistent with that literature. The faculty advisor is more equipped to provide an educational experience for the student.

Collaboration. Collaboration was recognized by professional advisors and administrators as an essential element of an effective CAAP. Collaboration focuses on communicating and working with colleges and schools, and academic and student success services. Because these professional advisors are housed in the advising center, they cater to specific types of students as previously explained, as such, they must be knowledgeable about the admission requirements for degree programs, and the curriculum for each program. Their primary goal is to facilitate the admission of those students to a specific degree program in a degree granting school or college. Professional Advisor Two explained his view on collaboration 
I don't get to see the students that graduate because my job is to get them into their major because when they applied to WVU, they didn't have the admission requirements or the ACT or SAT scores to get into their major. Really being able to have a relationship with the department allows us to know about changes in that department.

They advise students in their first year or two, and during that time, their main goal is to facilitate the transfer of these students to a specific college or school. Transferring to a specific school makes it imperative that the advisors know the admission requirements for degree programs, and the curriculum for each program. They advise students on the prerequisite courses that must be completed for the curriculum of the students' chosen degree. Professional Advisor Two noted the importance of selecting the appropriate course for admission to a degree program:

They [students] might look in the catalog and the student says, ok why don't you take these classes and they take them in random order, and that might postpone admission into their major or graduation. It doesn't matter what else they [advisors] do if they can't get them on the right path to take.

As such, the advisors collaborate with specific colleges and schools to obtain up to date information about courses and prerequisites. A second vital area of collaboration is with career services. The advising center has determined that students that focus on a career in terms of completing their degree are more likely to persist to graduation, thus the advisors refer students to the career services department for assistance with selecting a career. Professional Advisor One explained that career services teaches a class in career exploration as a mid-semester course, and stated "It's a really good opportunity for our students who either thought they had a major in mind and they're switching, or for students coming in that are exploring their options." The professional advisors emphasized a need to collaborate with the career services office and other 
resources on campus. Referrals to career services was not reserved for student persistence only, in fact professional advisor two viewed one component of good advising as prompting the student to see "the big picture" and that may not always include college. He stated, "Because my job, I don't feel is to just push students along, my job is to get them to succeed. I try to help students and say: if it's your best interest to graduate, let's get there." He recognized that students may not be ready for the rigor of college, "but sometimes you need to re-evaluate that and say, maybe right now is not the time for me." This professional advisor understood that college may not be for every student due to many different reasons and viewed career services as a referral to help these types of students succeed in life. He was attempting to look out for the overall best interests of the student.

Administrators recognized the importance of collaboration between professional advisors and other schools and colleges. They reasoned that in order to persuade the student to an appropriate degree program that aligns with the students' desired career path and academic aptitude, the advisor must be knowledgeable about many careers and degrees. According to Administrator Four, "We have to know their prerequisites, their programs, curriculum, and their degrees, otherwise our advisors cannot assist the student with getting over there [a degree conferring school or college]."

Findings concerning the data for professional advisors' perspectives on collaboration are consistent. Self (2008) found that professional advisors have a "willingness to obtain and share knowledge across multiple academic disciplines..." A notable feature of an effective CAAP is incorporating it into the organizational culture (Braxton et al., 2014; Kuh et al., 2010; Ahren, Ryan, Niskode',-Dossett, 2009). The collaboration finding support this research, in that, a deeply 
embedded phenomenon will lend itself to collaboration throughout the culture of the institution (Schein, 2010).

Preference for professional advisors. The use of professional advisors was acknowledged by two administrators and all professional advisors as the most effective advising delivery modality. The professional advisor model is not currently utilized at all colleges and schools throughout the University due to the decentralized organization model of advising, but professional advising was consider a better option by administrators than faculty academic advising and the hybrid model. Administrator Three staunchly advocated for the use of professional advising model but didn't want to remove faculty form advising. He deemed it more effective to redirect the advising energy of faculty, and stated "That does not mean you remove faculty from advising, what I think we need is a two-tier approach. The academic advising is provided by professional advisors and that moves us to the advising as teaching model." Through his experience as an administrator of a professional advising unit, professional advisor, and currently a University administrator, he viewed faculty more as mentors "Then faculty become mentors. That's where I think the real role for faculty members is. They provide mentorships." He believed the mentoring could advance the academic experience for students, and engage them in a scholarly manner, and he stated, "They help students understand the specific field, how to grow in that field, what kind of capabilities, knowledge, and experiences are needed ... so that when they leave the institution they can be a valuable contributor to that specific field." He further stated "Just like you have faculty members who concentrate on teaching and research in their specific domain or field, advisors can devote all of their attention and time to advising" and he compared that focus to faculty that devote their time and energy to becoming an expert in their discipline. Administrator Three expanded his perspective "That's where I view professional 
advisors providing the boots on the ground, the real heart and soul of the developmental approach and the intrusive." Administrator Two stated, "All of the other things which faculty members don't have time to do, nor do I think they necessarily need to do, would be done by professional advisors." Even though faculty saw these professional advisors as not as effective, he looked at using professional advisors as an improvement "that would really help change the course of advising on campus."

A second positive feature of using professional advisors is that, they are, trained in advising best practices, and have knowledge about various advising models, as Administrator Two notes:

Staff [the CAAP] with professional advisors who have had professional development, who are members of NACADA, who go to the NACADA conferences and learn best practices for advising and understand that sometimes you need to do developmental advising, sometimes appreciative, and sometimes prescriptive. But you need to know there are differences in advising types and styles, and you need to meet the needs of a very diverse body of students.

Administrator Two recognized that faculty advisors may have a different approach than professional advisors, but she chose to remain neutral in identifying the best approach: In some of the colleges and schools, students are advised primarily by faculty members. That's fine but it's a very different style from say [the advising center] where we employ full-time professional advisors that are not faculty. That has its own advantages and disadvantages but the flavor is very different.

Professional advisors concur with administrators and recognized that the use of centralized professional advisor model permitted the professional advisors time to obtain professional 
development to improve their knowledge base in regard to specific advising practices.

Professional Advisor Three stated, "The good thing about that [professional advisor] model is, if we have professional advisors, they will have to go to training, they will have to attend NACADA conferences." He further added that that training informs their advising practices in a manner that improves their knowledge of specific advising models, and how to implement those models. "For the faculty member, they have only, depends on the department, $10 \%$ of their responsibility for advising. They don't advise very often so faculty advisors forget things. That's important, you have to give out the accurate information." He continued, "Each department should have their own advising center run by professional advisors. And if you have peer advisors that would be good too." Data indicate that most administrators are in favor of using professional advisors and view them best approach for advising within a good CAAP. Faculty advisors have a divergent perspective, and contend that faculty advisors are more effective advisors. Their standpoint is that faculty are more proficient with providing students guidance towards career development in addition to providing an effective, efficient, and expedient degree completion plan.

\section{Specific Strategies Aimed at Retention}

Two common themes spanned the participant categories: admission to a degree conferring college, and the use of varied advising models. The remaining specific strategies aimed at retention were divergent across participants. Additional specific strategies aimed at retention include: the advising hold, parallel degrees, and other strategies: identifying at-risk students, focus on career development, embedding the CAAP in to the curriculum.

Divergent themes for retention are not uncommon in higher education (Braxton et al. 2014; Drake, 2011; Light, 2001; Noel-Levitz, 2009; Pascarella \& Terenzini, 1991: 2005; Tinto, 
2005). King (2008) identified several factors that influenced strategies for retention inherent in a CAAP: the institutional mission, student population, the role of faculty, programs and policies, budget, facilities, and administrative organizational structure. Each faction of the University would have a different perception of how these matters are factored in to retention. Braxton (2014) identified state leaders and policymakers as being influential for student success. Their role translates in to specific institutional policy set forth by the administration of the University to comply with governmental initiatives for student retention. In West Virginia, the West Virginia Higher Education Policy Commission, under Title 133 Legislative Rule, set forth performance indicators for Higher Education Institutions (HEIs). Section 3.3.3 specifically recognizes retention as a performance indicator. This policy is certainly influential for WV HEIs, in that, it impacts the institution's policy and strategic plans for retention because the State Legislature refers to the WVHEPC performance indicators when considering budgets. Thus, there are many influences on the determination of specific retention strategies that represent internal and external constituents at the University.

Admission to a degree conferring college. A common retention strategy recognized across participants was the need to admit students to a degree conferring school or college as earlier as possible. data indicated that students that were placed, as early as possible, in a degree conferring school or college were more likely to persist to graduation, and the literature supports that notion (Braxton et al., 2014, McArthur, 2005; Smith, 2007; Tinto, 1993; Tontodonato, 2006). Student data indicated that they believed they received the most knowledgeable advising at their degree conferring school or college within the University. Students had no preference for professional or faculty advisors as long as they were housed within the student's degree granting college. A prominent thread that developed through this theme was that all but one student 
interviewed were dissatisfied with the professional advising for undecided/general studies, or provisionally admitted students. Student Three expressed the following about her advisor in her degree conferring school:

He's very knowledgeable. He knows what he's talking about which goes toward credibility and makes me want to listen to him and because if he knows what he's talking about, I know that I will get a good education, have a great future, and get a good job when I get out of here.

One aspect of the mission of the professional advising unit at this institution is to place students in a degree conferring college or school as soon as possible. Advisors at this centralized advising unit primarily advise students that are undecided on a specific major, and students that have been accepted in to the University and have selected a specific major, but did meet the admission requirements of the college that house that major. Facilitating a student's transfer to a degree conferring college means that the advisors must be knowledgeable about the admission requirements and knowing the prerequisite courses necessary for the required courses in specific degree programs. All the professional advisors added that the information needed to be accurate so they were consistently updating their information about academic issues. Professional Advisor One indicated: "It's about communicating with other departments to make sure we know all the policies and curriculums ... any changes that are happening, because in our unit, we are affected by the entire university because we advise all students on campus." The clientele that professional advisors work with make it necessary for the professional advisor to be knowledgeable about many different academic majors, specific college and school admission requirements for multiple schools and colleges, as well as knowledge about the multitude of other resources available to students related to academics and residential issues. As such, the 
professional advisor must communicate with the college or school their assigned students hope to be admitted to in order to have knowledge of those admission requirements. Good advisors act as "the bridge between the student and the institution" according to professional advisor three. The bridge this professional advisor was referring to was knowledge about resources. They must provide them with accurate information so they can persist to graduation. He attributed knowledge with influencing their role in retention: "Because we are the bridge between student and institution, they listen to us and they do well, and they stay in school... Advisors really help retention."

Administrators considered advising to be a crucial element contributing to student retention, in that, advising was important for matching students to an appropriate degree program, and thereby admitting them to the school or college that confers that degree. Administrator Two stated “These [provisionally admitted and exploratory] students don't feel like they have an academic home. They need an academic home." Finding an "academic home" was identified as an issue for student retention. A major administrative concern was with students not being able to persist to graduation in a timely manner due to an inaccurate alignment of the students' academic aptitude with the curriculum requirements of the students' chosen degree. Administrator Three illustrated an example of that concern:

It helps to understand where a student is and helps to try to move that student. You can't say "all students should be here," but instead figure out where they are on the spectrum and say, ok how can we move a student from point A to point B or wherever that may be instead of trying to get all students to point B regardless of where they start.

A specific example of this concern would be a student that wanted to major in engineering but tested into remedial math. Potentially, it could take that student up to three additional semesters 
to complete that degree, and the administrators were aware of the elevated potential for student attrition in this type of case.

The importance of expeditiously admitting students to a degree conferring school or college was also evident in faculty advisor data. Faculty advisors were resolute about the need to connect a student with a specific college or school within the University. Their opinion concurs with the opinions of administrators and professional advisors. Faculty Advisor Six was very proud of the fact that his school advised their pre-major students. The sooner the student is housed within a specific school, the sooner they can begin building a relationship with their faculty academic advisor. Several faculty advisors explained that as faculty and academic advisors, the students see them more than they would a professional advisor since the students are in their classes, and see them for advising. Faculty Advisor Four stated "Because I'm teaching courses in their major, I'm certain to develop a much more personal relationship. That relationship lends itself to retention." Faculty Advisor Three said "By the time a student graduates, they are close with at least two faculty members who know them and have relationships with them as students." The connection between the student and advisor and department, allows the advisor to gain a thorough understanding of the students' career aspirations.

Faculty contended that they were in the best position to provide effective academic advising and other CAAP services and referrals to students. That contention was founded on the idea that faculty are curriculum and career experts in the degree of study. Faculty Advisor Two's stated, "Faculty are in the best position to know how to shepherd students through the university process and on to the next phase. So anybody can hand students or tell students what classes to take right, that's the trivial part." Faculty Advisor Three, a communications professor, further 
supported that idea: "A lot of what we do during advising is helping them not just figure out courses and their academic route but how that would apply in the professional world. Our mentoring system has been very helpful." Faculty Advisor Four further explained how course selection is only one element of an advising session. He additionally addressed the other services inherent to a good CAAP such as addressing internships, careers, and other academic opportunities as part of quality advising, and offered his idea of good advising, "So a good advising session is when the student comes in prepared...Then I can talk about the good stuff like where you can get a job, and have you heard about this internship..." Additional faculty discussed career planning, professional development, internships, and scholarships as topics related to academic success, such as Faculty Advisor Six, a sports science professor, who stated "But a lot of the other stuff that happens during advising in terms of career exploration and talking transitioning into professional positions, a lot of that happens as part of our curriculum." Faculty Advisor Five, a natural resource professor, incorporated scholarships into his advising program and recognized how important that was to student persistence:

I always like to mention the scholarships. If there's money to be had I think they should throw it at my students. I'm selfish that way but the students appreciate it. Many of them are not aware of some of the scholarship opportunities that are out there. So both in terms of scholarship and professional development those are the main things I try to focus on. Faculty advisors primarily focused on integrating information for academic success in to the advising session, but also recognized the relevance of providing referrals for psychosocial issues. They recognized that good advising focuses on the "whole person" and that psychosocial issues can hinder students' persistence and retention. 
Varied advising models. The second common retention strategy recognized across all participants was the use of varied advising models. As previously described, student data indicated satisfaction when the advisor incorporated developmental advising techniques, but their primary concern was with proper course selection, thus specifying a preference for the use of the prescriptive model of advising.

Administrators expected advisors to use, multiple advising models. They also expected advisors to match the appropriate advising model with the needs of the student. The prescriptive, developmental, appreciative, and intrusive models were all identified as important advising models for good advising. The administrators acknowledged that academic advisors must understand the underlying tenets and applications of these models, and other advising models, in order to align the most appropriate model with the needs of the student. Administrator Three proffered that "Hybrid models are the best. I don't think there's one model that works for every situation or addresses all the needs of all students." He suggested that a holistic approach be used, which "allows you in certain situations to use a certain model." The advisor must be an advising chameleon so to speak, or at least be intuitive enough to comprehend the needs of the student. Administrator Two recognized that "developmental advising is the one that works the best for most students in most times of the year" and administrator three added that developmental or appreciative should be used most often, but prescriptive was actually the model being used and stated "That's how a lot of our faculty view advising. It is prescriptive and concentrates on course scheduling." The following statement reflects the expectation of administrator three for utilizing multiple advising models:

There are occasions where you do need to use prescriptive advising and that is a time when you need to quickly see a lot of students, add/drop is a perfect time. During that 
time period we might want to confine most of our advising to prescriptive to help and address as many students as possible and get their needs met. Then there are times when we're gonna talk about a situation that you [students] may be grappling with; whether you stay in this class or not. We also may want to talk more holistically where you see your skills and whether this meets your skills, and any deficits you have, and how that impacts your major selection, impacts you total career selection, so we can talk about that but maybe during add/drop is not the best time to do that. Then do a more developmental approach during a non-peak time period where we can talk more holistically. Then we may need to use a more intrusive model for academic difficulties or there's gonna be a consequence. So there are certain times we need to use the different models, but overall I think developmental advising is the one that works the best for most student in most times of the year.

An additional perspective was offered by Administrator Two, "In terms of advisors: I really like advisors who understand when they probably need to be prescriptive." She further explained that students in certain majors, like pharmacy, are more likely to need prescriptive advising only, and she likes "an advisor who knows when to be more developmental or appreciative sitting there with an exploratory student. I love the advisor who's able to turn that on and turn that off." These divergent perspectives of good advising could be attributed to the highly decentralized model of advising at the University.

While all the above mentioned perspectives of good advising are in fact recognized in the literature as good advising approaches, it appears that this institution has not been able to bring them together for the common goal of student retention and persistence to graduation. The institution has made an effort to merge best practices in advising, that occur across the 
institution, through the University Academic Advising Council, but the council was too new at the time of data collection for this study to collect data on its effectiveness. The overall benefit derived from good advising, that were apparent throughout all four categories of participants, was the positive impact advising had on student success through referring students to the proper resources, retention of students, and persistence to graduation.

Faculty academic advisors specified their concern for students above and beyond the students' academic success and degree completion at the University although, those issues were deemed important for the good advising component of the CAAP. They conveyed that advising should address academic and psychosocial issues, and various advising models should be used that are conducive to the "whole person." The majority of faculty advisors identified the developmental model as being used most often. Interestingly, only two advisors referred to this model by name but explained their advising techniques which aligned with the developmental advising model. The advising model is a relevant finding because faculty advisors expressed interest in matching their advising style with the advising needs of the student, and that finding is supported in the literature. Faculty Advisor Three explained that she used the developmental model often: "I think mostly developmental [used most often]. Not so much intrusive but I think it just depends on the students and what I see their needs to be. It depends on the situation." She explained that some students require more advisor interaction than other students, and that the specific situation guides the advising model she used. "There are times when I may be concerned with a student and I'll bring them in to work with. There are other times when the student is independent and I let them come to me, but it depends on the student." She further explained that she used the developmental model in her advising to discuss academic issues, career concerns, and to encourage involvement with the University, based on the students' interests: "We talk a lot about 
what their passion and what their interests are, and the classes they enjoy the most. We try to figure out minors, careers, internships, how they can get involved on campus, or involved with jobs." She illustrated how the developmental model was used to match the student with resources and provide referrals to enhance student success and persistence: "If they really have no idea of what they want to do.... We encourage our students to research what our alumni have done to see if there is a mentor that would be a good match for them." Faculty Advisor Five described his use of developmental advising: "I encourage them all to do internships. I help them if they ask, or I offer to help them with resumes and cover letters." Faculty Advisor Four provided additional details about his developmental advising technique:

I have a standard list of issues that I always try to talk about with each student. First and foremost what they're interested in is scheduling classes, then I want to talk about study habits, extra-curricular activities, particularly professional development in terms of internships, summer jobs, and other ways they can develop academically and professionally. I talk a little bit about resume building, inquire about study abroad, professional field experience courses or something thy might not have thought about, but I think is usually important. I try to cover academic and professional development topics. I'm much more interested in how they develop professionally. Most freshman and sophomores haven't thought far enough ahead to where they might want to find a job, and if they wait till the last semester as a senior, then it's too late to develop a comprehensive resume. So I try to encourage them to be thinking about those things and offer help wherever I can during that session.

The professional advisors used a variety of advising models for helping students. One method of helping students was to guide them with decision making processes. A developmental 
model of advising was used, as stated by Professional Advisor One, when he was guiding the students with their decision making processes:

I use developmental advising. I really want to encourage my students to seek out their own information. Sometimes when students come to me, and they're like: can you tell me this, well I'm like why don't we look up this together. I want to equip them with the skills that helps them build a student's life as an adult. So, I don't want to feed them all the information. I want them to learn how to access information in hopes that they are going to be developing out of that advising style.

Professional Advisor Two did not address the developmental model by name, but he did provide an example of how he helped students develop, and his example aligned with the developmental model: "I use a style of: I like to provide students with all the options. I never want to tell the student ...you can't do this or you can't do that, or should do this or you should do that." He further explained that he guides the students with their decision making process, "I say: what would you like to do? I'll show you what you need to do to get there, and also tell you what your options are, and what the consequences of whatever choice you make might be.” Helping students was also explained in terms of academic issues. Professional Advisor One described the programmatic pieces professional advisors use to assist the students with academic success: “... through a series of seminars, we focus on certain aspects...that students will be able to benefit from. For example, next week we have students coming in to focus on midterms and what the importance of dropping and staying in courses." He further explained that additional seminars focused on the implications of dropping or staying in courses for the semester, implications for withdrawing from courses, or picking up mid-semester classes, and that students benefitted from these seminars because "It's not only information that's going to help them in that point in time, 
but its information that's going to carry over to different semesters and years they are at the university." Professional advisors acknowledged the importance of helping the student with proper course scheduling. Professional Advisor One stated

Another piece we do towards the end of the semester when they are about ready to register for their courses is helping them build that schedule. So we are looking at how to build a schedule, a lot of them will see classes that are just offered and they are like: okay that works, but they don't take into account: which campus is it on, what professors do you have. A lot of these are pieces that students could very easily look over if they're not instructed to be mindful of them.

All three professional advisors acknowledged that at times, the prescriptive advising model was used for helping students select courses. However, they were adamant about the idea that their role as an advisor entailed more than course scheduling. They recognized the importance of motivating and encouraging for building a rapport and fostering student persistence and success. They used other advising models other than the developmental model for motivating and encouraging students, as explained by Professional Advisor Three:

Most of the time I use intrusive and appreciative. I believe the students now need a little push. I will especially push my students that aren't very motivated. The population we serve at [the advising center], the reason they don't get admitted to their college directly is because of the low GPA, or ACT or SAT score. They already come in not very motivated. So, we have to push them. Also, I have reached the age that I could be their uncle or even their parents so I don't mind pushing them. For young advisors, it would be a problem for them because they are just a few years older than our students. It's easier 
for me to push them. [I use] the appreciative advising because you have to bring the best out of the students.

None of the three professional advisor presented themselves as someone that would tell the student what to do. In fact, they were adamant about allowing the student to make his or her own decisions, and felt that using the developmental model of advising was the best model to facilitate that student development. All three advisors recognized the need to use different models of advising dependent on the needs of the students. They also used prescriptive models at times and expressed using advising as teaching. The end result, for whatever model of advising they chose, was to help the student,

I think you have to have passion. People would think, oh that's [advising] a low paying job, but I love it, I like it. You have to have an advisor that has the passion or motivation to help the student. Advising is not only give them the class schedule, it's more than that, and a lot of people do not know that. That's why some faculty members or some people will think, ooh what do advisors do; they give classes to the student. No we do more than that.

These findings regarding the effectiveness of using multiple advising models for building rapport and student retention are consistent with the literature. These findings support the literature that some researchers recommend an integrated model of advising that incorporates multiple models (Cuseo, 2011; Freeman, 2008; Harrison, 2009; Heisserer \& Parette, 2002; Johnson \& Morgan, 2005).

Most research indicates a preference for the developmental model of advising due to the positive correlation it has with student satisfaction (Drake et al., 2013; Grites and Gordon, 2000; Hale et al., 2009; Kadar, 2001; Melander, 2005; Yarbrough, 2002) but they also recognize the 
need for a holistic approach which includes the use of many advising models including the prescriptive model (Creamer \& Scott, 2000; Crookston 1972; Robbins et al., 2009). Research did not recognize the use of the student success collaborative/parallel programs, as such, this finding adds to the body of literature.

Parallel degrees. Data produced divergent results for the strategy of parallel degrees. Administrators and professional advisors identified the use of parallel programs as a specific retention strategy. An administrator expressed the need for this strategy as follows:

We have got to match those students with an academic program where their skill set and academic competencies are going to help them succeed. I think what we have is a lot of students who are holding out for programs that they will never be eligible to get into. That's where we lose some of the attrition particularly in the junior and senior year. Several of the administrators found that advisors were in the best position to "get to know the student" and "help them find another major close to their first major of choice." This is where parallel programs come in to place. Parallel programs were explained with the following example: a student that wants to be a doctor but tested into remedial math should be persuaded to consider a career that matches his or her career goals such as a career as a medical technology or EMT. Then the academic advisor would communicate the realistic completion of the similar degree and explain to the student the similarities with the careers. The administrators' perspective is that the academic advisors are in the best position to persuade the students if they have the knowledge of program curriculums, admission requirement, and career requirements.

Administrators recognized advisors must have the communication and persuasion skills to persuade the student into setting realistic educational expectations. Administrator Four provided the following example as an explanation of the interpersonal skill of persuasion: 
Advisors must be able to help persuade our students into areas where their skill set is proficient enough to do that [degree], for example; students in remedial math may not be well suited academically for the engineering program. That particular case would take an additional three semesters for the student to even be admitted into the engineering program. Advisors need to persuade students into realistic expectations. Advisors need the interpersonal skills to make them understand the time involved to get the degree they want, and help them find another major close to their first major of choice. This is where parallel programs come in to place. It's [parallel programs] a thought process not a plan. It [parallel program] hasn't been implemented yet, but that's the direction we're moving in.

Persuading a student toward an appropriate degree is determined by the student's academic ability to complete the degree in a timely manner, and aligns with the students' career goals. All administrators agreed with this perspective and administrator one stated "Advising is critical from the aspect that somebody needs to work with the student one on one to help them identify their academic goals, what those career goals are going to be, and try to assimilate.”

A derivative strategy of the parallel program initiative is the newly developed Student Success Collaborative (SSC). Administrator Four stated, "We are focusing more on student retention and the way we're doing that is introducing a new system that's coming in to place called the Student Success Collaborative (SSC). This is a system that integrates with Banner (records grades, transcripts...).” The system will be used to set up a tracking and monitoring systems for students enrolled in different categories, for example classifications by GPA, major, and class standing. He further explained that "This system is set up to go in and look at a student profile, to see what area the student is suited for. We can look at success markers. It allows us to 
identify what we call success campaigns." A success campaign was explained as: if a student is struggling with courses they need for their major: it allows them to help direct them into a different field. They use to use what we called a plan B. The problems with plans A and B is that students perceive plan B as the failure plan. Plan B is now referred to as a parallel program which provides a positive outlook on success.

The use of parallel programs are of particular importance to professional advisors. Once the student has a career focus, they match the student with an appropriate major. The professional advisors addressed the fact that a career focus is important for pre-majors and exploratory students because, at times, the pre-majors do not reach the level necessary for admission to the college or school the first choose. An alternative, but similar career, may need to be examined. The undecided students need to match a degree with a potential career. Professional Advisor One expressed his view on a career focus:

I think there's a big push for career services which doesn't happen a lot within an academic unit, it's a student life unit, but career services really helps our students in terms of exploring their options for careers, such as what majors could lead to those careers. That's one thing, especially in our unit, that we encourage our students to seek out is help from career services, especially with our exploratory population. In addition to establishing a focus on careers, the professional advisors incorporated several advising services into their CAAP approach. The service most often cited as being central to student success was a series of seminars. The advising center offers seminars in the fall and the spring, but they are only available to students in their college. These seminars focus on the technical aspects of navigating college such as, schedule building, adding, dropping, or withdrawing from courses, and navigating technological tools and resources. A professional 
advisor referred to these seminars as follows: "It's not only information that's going to help them in that point in time, but its information that's going to carry over to different semesters."

These findings are supported by the literature. Braxton et al., (2014) found that academic advising influenced academic and intellectual development. Findings illustrate that when advisors used communication in the established student and advisor rapport to persuade the student to the appropriate degree program, the student was more likely to persist. Braxton et al. (2014) stated that “...academic advising fosters the academic and intellectual development of students given its emphasis on the realization of the academic potential of students" (p.189). The findings additionally support the literature in that, the art of persuasion as identified by administrators, aligns with the developmental advising model. The developmental model is premised on the idea that the student and advisor collaborate to resolve issues and develop goals and plans related to academic success and persistence, or psychosocial issues (Drake et al., 2013; Grites \& Gordon, 2000; Hale, et al., 2009).

The advising hold. Data produced divergent results for the strategy of the advising hold. The most significant student data concerning retention was related to the advising hold, and they were the only participants to identify this strategy. The University instituted an advising hold for all students which requires them to meet with their advisor prior to registering for courses. The advising hold is an essential component of the CAAP. Findings indicate that the purpose of the advising hold is two-fold. First, the hold prompts a review of the students' progress toward graduation which allows the advisor to address any issues related to student persistence. Second, the hold promotes interaction between student and advisor. This interaction is identified as a factor for student retention. 
Five students supported the advising hold, and four of the six students interviewed recognized academic advising as having a significant role in their persistence to graduation. Student Four even attributed advising with lowering the overall student attrition rate and stated, "If you're forced to go to an academic advising session, it forces you to have your stuff, I don't know, it just forces you to be on track, and if you're on track, you're more likely to stay in school." Student One recognized the importance of the advising for persistence and stated, "I think it's good but I don't think it's great, but I think it's necessary because otherwise you'd have plenty of people shrug off advising and say oh I'll figure it out. He viewed the advising hold as beneficial to himself and others to ensure a timely graduation and further stated, “...Then graduation would come and they wouldn't be ready, they wouldn't have the classes.... I am set to graduate and they said I don't need advising anymore. Even without making me go to an advisor, I still want to." Student Three simply stated, “It's [the advising hold] good just because it keeps kids on track and the advisor can help them." Students were not only interested in general course planning from the advising sessions that were prompted through the advising hold. They desired accurate course planning; accurate in the sense that they were fulfilling the degree requirements to ensure their timely graduation. Student One expressed his discontent with inadequate and inaccurate course selection as follows:

When I first got here they told me I didn't need to take a freshman orientation class, and now I'm a senior and preparing to graduate. The history advisor, [told me] you know, you never had an orientation class, and I was like yea when I first came here they told me I didn't need one. He started freaking out and said no, no one can get out of that. He tried to get me out of it and couldn't so now I'm in an orientation class. I was kind of angry 
about that cause I wish I would have taken that as a freshman if anything, you know. It was a student advisor. It was the orientation advisor."

Student Four explained how completing a degree in a timely manner appeared to be an important retention strategy for students, and stated "If you are on track, you're more likely to stay in school." She further explained that "Obviously it would be very difficult to stay in school if you knew you weren't going to graduate in time and had to take a whole other year." The advising hold is a CAAP initiative that forces the student to interact with their advisor. The interaction begins with the goal of course scheduling but often leads to interaction that forms the impetus for the student advisor relationship. In summary, students attribute the forced advising with having a significant role with their student persistence.

The findings support the literature related to student persistence and advising, however these findings expand the literature by presenting the high value on scheduling that students placed on that aspect of advising. This indicates a very strong tie to the prescriptive model of academic advising (Creamer \& Scott, 2000; Robbins, 2012), but the majority of literature subscribes to philosophy that students desire a more developmental model of advising (Drake et al., 2013; 2000; Grites \& Gordon, Hale, et al., 2009; Kadar, 2001; King 2005; Melander, 2005; Pascarella \& Terenzini, 2005; Yarbrough, 2002). The findings also align with the literature related to the intrusive advising model. Intrusive advising uses the skills of prescriptive advising (Earl, 1988). Glennen (1975) recognized that a major issue with developmental advising was student self-referral. Students are reluctant to seek out advising on their own, so the advising hold tactic implemented by the University can be viewed as an intrusive advising technique, in that, it forces the student to have contact with their advisor in order to register for courses. That advisor and student contact that began as prescriptive is widely recognized in the literature as a 
contributing factor for student retention (Bloom et al., 2013; Heisserer\& Parette, 2002;

Pascarella \& Terenzini, 2005; Truschel, 2008; Varney, 2012). The initial advisor and student contact is the first step toward building a positive student and advisor relationship. Another overlapping point in the literature and research findings for students is that increased student advisor contact and interaction improves student satisfaction, and student satisfaction has been linked to student persistence (Bahr, 2008; Braxton et al., 2014; Fowler and Boylan, 2010; Harrison, 2009; Johnson \& Morgan, 2005; Kadar, 2001; Kuh et al., 2010; Melander, 2005; Pascarella and Terenzini, 1991;2005; Pizzolato, 2008; Smith, 2007; Tinto, 1987; Titley \& Titley, 1982; Truschel, 2008; and Pizzolato, 2008). Student satisfaction heightens the students' social integration in the institution which also serves to positively impact student retention (Kuh et al., 2010; MacArthur, 2005; Pascarella and Terenzini, 1991: 2005; Tinto, 1987). Tinto (1993) stated "the greater the degree of social integration, the greater the level of commitment to the institution. The greater the commitment to the institution, the greater the likelihood of persistence" (pp. 147-148). Braxton et al. (2014) research findings supported those propositions, and added that "the more a student perceives that the institution is committed to the welfare of its students, the greater the student's level of social integration" (p.95). Students use academic advising as a method for gauging the commitment of the institution to the welfare of students. In summary, the two purposes of the advising hold as depicted from student data include: degree completion in a timely manner, and to promote contact with the advisor. Students recognized those purposes as being influential for their retention and the literature supports those findings.

Other strategies. Data produced divergent results for other strategies. Faculty advisors only acknowledged the use other specific strategies aimed at retention: identifying at-risk students, focus on career development, and embedding the CAAP in to the curriculum. Several 
faculty advisors considered the at-risk student population as an important factor for student retention and academic advising. Identifying, advising, and providing referrals for at-risk students was the first specific strategy aimed at retention. The at-risk population included those students with: emotional problems, relationship problems, family problems, drug problems, financial issues. Faculty Advisor Six categorized at-risk students in terms of the support services they may require for persistence and retention. They were identified as: first generation students, minority students, and students with disabilities. He explained that those were the groups that, through his experience, may require additional advising assistance and further stated, “...that relationship with the advisor and support might be increasingly important. How to do that, I think early and frequent contact with the advisor is important and I don't know how often that happens honestly." Faculty advisors understood that the type of student is correlated to the probability for retention, in that the at-risk student population were more likely to require more academic advising, or a different model of advising in order to retain that type of student. Faculty Advisor Three exemplified how her department uses a specific advising model to address the needs of at-risk students:

We are a really close, tight-knit faculty. A lot of faculty will come to me with questions. They are great about referring students if the students they have questions they can't answer. If I have concerns about a student, I go to an instructor I know they are working with and we work together to handle the issue, and that allows us to do more intrusive advising.

She further explained that her department uses a collaborative approach to address the needs of at-risk students in her department, and that a multi-faceted approach to advising was the approach they used. Multi-faceted was defined as using various advising models, and resources 
that addressed the academic and psychosocial needs of the students. As previously addressed, faculty determined their advising model based on the students' needs. Specifically, some students required prescriptive advising only while others required developmental. The faculty advisors used the developmental advising model most often with the at-risk students, and recognized matching the advising model they used to the specific needs of the student as a specific strategy for retention.

Interestingly, most faculty advisors seemed to associate a focus on career development with retention. Faculty advisors held the idea that students become motivated to persist to graduation when they can connect degree completion to a successful career. As such, some faculty advisors use their advising meetings, and classroom time to emphasize to students the alignment between coursework and work force requirements. That concept is exemplified in the following statement by Faculty Advisor Two:

Students tend to see their advisor as one of the teachers and somebody they interact with on several different levels. That forces them to get outside of their own little focus on just what classes will I take next semester and into where am I gonna be 10 years from now. I think some students disconnect their academic achievement from their personal life goals. Faculty advisor three stated, "We want them to start thinking: these courses, projects, assignments, writings, things I've done through leadership or extracurricular activities, work experience, study abroad, how will these look for potential employers." As a faculty advisor and instructor, the faculty advisor not only emphasizes these points in the classroom, but had the opportunity to reiterate them during advising meetings. Several of the faculty advisors offered details of the methods used by their departments for embedding a focus on careers and career planning into their course and program curriculum. Several faculty advisors recognized that a 
focus on careers and career planning was an essential attribute of an effective CAAP. They also offered detail regarding the embedding of certain CAAP attributes in to the curriculum

Two of the faculty advisors elaborated on how their department has recognized advising as a contributing factor for student retention and persistence and how they have embedded the CAAP in to the curriculum. The following is an example, offered by faculty advisor three, of an advising initiative embedded in this Departments CAAP: "We just had a speed networking event. We had 18 alumni. Students met with them 8-10 minutes and there was a reunion afterwards for career advice. We want to make the alumni accessible to them." She further illustrated how this event aligns with the focus on career development which is a CAAP initiative in her department, "We want you to see the options but then be able to focus on something you are interested in, do an internship there, informational interviews, or volunteer there to learn about that career path." Faculty Advisor Five offered another example of embedding the CAAP into the curriculum through a specific course, "It [advising] is something that is emphasized in orientation courses. In the AG 111 course, the instructor does a scavenger hunt.” The scavenger hunt was explained as an initiative used to promote student engagement with the University, department, program, and advisor. He further stated that the activity “...requires all the freshman in that course to meet with their academic advisor... go to a farm, go to the green house, and get a faculty advisor signature for at least one of the student organizations in our department." He elaborated that "Students get a chance to be exposed to the opportunities of student organizations." The following is an example of how the CAAP is interwoven across the curriculum and was explained by Advisor Six:

The students are advised extensively by faculty across the program of study. A lot of that happens within our classes because we really are a professional preparation program and 
we have standards related to accreditation and that type of thing. So there is a lot of focus on that within the plan of study.

Other departments embedded components of the CAAP in to their degree specific student orientation class and their capstone courses as well.

The findings related to focusing on career and connecting courses to workforce requirements, connecting students' to a degree conferring college or school, and embedding the CAAP into the curriculum expands the research. The body of literature related to student retention does not address those elements of a CAAP. These findings support research related to identifying at-risk students. Academic advising programs have been recognized as a vital component of retention programs, first-year programs, and at-risk student programs (Braxton, Hirschy, \& McClendon, 2004; Sams, Brown, Hussey, \& Leonard, 2003; Chiteng Kot, 2014; Cuseo, 2011; Wirth \& Padilla, 2008; Trotter \& Roberts, 2006; Turner \& Thompson, 2014). Research indicates that two advising models are best suited for the at-risk student: counseling liaison, and intrusive. Kadar's research (2001), found that the counseling liaison model uses a goal-centered approach to advising which addresses psychosocial adjustment to academia as well as academic issues. The intrusive advising model takes a proactive approach to intervening in the students' progress at the first indication of academic difficulty (Glennen, 1975; Earl, 1988; and Varney, 2013). Research by Crookston (1972) Earl (1988), Cuseo (2011), Drake (2013), and Braxton (2014) concurs with this holistic approach to advising.

These specific retention strategies findings support research by Freeman (2008) and Nitecki (2011) in which they found that institutions that implemented or improved advising programs experienced an improvement in student satisfaction. Research also indicates a link 
between student satisfaction and student retention (Braxton, 2014; Cuseo, 2011; Fowler \&

Boylan, 2010; Kuh et al., 2010; Pascarella \& Terenzini, 2005; Tinto, 1993).

\section{CAAP Characteristics Embedded in the Institution's Culture}

Two themes evolved from data connected to the second research question regarding ways in which the institution has embedded the CAAP into its institutional culture: visibility of the CAAP, and the value of the CAAP. These themes overlapped across all categories of participants. Edgar Schein's theory of organizational culture serves as the theoretical framework for this study, and it is the foundation I use to examine how culture affects a successful CAAP. Findings indicated that academic advising has a pivotal role in the CAAP at the institution under study. Schein's theory revolves around three cultural levels: artifacts (surface level), espoused beliefs and values (middle level), and basic underlying assumptions (deeply embedded level) (p.24). Each level indicates how deeply embedded a phenomenon is within the institution's culture. Findings from this research study indicate that the University's CAAP has successfully embedded itself into the surface and middle levels of the culture.

Visibility of the CAAP. The visibility of the CAAP relates to the surface, first, level of culture, and relates to anything about a phenomenon that one can see, feel, or hear. All participant categories identified that CAAP visibility can be determined through the methods in which students gain knowledge that a CAAP exists.

Findings from students indicate that the CAAP is highly visible. Students become knowledgeable that a CAAP exists through new student orientation, the "Academy", emails, and the advising hold used to promote advisor contact. Student Five explained how he became aware of the CAAP: "We usually get an email around the time advising is about to start telling us that we should make an appointment with our advisor." Student One described gaining knowledge 
about the CAAP through student interaction with other students, advisors, faculty, and other staff and stated, "Advising is audible, people talk about it. It's not visible" but also said "Advising should be "flashy." In other words, he was conveying that people should be easily aware of the CAAP. Other students explained that advising is communicated through emails and flyers at the education learning center, is easily accessed, and appointments are usually required. One of my interview questions was related to how easy it would be for a new student to become aware of the CAAP. This question is directly aligned with the visibility of the CAAP. Student responses varied. Student Three believed that the CAAP was readily available and was easy as a freshman to maneuver through and navigate. She stated:

During the summer thing [new student orientation] when you get introduced to WVU, they usually have you schedule your classes that day, they assign you an advisor, and they tell who to email if you have a question, so I think so [it is visible].

Student Six contended that the CAAP was visible and that the advising hold helped make it visible for him, "You can't schedule until you meet with one [advisor] so it forces you to figure it [advising] out. Scheduling is kind of important and if you don't do it [advising] in time you get crapping scheduling times..." He further stated "I think it's just you're forced to know. You get emails. They'll contact you." The observable rituals and ceremonies as identified in Level one are evidenced in the manner in which the CAAP is embedded in the new student orientation. Student three explains her experience with becoming knowledgeable about the CAAP as follows: "My freshman year, I was in the [new student orientation program], and I had an advisor through that program. ... She really helped me decide this was a good major for me and what I wanted to do." 
Observed behavior is difficult to decipher (Schein, 2010), and the visibility of CAAP in a decentralized structure is even more difficult to decipher. Due to the decentralization of academic advising, every department in every college and school within the University has their own method of providing academic advising services. Faculty data indicated that the CAAP was visible at the University. Faculty Advisor Six provided an excellent summary of his perception of the visibility of academic advising and stated, "I imagine what you find is pockets of very excellent academic advising where it is the culture of that academic program, but then you probably see pockets where academic advising is not rewarded, not valued, and left to be desired." Most faculty advisors agreed that the CAAP was visible, however, faculty advisor two offered a slightly different perspective: "The culture of advising is not visible to an outsider. You'd have to be a student concerned with course selections."

The institution for this study appears to be undergoing a cultural shift for academic advising component of the CAAP, as noted by four faculty advisors. Specifically, the cultural shift is related to the organizational structure of the CAAP. Approximately two years ago, the University began a targeted centralized approach to academic advising wherein the "pre-majors" and undecided students, also referred to as undergraduate studies students, were advised at a central location which was not associated with a specific degree granting college or school in the University. Pre-majors are students also referred to as provisionally admitted students. They were admitted to the University but did not meet the admission requirements for a specific degree program. The majority of faculty interviewed for this study found the centralized approach to be counter-productive to a culture conducive to good CAAP. Faculty Advisor Three stated, "In terms of over the years, departmental advising was valued. Then [the advising center] 
came around and the advising system seemed to be moving to a centralized structure and there was less value on departmental advising."

Other faculty comments regarding that centralized approach echoed that sentiment. Faculty Advisor Six stated, "Not allowing students to receive advising in their desired major because they don't meet the admission criteria is doing them a huge disservice." Faculty Advisor Three argued, “The whole [advising center] experiment was really bad for our culture of advising. It's one thing if the student is undecided but it's another thing if the student knows what major they want." The data did indicate the beginning of a cultural shift at the institution. This cultural shift impacted the visibility of the CAAP, in that, new advising initiatives were being implemented to improve the visibility of the CAAP and to expand advising services. At the commencement of data collection at this institution, a new administration was beginning its tenure. That administration included an academic advising dean, and a new undergraduate associate provost, both of which had new initiatives for the CAAP, and explicitly academic advising. Specifically, that centralized approach to academic advising, albeit very targeted, was being re-visited, a new approach to embedding academic advising into the student success initiatives was being developed, and a targeted approach to making academic advising more visible on campus was under way. The faculty advisors recognized the ways in which academic advising was becoming more visible on campus. In that regard, Faculty Advisor Three expressed that "we are moving in the right direction." Three of the advisors identified the newly created University Academic Advising Council as an example of the cultural shift. In one particular college, the Dean created an advising council specific to that college, and held meetings once a month to discuss advising and other academic and CAAP related issues. Two colleges represented in the study had their own undergraduate advisory council. These councils, revisions 
to the centralized advising model, new advising administration contributed to the visibility of the CAAP through communicating CAAP initiatives, having a designated venue, and instituting CAAP processes and procedures. Faculty Advisor Three described the visibility of the CAAP in her college as "a climate committed to providing academic advising and providing the support services necessary for student success.”

Another method in which the knowledge of a CAAP and the importance of academic advising was observed was often identified by faculty advisors as the advising hold. The advising hold is a registration hold placed on every student's account. Students may not register for classes until they meet with an advisor and the hold is released. Several faculty advisors acknowledged that the hold was a method to initiate the face to face interaction necessary to engage the student with details of the CAAP, academic requirements, and to provide any necessary referrals. The advising hold prompted the student to become aware of the physical environment and the ceremonies surrounding the advising process.

Emphasizing academic advising early, at freshman orientation during the summer, and assigned a faculty advisor early were acknowledged as means for supporting the visibility of academic advising. Several of the faculty advisors' departments have embedded the CAAP in to the curriculum, specifically, the orientation classes, and that increased student exposure to the CAAP. Lastly, but of no less importance than the other methods of how the University made the CAAP visible is advising "pre-majors" and all other students within the department. Faculty advisors recognized that advising method as being paramount for advising visibility.

Professional advisor data indicated that the visibility of academic advising is limited. Interestingly, faculty academic advisors regarded the use of a centralized advising unit as stifling and detrimental to student persistence, but the professional advisors regarded the centralized 
advising unit as a positive feature of the CAAP. The professional advisors view the advising unit as a means of providing visibility and consistency with the CAAP. Professional Advisor One stated, "The University has made strides in the past couple years to make advising not necessarily more centralized, but ... utilizing the same things across the board. "He gave the following example, "Degree works is one way advisors will keep consistency between departments, between majors, and between colleges, and things like that." The professional advisors considered the advising unit as a means for making advising more visible throughout the University. That opinion is due, in part, to the fact that the advising unit has to collaborate with all colleges and schools across the University. The professional advisors must be up to date on all degree admission requirements to assist the student with finding an academic home.

The advising hold was identified by professional advisors as a means of making academic advising visible. All three professional advisors believed the advising hold was an excellent method for conveying the importance of academic advising to students. As conveyed by Professional Advisor Two,

"One thing that I find that is relevant across the University, no matter if they do group advising, or single appointment advising, students are required to come in for one appointment at some point during the semester with their assigned advisor."

The professional advisors recognized the advising hold as especially relevant to the decentralized model for academic advising at the University. They reasoned that the advising hold is a consistent practice across the University that promotes advisor and student interaction.

Overall, administrators believed the CAAP was a visible structure with observable behavior. Administrator data indicated that through the decentralized CAAP approach, student success initiatives, and the University Academic Advising Council, students were knowledgeable 
of CAAP services, and the CAAP was in turn visible. The administrators were quick to accentuate the positive attributes of advising throughout the University, and espoused that the visibility of the CAAP is first dependent on the college or school in which it is housed. They attributed this decentralized approach to enhancing the visibility of advising because there was more student communication about the CAAP within individual schools or colleges. The communication was through first-year student programming, the advising hold. The administrators recognized that due to the decentralized organizational model of the CAAP, the visibility will be divergent. Administrator Four stated, "Some colleges provide good sound advising" and these were the colleges in which the CAAP was the most visible. He further stated that "There are some faculty that are amazing [advisors]" and those advisors were attributed with enhancing the visibility of advising.

The second method of providing for the visibility of the CAAP was identified as the student success initiatives. These initiatives were commended, by administrator two, for embedding the CAAP into the Mountaineer Success Academy, Pathways program, and Firstyear orientation courses. All students are affected by one of these programs in some way, so all students become aware of the CAAP through one of these programs. It should be noted that several departments have developed their own first-year orientation course. The advisors I interviewed explained that their departments have embedded academic advising into their degree specific orientation courses as well. The first-year orientation classes add tremendous value to the visibility of academic advising. These specific student success initiatives impact the presence of advising in the lives of the "pre-major" students, and exploratory students. In addition to the student success initiatives, and first-year orientation courses, administrators identified the University Advising Council as contributing to the visibility of academic advising. 
The administrators identified the University Academic Advising Council (UAAC) as a major contributing factor to the visibility of advising. The council, through its cross-campus collaboration has enhanced the knowledge of the CAAP. Administrator Three evaluated the period before the UAAC as discombobulated and stated,

There is no thread connecting advising across campus. Every college does it their own way. They do what they want to do. Even within a college, every department does it their own way. No one has provided any guidance oversight or direction for where advising should go and how we can make it part of the real fabric of the institution.

His perspective has since changed as a result of the UAAC. The University Academic Advising Council was created to measure the needs of advising in order to improve advising across campus. The Council has developed an advising mission statement, advising values, goal statement in an attempt to build some consistency across colleges and schools. The Council has completed an advising needs survey that was administered to faculty and staff. They plan to conduct an advising needs survey to be administered to students. One of the goals of the surveys, according to Administrator Three, is to determine "how people view advising, what do they view the needs on this campus are, and how do we connect that with the values, vision, and mission we have created to inform how we want advising to be." He further stated:

Through that I think we can transform advising and help it so that people can come on campus and say okay I understand how this institution views advising. I understand how they plan to implement really good advising across campus, and how they plan to evaluate reward etc. on campus.

These findings support the literature related to cultural level one, artifacts. Level One is the surface level of the culture and consists of artifacts which are the visible and feelable 
structures and processes (Schein, 2010, pp. 23-24). He identified the architecture, and physical environment, and observable rituals and ceremonies as indicative of a phenomenon being visible. Schein (2010) describes the artifacts as being easy to observe, and according to the findings this CAAP has many procedures, processes, and services that are easy to observe. It is apparent from student data that students can see the physical structures for advising.

The observable rituals and ceremonies are evidenced in the manner in which the CAAP is embedded in the new student orientation which were identified by students and faculty for CAAP visibility. Faculty additionally identified the new student orientation classes as an organizational process that made the CAAP visible. The administrators recognized the processes in the student success initiatives as contributing activities for CAAP visibility. These programs, and processes related to these programs are all indicative of level one phenomenon, as stated Schein (2010) "Observed behavior is also an artifact as are the organizational processes by which behavior is made routine" (p. 24). Students, faculty advisors, and professional advisors acknowledged the advising hold as a contributing factor for CAAP visibility, and pursuant to Schein's level one definition, it is. The advising hold is viewed as a ritual according the Schein, additionally, the advising hold prompted the student to become aware of the physical environment and the ceremonies surrounding the advising process, also a level one element. Schein (2010) stated that "Structural analysis tells us that a culture manifests itself at the level of artifacts and espoused values, but that its essence lies in the underlying basic assumptions" (p.69) The undergraduate advisory councils with an advising initiative, the University Academic Advising Council, revisions to the centralized advising model, and new advising administration contributed to the visibility of the CAAP through communicating CAAP initiatives, having a designated venue, and instituting CAAP processes and procedures. Therefore, those 
aforementioned elements of the CAAPs visibility contribute to the underlying assumptions regarding the visibility of the CAAP. Specifically, the underlying assumptions by all participant groups are that people are knowledgeable about the CAAP, and that the CAAP is visible.

The CAAP appears to be visible, and the institution seems to be making great strides to embed the CAAP deeper in to the culture of the University. This institution has embedded the CAAP into the most visible surface of the culture, level one. A deeper embedding of the CAAP would be apparent in the ideals, goals, values, and aspirations for academic advising. That is the second level of organizational culture as depicted by Schein's theory, and was examined in the value of advising at the University.

Value of the CAPP. The value of advising relates to level two of the organizational culture as identified in the theoretical framework of the study. Level two is the middle level of the culture and consists of espoused beliefs and values. The espoused beliefs and values "provide the day-to-day operating principles by which the members of the group guide their behavior" (Schein, 2010, p. 25).

Student data indicated that the CAAP was valued. The overall student opinion, used to describe the CAAP, was that it was "good", "really great" and "highly valued." One issue that became outwardly apparent was that all students interviewed, except the freshman, were adamant about pointing out that a good CAAP is determined by the college in which one receives advising, and a good CAAP is valued much more by students. Fully admitted students to a specific college within the University receive advising from that college, or a department within that college. But, students that had not declared a specific academic major, or did not meet admission requirements for a specific college received advising from the University's advising center. When the CAAP is located at a specific college, the advisor may or may not be faculty. 
Due to the decentralized approach to CAAPs at this institution, the advising model is determined by the specific college or school in which it is located. This organizational structure of the CAAP has a direct influence on how the CAAP is valued. Students tend to value faculty advisors more than professional advisors, as expressed by Student One,

I know a lot of people that have great advisors and I know a lot that have terrible ones. The ones that really like their advisors are usually professors that are tenured here, been here a while, and really know what they are doing, not like the orientation workers that only train for the summer. That makes sense when you think about it.

This sentiment was expressed by other students as well. Thus, students believed they received a better advising experience at the college they were enrolled in to receive their degree. Student One indicated that when you receive advising services from your department or college, the advisor gets to know you better:

If you don't know the student, and the professor and student don't have a one on one relationship, it's just mundane it's like looking at a paper and saying you need this class. I think it's [advising] pushed off to people they can make do the work like people who are pursuing a masters or something like that.

The advisor and student connection had a positive impact on the value of the CAAP. Students that felt more connected, valued the CAAP more. Student one was referencing his experience with the advising center. Interestingly, students determined the value of the CAAP as it related to the college or school or the academic department, for example, student one stated "The liberal arts seem like they have better advisors than the sciences." Student Four stated, "For the school of science it was a great experience but for the undergraduate studies, that [advising] can be 
really frustrating for students coming in and like transfer students cause it's not structured well at all."

Most students determined their opinion on the value of the CAAP based on their individual experiences with their advisor. Most valued advising when they viewed their advisor as being knowledgeable about degree completion, but Student Two stated "they are not much help unless you know what questions to ask them," suggesting the need for students, at least in some settings, to be proactive in ensuring a positive advising experience. Students generally felt comfortable with their advisor and viewed them as personable which contributed to their value of the CAAP. Advisors described as "can talk to him easily" "friendly" and "open, likes to talk" were highly valued. Students described those types of advisors as useful and valuable to their educational experience. Specifically, students valued advisors they found to be useful for future recommendation letters for employment, to "keep on track" degree completion, and helpful in "many situations." In summary, students' espoused beliefs and values pertaining to the CAAP is good, depending on what college the advising was from. They valued the CAAP because they felt comfortable using advising, found their advisors knowledgeable and personable, and they knew advising was valued because it is required.

According to faculty data, the value of the CAAP is not as apparent in this cultural level two, the deeper level of this institution's culture. The overall faculty advisor perception of the CAAP is that the University espouses to have a CAAP, but it does not have systems or processes in place to corroborate that idea. Specifically, faculty advisors associated the value of the CAAP with it being tied to the promotion and tenure evaluation process. This was only one process that faculty advisors associated with valuing the CAAP. Faculty Advisor Five stated, "I do not think that the promotion and tenure process factors in how difficult advising is. It's largely ignored so 
in that sense it's not valued." The only component of the CAAP that is evaluated is the advising component although, the newly created University Advising Council recently conducted an advising needs survey for faculty and staff. The Council intends to use the results of that survey as a benchmark for future evaluations of the CAAP. Faculty Advisor Four expressed his view on evaluating advising as follows: "I think there are limited mechanisms by which they [administration] can show it [advising] is a valued activity. It's one of those assignments people are given and expected to fulfill." He further stated that you will not hear things like, "His research is mediocre and they complain about his teaching but boy is he a good advisor. That just has never happens." He deemed advising as a low priority in the evaluation process at the University, and stated 'It's still clear that research and teaching is what drives promotion and tenure at [the University] which it probably should be a priority for a Research I institution.” The evaluation of academic advising emanates in several forms that include: student evaluation surveys, promotion and tenure, and advising awards. Two faculty advisors provided the researcher with copies of the student satisfaction surveys used by their departments to evaluate academic advising, and a review of those documents indicate that the results are primarily related to the course scheduling feature of advising, and no other CAAP components are addressed. Faculty Advisor Six explained the student evaluation process in their department as follows: After students meet with us, there's an advising evaluation form they fill out anonymously and the forms are returned to the academic advising office. At the end of each semester, the advising office does a report on each advisor in terms of here how they were rated: strengths, weaknesses, suggestions for improvements. At the end of the year, when faculty submit their performance review materials, in there we need to include our evaluations. I think that is reflective of our college's commitment to academic advising. 
Faculty that use a student satisfaction survey of academic advising are very receptive to its use, value the results, and use the results to improve their advising practices. Academic advising is one small piece in the promotion and tenure process for all faculty advisors. The faculty advisors are evaluated in three categories: teaching, research or professional development, and service. Advising is one small piece of the larger teaching category used in the promotion and tenure process, and faculty advisors indicated that their advising is not evaluated with any consistency. Only two out of the six faculty discussed the use of student satisfaction surveys for advising. Even though advising is used in the promotion and tenure process, faculty do not view advising as a valued component of teaching. Faculty Advisor One conveyed his perspective as follows: "Advising is not rewarded if looking at promotion, tenure, and salary increases." Faculty Advisor Five stated, "The administrative process values what it can quantify." He added that it is difficult to quantify helping people, and how would you evaluate an advisor "like when you take a little more time with a student to illicit the responses you need to be a good advisor and to help them with whatever issue they are having."

In addition to the formal promotion and tenure process, several faculty advisors indicated that they are given feedback in their department and at college faculty meetings. The third form of evaluation of advising as identified by faculty advisors was advising awards. The faculty were aware of only one University-wide award for academic advising, and no faculty identified any type of departmental award for advising. Faculty Advisor One conveyed the idea that good faculty advising could be rewarded through the use of release time for academic advising. Most faculty articulated that they did not need to be rewarded for them to value advising, but did contend that good advising should be recognized to be valued. 
All three professional academic advisors believed advising was valued at the University. Two initiatives were identified by the advisors that support the value of academic advising: the University Academic Advising Council, and the advising hold. First and foremost was the creation of the University Academic Advising Council. Professional Advisor One expounded on the value of the UAAC, in that, professional advisors viewed the UAAC as an important venue for improving academic advising, and thereby cultivating the value of it across the University. The corroboration between colleges and schools, and administrators, faculty, and professional advisors serves to enhance the overall espoused value of academic advising from a Universitywide perspective.

The second initiative, as identified by professional advisor one, was the creation of the advising center. Professional Advisor Three has 13 years of advising experience at the University. The centralized advising center was created approximately two years ago, and this advisor recognized the advising center as a way that the University exhibited the importance of advising. He adamantly promoted the professional advisor model at the advising center and for each college and stated, "Ideally, in the future, I hope that we will have, each department, each college, will have their own advising center run by the professional advisor, not by faculty advisors." He believed the centralized model enhanced the value of advising due to the ability of professional advisors to spend more time with students which, in turn, leads students to value advising more. It would also lead faculty to value professional advising more because as he stated "If we have that model, the faculty members will have less time [advising]...but they will have more time for the teaching and their research." The University Academic Advising Council and the advising center were recognized as examples of how academic advising is embedded in the deeper level of the University's culture. 
Administrator data indicated that the CAAP is valued to some degree, but there are few mechanisms in place that support the CAAP as being valued. The administrators espoused the importance of having a CAAP and presented several initiatives that are currently used and are being planned to embed the value of a CAAP into a deeper level of the institutions culture.

Administrator Three expressed concern that in order for a CAAP to be truly valued, it should work in conjunction with the needs and culture of the institution. "It [the CAAP] has to respect the needs and the culture of the institution so if there is an institution that heavily values community engagement then your advising [CAAP] has to encompass that, if it's good advising." He further added that the CAAP should "... interact with students in that manner to always help the student understand the values of the institution and reflect that as well."

The administrators admit that it is problematic to consider CAAP related duties and advising in a limited manner in the promotion and tenure process as it is currently done, and that de-values the CAAP. Administrator Four stated "The problem is that academic advising does not weigh heavily in the promotion and tenure process. For faculty members to really take it seriously, there's very little weight in that process." They recognize that attaching evaluation incentives and rewards to advising will enhance the value placed on advising by both faculty advisors and professional advisors. Administrator Three expressed his concern about the value of advising as follows: "My perception, we have not valued it [academic advising] in the same way we value teaching and research in the same institution." Furthermore, he explained:

Advising here seems to be a valued as a supplementary activity as opposed to a primary activity. What I mean by that is that, typically in some of our colleges, we have a decentralized model, but we still use a significant faculty advising model. Often times there are not course releases in some of the colleges. It is additional duties and it goes 
toward service for that particular faculty member. So it is not, in my opinion, viewed as being the heart and soul or the real crux of an academic experience for students. Instead it's viewed as a supplementary activity.

Weighting advising more in the evaluation process and providing incentives such as course releases, were two key ways to improve the value of advising, although the administrators did recognize a weak connection of advising to the evaluation process for faculty advisors. Instruction is the primary concern for most administrators, but that does not support the contention that advising is not valued.

The data of all four participant categories revealed that the institution has undertaken several initiatives to instill the value of advising into the culture of the institution. The first step was the creation of the University Academic Advising Council. The chair of the council, also an administrator, stated "One of the goals of the advising council was to help create a new value about the role of advising and the impact of advising on campus." A new position was created, the Executive Director of Academic Advising and Student Success, and one of the goals of that office is to improve student retention with academic advising in mind. Advising has been embedded into the curriculum in several departments throughout campus and it is a vital component of the student success initiatives. All administrators recognized that their direct supervisor, the Associate Provost is committed to enhancing the advising model at the University and recognizes the importance of advising for student retention. The associate provost was interviewed by the researcher and that ideology of commitment to advising was confirmed.

These findings support the literature related to the CAAP being embedded into the middle layer of the culture. Students believe and espouse that the CAAP is valued, but faculty and professional advisors, and administrators regarded the value of the CAAP as limited. 
Pursuant to Schein (2010), this espoused belief came to fruition through a cultural process. When a group faces a new issue, problem, or task, they adopt an approach to the issue. If the approach works, and the group perceives the solution as a success, then that perceived value then becomes a shared value or belief, and ultimately a shared assumption (Schein, 2010, pp. 25-26). This approach aligns with the processes, procedures, and services that make up a CAAP. Students are required to engage in the advising process through the advising hold, and based on their experiences with the CAAP program, they form a perception of the program. A positive CAAP experience for the student prompts them to dub the CAAP as a success. This process is evidenced through the way students discuss the CAAP at the University.

Faculty and professional advisors, and administrators shared a common assumption that the CAAP had limited value throughout the University. According to Schein (2010), a shared value or belief will ultimately become a shared assumption. In the case of these three participant categories, the fact that advising is not heavily weighted in the evaluation process, and that there is a limited reward system for good advising, led to the shared assumption that the CAAP is not seriously valued.

Schein (2010) further posited that espoused beliefs and values as; the more the process, or program in this case, works, the more the espoused beliefs and values are explicitly articulated because they serve as the norm for the group (pp. 26-27). He further stated that "Such beliefs and values often become embodied in an ideology or organizational philosophy, which then serves as a guide to dealing with...events" (Schein, 2010, p. 27). The findings support that literature. The more students have positive and successful experiences with the CAAP, the more the opinion of it as "good" became embedded in to their sub-culture. The findings from professional advisor data support that tenet of Schein's theory. They believed that the centralized advising unit, which 
uses professional advisors, worked well for the University. The "ideas, goals, values, and aspirations" (Schein, 2010) of the centralized advising unit corroborated well with the University's mission for the CAAP. Thus, data for students and professional advisors indicate the CAAP is embedded in to the middle cultural layer pursuant to Schein's theory. Data for faculty advisors and administrators indicate that the CAAP is only moderately embedded in to cultural level two. Data that support that finding include: the limited value of advising for the evaluation process, a limited reward system for advising, and limited resources and administrative support.

\section{Summary}

Chapter four provided the findings from data for the research questions. The findings supported the literature and in some cases expanded the body of literature related to the impact of an effective CAAP on retention. The characteristics of a CAAP were fully developed from the findings, and the findings were used to explain the cultural levels in which the CAAP was embedded. 


\section{Chapter Five}

\section{Discussion, Implications, and Recommendations}

Academic advising has been recognized as a crucial contributor to student retention (Braxton et al., 2014; Drake, 2011; Light, 2001; Noel-Levitz, 2009; Pascarella \& Terenzini, 1991:2005). The advising structure and advising models play a vital role in effective academic advising. (Braxton et al., 2014; Cuseo, 2011; Gordon et al., 2008; O’Keeffe, 2013; Pascarella and Terenzini, 2005). While academic advising is still considered a crucial factor in student retention, it is now viewed as only one of several elements of an institution's over-arching retention plan (Braxton, Hirschy, \& McClendon, 2004; Brown, Hussey, \& Leonard, 2003; Chiteng Kot, 2014; Cuseo, 2011; Sams, Wirth \& Padilla, 2008; Trotter \& Roberts, 2006; Turner \& Thompson, 2014). Extensive research has been published on academic advising in general, but the literature is limited regarding CAAPs. (Drake, 2011; Freeman, 2008; Gordon, Habley, Grites \& Associates, 2008; Johnson \& Morgan, 2005; Kuh,2008; Melander, 2005), as such, comprehensive academic advising is acknowledged as an emerging field and warrants this research (Braxton et al., 2014; Chiteng Kot, 2014; Cuseo, 2011; Drake et al., 2013; Gordon et al., 2008; Tinto, 1993; Wallace, 2011).

The purpose of this study was to describe a successful CAAP in-depth at one public fouryear degree-granting higher education institution. A successful CAAP is one that can be identified as a contributing factor for improving student retention rates, or a contributing factor for maintaining an already established high level of student retention (Braxton et al., 2014; Bahr, 2008; Drake 2011; Cuseo, 2011; Fowler \& Boylan 2010; McArthur 2005; Robbins et al., 2009; Smith 2007). 


\section{Strategies the CAAP Uses to Increase Retention}

The first research question of the study was: What are the strategies the CAAP uses with the aim of increasing retention rates?

Good academic advising was recognized as an essential strategy of an effective CAAP by all participant groups. It consisted of two pillars: knowledge and rapport. Knowledge concerning admission requirements for specific programs was of paramount concern for ensuring student persistence. Students that were placed, as early as possible, in a degree conferring school or college were deemed, by administrators, and faculty and professional advisors, more likely to persist to graduation, and the literature supports that notion (Braxton et al., 2014, McArthur, 2005; Smith, 2007; Tinto, 1993; Tontodonato, 2006). Student participants overwhelmingly reported more satisfaction with their academic advising, other CAAP services, and educational experience when they received advising from their degree conferring department or school. Research indicates that student satisfaction is a contributing factor for retention (Kuh et al., 2010; Light, 2001; Pascarella \& Terenzini, 1991:2005; Tinto, 1993). Students that were unable to meet the admission requirements for their chosen degree were persuaded to enroll in a parallel degree program that aligned with the students' desired career path. Students contended that they received the most knowledgeable advising at their degree conferring school/college, and were dissatisfied with the professional advising for undecided/general studies, or provisionally admitted students. Thus, knowledge about specific careers was considered vital. Once the student was placed in an appropriate academic program, data indicated that it was imperative for advisors to have knowledge related to degree completion. Knowledge about course requirements for degree completion was considered paramount, by faculty and professional advisors, and administrators, to ensuring the student completed their degree in a timely manner. Students that 
believed they were going to graduate in a timely manner reported more satisfaction with the CAAP, and student satisfaction has been supported by research to contribute to retention (Kuh et al., 2010; Light, 2001; Pascarella \& Terenzini, 1991:2005; Tinto, 1993).

The second pillar of good advising was rapport. Students that had positive rapport with their academic advisor reported more satisfaction with the CAAP. Building rapport involved advising that focused on the "whole person." That entailed providing programs and services related to the academic and psycho-socio needs of the student. Advisors needed to have good communication skills and in order to ascertain the needs of the student. Good communication skills also facilitated the placement of the student in the appropriate degree program. Students were prone to communicate more, and have better rapport, with advisors they viewed as caring and concerned for them as the "whole person." Encouragement was a key element for care and concern. Student data indicated that they viewed the advisor as caring and concerned when the advisor encouraged them academically and psychosocially. Advisor accessibility with early and frequent contact, face to face meetings, ample meeting time allotted to discuss issues other than course selection, individualized degree completion plans, providing referrals to resources for academic and psychosocial needs, being compassionate and empathetic, and empowering students to make decisions were recognized as contributing factors for rapport.

A relevant finding related to both knowledge and rapport was the use of multiple advising models, which supports the literature. Harrison (2009) posits that an array of advising models and theories serve to promote and facilitate an effective advising program. All students were concerned with proper degree completion plans that ensured graduating in a timely manner thereby supporting a prescriptive model of advising, but some students also appreciated the interaction with advisors that used a developmental advising model. Significantly, both advising 
models had a positive influence on rapport and knowledge. Findings indicated that advisors need knowledge of multiple advising models and they need to use that knowledge to match the appropriate advising model with the needs of the student. Knowledge related to the following advising models were deemed important: prescriptive, developmental, appreciative, and intrusive models.

The findings indicated that knowledge related to degree completion, academic and psychosocial resources, and advising models were recognized as crucial factors for student retention. These findings were supported by the existing body of research (Corts, Lounsbury, Saudargas \& Tatum, 2000 Tinto, 1993; McArthur, 2005; Smith, 2007). Additionally, the findings support the literature related to rapport (Bahr, 2008; Harrison, 2009; Johnson \& Morgan, 2005; Melander, 2005; Pizzolato, 2008; Tinto, 1987; and Truschel, 2008). A good rapport between the advisor and student was built through using various advising models, interpersonal skills, communication, building trust, empowering the student to make decisions, helping the "whole person," and exhibiting care and concern. Rapport influences and empowers the student (Kadar, 2001; Pizzolato, 2008; Titley \& Titley, 1982).

Two emergent concepts evolved from the data and expands the existing body of literature. First, students preferred advising from their degree conferring school or college, and that they had no preference for a professional or faculty advisors as long as accurate information was provided, and they were going to graduate in a timely manner. Students contended that they received the most knowledgeable advising at their degree conferring school/college, and were dissatisfied with the professional advising for undecided/general studies, or provisionally admitted students. This is a relevant addition to literature because many institutions of higher education use faculty advisors (Gordon, Habley, Grites \& Associates, 2008; Self, 2013), but 
presently, the use of professional advisors through a centralized advising model has increased tremendously since 1979, according to the ACT's Sixth Survey of Academic Advising (Habley, 2004). Additionally, the finding expands the literature related to the recommended model of advising. Most research supports using the developmental model (Crookston, 1972; Grites, 2013), or one of the three derivative models of academic advising that emerged from developmental advising: the engagement model (Yarbrough, 2002), the counseling liaison model (Drake et al., 2013; Kadar, 2001), and the advising-as-educating model (Drake 2013; Melander, 2005). Hale, Graham, and Johnson (2009), found that students were more satisfied with academic advising when their advisor used a developmental style of advising. These research findings, however, indicated that students are satisfied with advisors that use a prescriptive model of advising, and that the students' primary concern was with having an accurate degree completion plan that would ensure graduating in a timely manner. That finding is supported by McArthur (2005), Smith (2007), and Tinto (1993), which theorize student and faculty interaction through a variety of advising models increases retention, and others that suggest using an integrated model of academic advising that incorporates multiple models (Cuseo 2011; Freeman, 2008; Harrison, 2009; Heisserer \& Parette, 2002; Johnson \& Morgan, 2005).

The second emergent theme that adds to the existing body of literature is related to encouragement which was identified as a contributing factor for building rapport. Most literature concerning advising does not specifically address the issue of encouragement. The literature usually recognizes behaviors related to encouragement such as setting goals, and assisting the student with taking ownership of decisions, and being a mentor and student advocate (Cuseo, 2011; Drake, 2011; Harrison, 2009; Jordan, 2000; McArthur, 2005; Tontodonato, 2006). 
The second strategy of an effective CAAP combined several elements. The findings indicated that a committed Dean enriched the advising process. A decentralized advising structure was deemed essential. Faculty advisors sought to provide advising services themselves, but professional advisors and administrators determined that a centralized approach that utilized professional advisors was more effective. And, collaboration, adequate advising resources, integrating advising in to the evaluation process, and rewarding advising, were all deemed relevant for an effective CAAP.

A committed Dean was viewed as one that provided resources for the advising program such as additional staff and support to attend conferences. A committed Dean also included advising in the promotion and tenure process, and created advisory councils specific to their school or college which focused on advising. A decentralized organizational structure was preferred by faculty and administrators, since it allowed each school and college to select their own advising structure, be it faculty advisors, professional advisors, or the hybrid model which used both faculty and professional advisors.

The decentralized approach data indicated divergent findings. Faculty believed that advising should be completed by a faculty advisor, within the department the student is admitted to or provisionally admitted to. That approach was identified as a contributing factor for student retention, in that, they could provide more accurate degree completion information to students because the faculty in specific programs have more knowledge about: degree requirements, professional licensure and certifications, and career opportunities. Using professional advisors as opposed to faculty advisors was preferred by administrators, and professional advisors. The contention was that using professional advisors would allow faculty to focus on the advising as teaching model and engage students academically outside the classroom. Professional advisors 
were recognized as having more training in advising best practices, and more knowledge about various advising models.

Collaboration, adequate advising resources, integrating advising in to the evaluation process, and rewarding advising, were all deemed relevant for an effective CAAP. Collaboration between professional advisors and other colleges and schools was relevant to facilitating the transfer of students to a degree conferring college or school. Collaboration with career services was deemed vital, in that, the advising center has determined that students that focus on a career in terms of completing their degree are more likely to persist to graduation. Resources included adequate staffing, money for professional development, and money for memberships in professional advising organizations. Advising needed to be rewarded through the evaluation process. It was recognized by faculty advisors and administrators that advising is taken more seriously when it is weighted in that process. Faculty and professional advisors, and administrators, identified the need to provide extrinsic rewards for good advising.

These findings were supported by the existing body of research (Braxton et al., 2014; Brown, 2008; Cuseo, 2011; Drake et al., 2013; Gordon et al., 2008; King, 2008; O’Keeffe, 2013; Pascarella and Terenzini, 2005; Self, 2008). An emergent concept that expands and supports the existing research is that of a committed Dean. Findings related to a committed Dean expand the existing literature related to good advising. Most literature concerning advising does not specifically address the issue of a committed Dean, but it does address the need to have strong advising leadership as an element of any CAAP (Brown, 2008; Cuseo, 2011; King, 2008; Self, 2008). What makes this finding unique is that the finding spanned across all participants in the categories of faculty and professional advisors, and administrators. 
The third strategy of an effective CAAP combined several specific retention strategies that included: the advising hold, identifying at-risk students, and connecting a student to a specific school or college and focusing on career development. The advising hold prompted student contact with the advisor and promoted student engagement thereby impacting student persistence. The advising hold prompted students to initiate contact with their advisor, thereby facilitating the beginning of building a rapport. It also prompts a review of the students' progress toward graduation, promotes proper course scheduling, and permits the advisor to review any academic and psychosocial issues the student may have. These actions promote student satisfaction which tends to improve student persistence (Braxton et al., 2014, Cuseo, 2011; Kuh et al., 2010; Pascarella \& Terenzini, 1991:2005; Tinto, 1993). Identifying at-risk students permitted the advisor to provide additional advising assistance such as additional academic support offered through student success initiatives at the University. Identifying the specific issues at-risk students had prompted the faculty advisors to use varied advising models which matched the students' needs. Connecting a student to a specific school or college expedites the connection between the student and degree specific advising. The rapport can begin sooner if students are advised by an advisor in their degree conferring school or college. A focus on career development through aligning coursework and work force requirements began in the students' college or school, and was identified as a student persistence strategy. That course to career focus was best addressed when the student was placed in the appropriate degree program. Students were motivated to persist to graduation by aligning their coursework to their chosen career. Students could ascertain how their courses make them more marketable for viable employment. 
An emergent concept that evolved from data was related to the finding that identified the advising hold as a specific strategy for retention. That finding expands the literature by

presenting the high value on scheduling that students placed on that aspect of advising (Braxton et al., 2014; Crookston, 1972; Heisserer \& Parette, 2002). The advising hold was considered a proactive approach. Earl (1988), and Varney (2013) depict proactive advising as the intentional contact between the student and the advisor with the goal of developing a caring and beneficial relationship that leads to increased academic motivation and persistence. Research by Bloom, Hutson, \& Ye He (2008), Truschel (2008:2013) and Bloom, Hutson, \& He, (2013) found that appreciative advising was much like intrusive, or proactive, advising, in that both used structured, intentional and collaborative interventions to motivate students. The advising hold was created to accomplish the goals as depicted in the proactive advising approach.

\section{CAAP Embeddedness}

The second research question was: What are the ways in which the institution has embedded the CAAP into its institutional culture?

Two themes evolved from data connected to the second research question: visibility of the CAAP, and the value of the CAAP. These themes overlapped across all categories of participants but the elements identified by each group were divergent. Edgar Schein's theory of organizational culture served as the foundation to examine embeddedness. Data indicated that the CAAP at this University was firmly embedded in level one of the culture, and moderately embedded in level two. There was no indication in the data that the CAAP was embedded in level three of the organization's culture.

The CAAP at this University was firmly embedded in level one of the culture as determined by its visibility. The University had several artifacts that led to the visibility of the 
CAAP. The artifacts included visible and "feelable" structures and processes, and observed behavior. The advising hold was again identified as a process which made the CAAP visible. CAAP services were visible in other forms of communication, such as emails and flyers. The CAAP was visible through the summer new student orientation programs and classes, the latter of which were a requirement for all freshman. The new student orientation programs were identified as processes that prompted the assigning of an advisor early in the students' academic experience. The orientation programs and classes were identified as student success initiatives and were recognized as observed behavior. The centralized advising unit was located in a designated structure identified by all participants. The structure was highly visible, easily accessible to students, and the location of the building was known by all participants.

University councils with an advising focus, and the new academic advising and student retention administrator, were contributing characteristics to the CAAP visibility. Specifically, the University Academic Advising Council was recognized as a process and observed behavior that marketed and educated faculty and staff university-wide for effective academic advising practices and procedures. The advisory councils at designated schools or colleges also contributed to the CAAP visibility. The newly appointed Executive Director of Academic Advising and Student Retention is one identifiable person known campus-wide as being responsible for advising and retention.

These findings support the literature related to cultural level one (Ahren, Ryan, \& Niskode',-Dossett, 2009; Braxton et al., 2014; Kuh et al., 2010; Schein, 2010). The visibility of the CAAP in summer orientation programs, and the required new student orientation courses, depict how this University improved the CAAP's visibility. This finding expands the existing literature by specifically identifying a method for enhancing the CAAP's visibility. Research has 
established that an effective CAAP incorporates CAAP services in to the first academic year (Braxton et al., 2014; Kuh et al., 2010; Tinto, 1993; Trotter \& Roberts, 2006) and makes the CAAP accessible to all students (Trotter \& Roberts, 2006), but specific methods to accomplish those requirements have not been firmly established in the literature. This finding illuminates a specific method for embedding the CAAP in first-year student programming through summer orientation programs, and the required new student orientation courses.

The CAAP at this University was moderately embedded in level two of the culture as determined by its perceived value. The data produced divergent results for the middle layer of the culture: espoused beliefs and values. Overall, the CAAP was perceived as valued because advising was required. The intensity of value for students was based on the school or college in which the advising was located. They specified that schools or colleges in which advising was more highly valued were the ones that provided "good" advising, as defined earlier in this chapter. Students tended to value faculty advisors more than professional advisors, but did not express a preference. The advisor and student connection had a positive impact on the value of the CAAP. Knowledgeable and personable advisors positively impacted rapport which, in turn, enhanced the value of advising for students. In addition to the advising requirement, advising was valued at the University based on the creation of the University Academic Advising Council (U.A.A.C.), and the centralized advising unit. The U.A.A.C. was a venue for sharing best practices and developing policies and procedures that could be used throughout the University. The centralized advising unit exhibited the value of the CAAP since it was created to cater to the advising need for a specific student clientele.

The divergent result is related to the finding that faculty advisors and administrators determined that the CAAP was not valued at the University because it was not significantly 
factored in the tenure and promotion process, and it was not rewarded. Faculty noted a lack of student evaluation of faculty in every department, and administrators indicated that there was only one award offered for advising as examples of the lack of value placed on advising.

These findings support the existing body of research. The advising hold, which requires that every student meet with an advisor prior to registering for courses, indicates that advising is a relevant element in the institution's culture (Bloom et al., 2013; Truschel, 2008:2013). The U.A.A.C. and the centralized advising unit convey the importance of advising from an institution-wide perspective (Freeman, 2008; Robbins et al., 2009; Johnson \& Morgan, 2005). And, advising is valued when it is rewarded (Drake, 2008).

\section{Recommendations for Practice}

The University is utilizing many effective CAAP procedures and practices to positively impact student retention. I have identified several of the procedures and practices that could be improved. The data and literature suggests the continued use of the centralized advising center, but use it for exploratory/undecided students only. Using the centralized advising center for provisionally admitted and pre-majors students only serves to hinder the students' engagement with faculty advisors and subsequently, the University, according to faculty data. Expeditious placement of students in a degree conferring school or college serves as the impetus to forming a student and faculty relationship, and that relationship heightens students' commitment to the

institution. Research conducted by Tinto (2006), Braxton, Hirschy, and McClendon (2004), and Braxton et al. (2014) identified institution commitment as a major contributing factor for student retention, and research by McArthur (2005) and Tontodonato (2006) found that student satisfaction, which has been linked to retention (Corts et al., 2000; Kuh et al., 2010; McArthur, 2005) increased when there was quality faculty-student interaction. 
Student data indicated dissatisfaction with the advising services offered by the centralized advising center, and faculty data indicated that students receive better CAAP services when they are advised in their degree conferring school or college. Faculty data indicated that they are more proficient than professional advisors at conveying academic and career advice, and proffering information related to research opportunities and professional licensing. Faculty and student data indicated that students are more satisfied, and feel more confident, about completing their degree in a timely manner when they are advised in their degree conferring school or college, and graduating on time was a major concern according to student data. These issues are related to student satisfaction and retention (Braxton, et al., 204; Corts et al., 2000; Kuh et al., 2010; McArthur, 2005; Tinto, 2006).

The implication with that suggestion is that each school or college would need a plan and procedures for providing CAAP services to pre-majors and provisionally admitted students. Currently, schools or colleges that did not use a professional or hybrid model of advising, did not have formal advising procedures. Even in a decentralized model, such as the one used by this University, best practices for comprehensive advising dictats the need for consistency and common goals across the organization (Braxton et al., 2014; Chiteng Kot, 2014; Cuseo, 2011; Drake et al., 2013; Gordon et al., 2008; Pascarella and Terenzini, 2005; Tinto, 1993). Additionally, the data and research support the suggestion that the Advising Center should create programs to facilitate the expedient selection of a degree program based on career aspirations and academic aptitude of exploratory/undecided students (Braxton et al., 2014; Cuseo, 2011; Gordon et al., 2008; Habley, 2004; King, 2005; O’Keeffe, 2013; Pardee, 2004; Pascarella and Terenzini, 2005). 
The continued use of the decentralized model is recommended, but administrators should consider providing professional development opportunities in academic advising to faculty advisors in schools or colleges that use a faculty advising model. The professional development should be related to understanding the major tenets of different advising models, and using those models by aligning them with the needs of the student. Professional development regarding best practices for advising, and professional membership in NACADA or another nationally recognized advising professional organization is recommended. That would provide up-to-date research findings about advising practices. In schools or colleges that choose to use the professional advising model, continue to use faculty advisors but utilize them in the advising as educating model. That model promotes student engagement. The implication with these suggestions is that funding would be required for professional development, and curriculum revisions may be necessary for the faculty advising as educating.

Research supports the use of a decentralized structure (Drake, 2008; King, 2005:2008; Pardee, 2004) and faculty advisors continue to be a source of effective academic advising (Beatty, 1991/2009; Brubacher \& Rudy, 1997; Cohen, 1998; Cook, 2009; Crookston, 1972; Lucas, 2006; Thelin \& Hirschy, 2009). Providing professional development is imperative to a successful advising program (Brown, 2008; Cuseo, 2011; Gordon et al., 2008; Pascarella and Terenzini, 2005).

Continue to use the advising hold, students found it useful. It promoted student engagement and satisfaction through advisor contact. It promoted timely degree completion, and facilitated advisor evaluation of students' academic needs. Research supports initiatives that promote student and advisor contact (Braxton et al., 2014; Cuseo, 2011, Drake, 201; Johnson, 2009; Jordan, 2000). 
Incorporating advising in to the promotion and tenure evaluation process is recommended. Faculty and professional advisors, and administrators recognized this issue as relevant for improving the value of advising. It would be beneficial to consider advising and other CAAP duties in the evaluation process due to its impact on making advising more valued and embedding it deeper in the culture. Research supports the recognition of good advising (Cuseo, 2011; Drake, 2011; Drake et al., 2013; Pascarella \& Terenzini, 2005; Tinto, 1975:1995; Turner \& Thompson, 2014). Research further indicates that in order for recognition and reward to effective, it should be relevant and reflect the mission and goals of the institution (Brown, 2008; Cuseo, 2011; Drake, 2011; Drake et al., 2013. Pascarella \& Terenzini, 2005). The promotion and tenure evaluation process is a relevant and meaningful process for assessing and evaluating advising and advising services.

There would be an implication for administration, in that, a clearly defined evaluation criteria would need developed and then adopted by faculty and professional advisors. Advisor buy in is imperative under a shared governance process. Another implication for this suggestion is that it is difficult to quantify good advising. In addition to using an established evaluation criteria, the use of student evaluations of advising could also be incorporated in to the process. Rewarding good advising is suggested. Faculty and professional advisors, and administrators, recognized the need for addition advising rewards. Funding is an implication from this suggestion, however, all rewards do not have to be monetary rewards. More recognition rewards could be utilized, and release time could be offered to faculty advisors. Implementation of this suggestion should improve the value of advising and embed the CAAP deeper in to the University's culture. Research further supports rewarding good advising (Brown, 2008; Cuseo, 2011; Drake, 2011; Drake et al., 2013. Pascarella \& Terenzini, 2005). 
Additional recommendations for practice include several other initiatives. Continue collaboration across the University and use the U.A.A.C as the venue to communicate best practices and advice schools and colleges on advising policies, procedures, evaluation of advising, and to keep advisors abreast of University resources so advisors can provide the proper referrals. Develop career focused advising initiatives. Incorporate a focus on parallel programs, and advice students on how their course work aligns with workforce requirements. Continue to use strong leadership for the CAAP and expand the leadership to designated leaders at each college or school since the decentralized model is used. Research supports these initiatives and in reference to retention, first-year programs, and identifying at-risk students, researchers found that those initiatives should be prioritized (Braxton, Hirschy, \& McClendon, 2004; Sams, Brown, Hussey, \& Leonard, 2003; Chiteng Kot, 2014; Cuseo, 2011; Wirth \& Padilla, 2008; Trotter \& Roberts, 2006; Turner \& Thompson, 2014).

\section{Recommendations for Future Research}

The recommendations for future research are guided by the emergent concepts of the findings. The role of student success initiatives were identified, by all participants, as contributing to the visibility of advising. Research concerning the role of student success initiatives with the CAAP is suggested. A comparative study of CAAPs across institutions may contribute to a better understanding of why some students prefer advising from their degree conferring school or college.

Data related to the embeddedness of the CAAP in the culture indicated that this institution effectively embedded the CAAP in the first level of culture pursuant to Schein's (2010) theory, moderately embedded it in level two, but it was not present in level three. This study focused on the culture from a University-wide perspective. Due to the decentralized 
structure of CAAPs throughout the institution, additional research may be warranted concerning subcultural elements of the institution. That research could also shed some light on the finding derived from student data that some schools or colleges provide better CAAP services than others.

The centralized academic advising unit, known as University College in this study, was dissolved at the conclusion of the collection and analysis of this study. The exploratory, premajor, pre-professional students continue to receive CAAP services through a centralized dedicated department staffed by professional advisors. The department is housed in an office for undergraduate education and has implemented a focus on parallel degrees. The dissolution of the previous centralized unit within the University College serves as an impetus for additional research.

More research regarding encouragement as a contributing factor for building a rapport with their advisor is suggested. The existing body of literature is limited regarding this student specified factor for building rapport with their advisor. Findings related to a committed Dean expand the existing literature related to good advising, but most literature concerning advising does not specifically address the issue of a committed Dean. More research would contribute to explaining how strong advising leadership contributes to an effective CAAP. Case study literature on an effective CAAP is limited. Finally, additional research regarding the advising hold as a specific strategy for retention is suggested.

\section{Conclusion}

An effective comprehensive academic advising program has specific characteristics, and uses specific strategies to improve the student retention rate, or contribute to sustaining an established excellent student retention rate. This University has successfully accomplished the 
development and use of an effective CAAP. The 2014-2015 freshmen to sophomore retention rate for this University was above the national average (NCES) while the University's six-year graduation rate for 2013, was just under the national average (NCES, 2016). The 2015 six-year graduation rate was over $50 \%$ but the majority of the remaining students that did not graduate from the University transferred to a different institution. Selectivity should be considered in an analysis of graduation rates (www.collegefactual.com). Successful or high retention rates for this study were established at rates at or above $75 \%$ which depicts the mid-range point as established by NCES (U.S. Department of Education, 2014). For the past seven years, the University's retention rate has been above the national average. While quantitative research is limited in reference to the impact of a CAAP on improving the student retention rate, or contributing to sustaining an established excellent student retention rate, the student data from this study indicates that the academic advising as offered through the CAAP has been influential on their persistence to graduation. There is a research implication for the need of quantitative research that can address the cause-effect questions around the impact of the CAAP on retention rates.

The findings of this study indicated several practical implications that have been effective at this institution, and may serve as potential avenues for greater retention rates at similar institutions. An effective CAAP should utilize good advising which research identifies as having the two-pillars of knowledge and rapport. Incorporating adequate resources and rewards in the CAAP lends itself to embedding the CAAP in to the institutional culture. A committed Dean fosters the success of the CAAP. A decentralized CAAP structure affords each school and college the opportunity to develop the CAAP according to the unique needs of their students. Collaboration is imperative to success. Collaboration not only embeds the CAAP deeper into the culture, but also fosters the admission of students to degree conferring schools or colleges which 
is a vital practical implication. Other suggested strategies include: using parallel degrees, implementing an advising hold, identifying at-risk students, focusing on career development, and embedding the CAAP in to the curriculum.

Research has historically suggested the use of the developmental model of academic advising for having the greatest impact on student satisfaction and student retention (Braxton et al., 2014; Cuseo, 2011; \& Gansemer-Topf \& Schuh, 2006; Drake, 2011; Gordon et al., 2008; Pascarella and Terenzini, 2005; Robbins et al., 2009; Smith, 2007; Tinto, 1993 \&2006;), and advisors have been encouraged to develop their advising techniques around the major tenets of developmental advising. But findings from this study indicate that students are satisfied and persist to graduation when they primarily receive advising using the prescriptive model. Students are principally concerned with graduating in a timely manner. Findings also indicated that the initial advising concern of faculty advisors is adequate course scheduling to facilitate degree completion in an expeditious manner. The initial advising concern for professional advisors is placement in a degree conferring school or college. Administrators concur with those concerns. So perhaps the most insightful scholarly contribution of this study is that higher education institutions may be entering a new phase of academic advising in which advisors are not dissuaded from using the prescriptive model. This phase would align with the changing context of higher education which promotes the mission of graduating students in an expeditious manner. 


\section{References}

2011 NACADA National Survey of Academic Advising. Retrieved from http://www.nacada.ksu.edu/Resources/Clearinghouse/View-Articles/2011-NACADANational-Survey.aspx

American College Testing Program (ACT) (2015). National Collegiate Retention and Persistence to Degree Rates for 2005-2014. Retrieved from http://www.act.org/research/policymakers/reports/graduation.html

Abel, J. R. \& Deitz, R. (2014) Do the benefits of college still outweigh the costs? Current Issues in Economics and Finance 20(3), 1-11. Retrieved from www.newyorkfed.org/research/current_issues

Ahren, C., Ryan, H., \& Niskodé-Dossett, A. (2009). Making the familiar strange: How a cultural audit can boost your advising impact. About Campus, March-April, 25-32. doi: $10.1002 / \mathrm{abc} .281$

Bahr, P. R. (2008). Cooling out in community college: What is the effect of academic advising on students' chances of success? Res High Educ, 49, 704-732. doi:10.1007/s11162-008$9100-0$

Baum, S., Ma, J. \& Payea, K. (2010). Trends in higher education series: Education pays 2010 the benefits of higher education for individuals and society. College Board Advocacy \& Policy Center. retrieved from: http://trends.collegeboard.org/downloads/Education_Pays_2010.pdf

Beatty, J. D. (1991/2009). The National Academic Advising Association: A brief narrative history. NACADA Journal, 29(1), 68-77. Retrieved from 
https://www.nacada.ksu.edu/Portals/0/Journal/documents/11-1-Beatty-pp5-25.pdf

Bloom, J. L., Hutson, B. L., \& He, Y. (2013). Appreciative advising. In Drake, J. K., Jordan, P., \& Miller, M. A. (Eds.), Academic advising approaches: Strategies that teach students to make the most of college (pp. 137-152). San Francisco, CA: Jossey-Bass.

Braxton, J. M. (2008). Toward a practice centered on college student retention. New Directions for Teaching and Learning, 115, 101-112. DOI: 10.1002/t1.328

Braxton, J. M., Doyle, W. R., Hartley, H. V., III, Hirschy, A. S., Jones, W. A. \& McLendon, M. K. (2014). Rethinking college student retention. San Francisco, CA: Jossey-Bass.

Braxton, J. M., Hirschy, A. S., \& and McClendon, S. A. (2004). Understanding and reducing college student departure. In ASHE-ERIC Higher education report, 30 (3). San Francisco: Jossey-Bass.

Braxton, J. M., \& Lee, S. D. (2005). Toward a reliable knowledge about college student departure. In A. Seidman (Ed.), College student retention: Formula for student success (pp. 107-127). Westport, CT: Praeger Publishers.

Braxton, J. M., Sullivan, A. S., \& Johnson, R. M. (1997). Appraising Tinto's theory of college student departure. In J. C. Smart (Ed.), Higher education: Handbook of theory and research, volume 12 (pp. 107-164). New York: Agathon Press.

Brown, T. (2008). Critical concepts in advisor training and development. In Gordon, Habley, Grites, and Associates (Eds.), Academic advising: A comprehensive handbook ( $\left.2^{\text {nd }} \mathrm{ed}.\right)$ (pp. 309-322). San Francisco, CA: Jossey-Bass.

Brown, T. E., \& Ward, L. (2007). Preparing service providers to foster student success. In Kramer, G. L. (Ed.). Fostering student success in the campus community. San Francisco: Jossey-Bass. 
Brubacher, J. S., \& Rudy, W. (1997). Higher education in transition: A history of American colleges and universities. New Brunswick, NJ: Transaction.

Carnegie Classification, http://classifications.carnegiefoundation.org/lookup

Chiteng Kot, F. (2014). The impact of centralized advising on first-year academic performance and second-year enrollment behavior. Research in Higher Education, 55(6), $527-$ 563. DOI: $10.1007 / \mathrm{s} 11162-013-9325-4$

Christian, T. Y., \& Sprinkle, J. E. (2013). College student perceptions and ideals of advising: An exploratory analysis. College Student Journal, 47(2), 271-291. Retrieved from www.connection.ebscohost.com

Cohen, A. (1998). The shaping of American higher education: Emergence and growth of the contemporary system. San Francisco: Jossey-Bass.

College Board Advocacy \& Policy Center (2010). Trends in higher education series: Trends in college pricing. Retrieved from: http://trends.collegeboard.org/downloads/College_Pricing_2011.pdf

Cook, S. (2009) Important events in the development of academic advising in the United States. NACADA Journal, 29 (2), 18-40. doi: http://dx.doi.org/10.12930/0271-9517$\underline{29.2 .18}$

Corts, D., Lounsbury, J., Saudargas, R., \& Tatum, H. (2000). Assessing undergraduate satisfaction with an academic department: A method and case study. College Student Journal, 34, 1-7. http://web.ebscohost.com/ehost/detail?vid=5\&hid=110\&sid=96bd0bfb$\underline{\text { a1c1-4004-af1e- }}$ eb4690178119\%40sessionmgr113\&bdata=JnNpdGU9ZWhvc3QtbG12ZQ\%3d\%3d\#db=f $\underline{5 h \& A N=3728492}$ 
Creamer, E. G. \& Scott, D. W. (2000). Assessing individual advisor effectiveness.

In Gordon, Habley, Grites, and Associates (Eds.), Academic advising: A comprehensive handbook (2 $2^{\text {nd }}$ ed.) (pp. 137-152). San Francisco, CA: Jossey-Bass.

Creswell, J. W. (2014). Research design: Qualitative, quantitative, and mixed methods approaches. Thousand Oaks, CA: Sage.

Crookston, B. B. (1972). A developmental view of academic advising as teaching. Journal of College Student Personnel, 13, 12-17. Reprinted: Classics revisited: A developmental view of academic advising as teaching (1994). NACADA, 14 (2), 5-9 http://www.nacada.ksu.edu/Clearinghouse/AdvisingIssues/documents/14-2-Crookstonpp5-9.pdf

Cuseo, J. (2011). Academic advisement and student retention: Empirical connections and systemic interventions. Retrieved from University of Hawaii: Honolulu Community College, Programs, Intranet website: http://programs.honolulu.hawaii.edu/intranet/node/739

Davis, K. J. (2008). Advising administrator perspectives on advising. In Gordon, Habley, Grites, and Associates (Eds.), Academic advising: A comprehensive handbook ( $2^{\text {nd }}$ ed.) (pp. 438-444). San Francisco, CA: Jossey-Bass.

Drake, J. K. (2008). Organization of academic advising services. In Gordon, Habley, Grites, and Associates (Eds.), Academic advising: A comprehensive handbook ( $2^{\text {nd }}$ ed.) (pp. 242-252). San Francisco, CA: Jossey-Bass.

Drake, J. K. (2008). Recognition and reward for academic advising in theory and in practice. In Gordon, Habley, Grites, and Associates (Eds.), Academic advising: A comprehensive handbook (2 $2^{\text {nd }}$ ed.) (pp. 396-412). San Francisco, CA: Jossey-Bass. 
Drake, J. K. (2011). The role of academic advising in student retention and persistence. About Campus, July-August, 8-12. DOI: 10.1002/abc.20062.

Drake, J. K. (2013). Advising as teaching and the advisor as teacher in theory and practice. In Drake, J. K., Jordan, P., \& Miller, M. A. (Eds.), Academic advising approaches: Strategies that teach students to make the most of college (pp. 17-32). San Francisco, CA: Jossey-Bass.

Drake, J. K., Jordan, P., \& Miller, M. A. (Eds.). (2013). Academic advising approaches: Strategies that teach students to make the most of college. San Francisco, CA: JosseyBass.

Earl, W.R. (1988). Intrusive advising of freshmen in academic difficulty. NACADA Journal 8, 27-33. doi: 10.12930/0271-9517-8.2.27

Elkins, S. A., Braxton, J. M., \& James, G. W. (2000). Tinto’s separation stage and its influence on first-semester college student persistence. Research in Higher Education 41(2), 251268. Retrieved from http://www.jstor.org/stable/40196366

Erwin, J. M. (1997). An intrusive, comprehensive advising and career planning system: Eastern Michigan University. New Directions for Institutional Research, 90, 89-95. Retrieved from http://web.ebscohost.com/ehost/resultsadvanced?sid=bb06143b-a39f-4259-9c240f728c36d49c\%40sessionmgr10\&vid $=6 \&$ hid $=9 \&$ bquery $=(T I+($ The + role + of + academic + $\underline{\text { advising }+\&=\operatorname{amp} \% 3 \mathrm{bquot} \% 3 \mathrm{bin} \% 2 \mathrm{camp} \% 3 \mathrm{bquot} \% 3 \mathrm{~b}+\text { student }+ \text { retention }+\mathrm{AND}+\text { persist }}$ ence))\&bdata=JmRiPWFwaCZ0eXB1PTEmc210ZT1laG9zdC1saXZ1

Flatley, R., Weber, M. A., Czerny, S., \& Pham, S. (2013). Librarians and mandatory academic 
advising at a mid-sized public university: A case study. Journal of Academic

Librarianship, 39(6), 582-587. doi:10.1016/j.acalib.2013.01.006

Fowler, P.R. \& Boylan, H.R. (2010). Increasing student success and retention: A

multidimensional approach. Journal of Developmental Education, 34 (2), 2-10. Retrieved $\underline{\text { from }}$

http://web.a.ebscohost.com.www.libproxy.wvu.edu/ehost/pdfviewer/pdfviewer?sid=f94c 616d-0352-4695-b247-ec4ad8ad8aa0\%40sessionmgr4003\&vid=5\&hid=4104

Freeman, L. C. (2008). Establishing effective advising practices to influence student learning and success. Peer Review, 10, 1-5. Retrieved from http://www.aacu.org/peerreview/prwi08/pr-wi08_EstabEff.cfm

Gansemer-Topf, A. M. \& Schuh, J. H. (2006). Institutional selectivity and institutional expenditures: Examining organizational factors that contribute to retention and graduation. Research in Higher Education, 47(6), 613-642. Doi: 10.1007/s11162-0149360-9

Gerdes, H. \& Mallinckrodt, B. (1994). Emotional, social, and academic adjustment of college students: A longitudinal study of retention. Journal of Counseling \& Development, 72, 281-288. Retrieved from http://web.ebscohost.com/ehost/resultsadvanced?sid=bb06143b$\underline{\text { a39f-4259-9c24- }}$ 0f728c36d49c\%40sessionmgr10\&vid $=4 \&$ hid $=9 \&$ bquery $=(T I+($ The + role + of + academic + advising $+\&=a m p \% 3$ bquot $\% 3$ bin $\% 2$ camp $\% 3$ bquot $\% 3 b+$ student + retention + AND + persist ence))\&bdata=JmRiPWFwaCZ0eXB1PTEmc210ZT1laG9zdC1saXZ1

Glennen, R. E. (1975). Intrusive college counseling. College Student Journal, 9 (1), 2-4.

Gordon, V. N., Habley, W. R., Grites, T. J. \& Associates (2008). Academic advising: A 
comprehensive handbook. San Francisco, CA: Jossey-Bass.

Grites, T. J. (2013). Developmental academic advising. In Drake, J. K., Jordan, P., \& Miller, M. A. (Eds.), Academic advising approaches: Strategies that teach students to make the most of college (pp. 137-152). San Francisco, CA: Jossey-Bass.

Grites, T. \& Gordon, V. (2000). Developmental academic advising revisited. NACADA Journal, 19(1), 12-15. Retrieved from http://nacadajournal.org/doi/pdf/10.12930/0271-9517$\underline{20.1 .12}$

Habley, W. R. (Ed.). (2004) The status of academic advising: Findings from the ACT sixth national survey. (pp. 14-26) (Monograph Series No. 10). Manhatten, KS: National Academic Advising Association

Hale, M., Graham, D., \& and Johnson, D. (2009). Are students more satisfied with academic advising when there is congruence between current and preferred advising styles? College Student Journal, 43, 313-324. http://web.ebscohost.com.www.libproxy.wvu.edu/ehost/detail?vid=5\&hid=111\&sid=fe5e fdba-e5f6-4b3e-bd78e5609d5a660c\%40sessionmgr10\&bdata=JnNpdGU9ZWhvc3QtbGl2ZQ\%3d\%3d\#db=a9 $\underline{\mathrm{h} \& \mathrm{AN}=42517480}$

Harrison, E. (2009). Faculty perceptions of academic advising: I don't get no respect. Nursing Education Research, 30, 229-233. Retrieved from http://web.ebscohost.com/ehost/pdfviewer/pdfviewer?hid=113\&sid=57e691f5-89e4441d-b2f7-4f6ea9211aea\%40sessionmgr114\&vid=12

Heisserer, D. L. \& Parette, P. (2002). Advising at-risk students in college and university settings. 
College Student Journal, 36 (1), 69-84. Retrieved from

http://web.ebscohost.com.www.libproxy.wvu.edu/ehost/detail?vid=5\&hid=125\&sid=a9b d8bad-3ada-46ac-95d4b990de829787\%40sessionmgr110\&bdata=JnNpdGU9ZWhvc3QtbGl2ZQ\%3d\%3d\#db=a $\underline{9 h \& A N=6539430}$

Heldman, C. (2008). Looking at the costs of student acquisition and attrition. Recruitment and Retention in Higher Education, 22 (5), 6-7. Retrieved from https://rapid2.library.colostate.edu/Ill/ViewQueue.aspx?ViewType=PendingByBranch\&I

Hurt, R. L. (2007). Advising as teaching: Establishing outcomes, developing tools, and assessing student learning. NACADA Journal, 27(2), 36-40. Retrieved from http://nacadajournal.org/doi/pdf/10.12930/0271-9517-27.2.36

Johnson, E. J. \& Morgan, B. L. (2005). Advice on advising: Improving a comprehensive university's program. Teaching of Psychology, 32, 15-18. Retrieved from http://www.uwlax.edu/faculty/morgan/documents/advising.pdf

Jordan, P. (2000). Advising college students in the $21^{\text {st }}$. century. NACADA Journal, 20 (2), 2130. Retrieved from http://nacadajournal.org/doi/pdf/10.12930/0271-9517-20.2.21

Kadar, R. S. (2001). A counseling liaison model of academic advising. Journal of College Counseling, 4, 174-178. http://web.ebscohost.com/ehost/pdfviewer/pdfviewer?hid=113\&sid=57e691f5-89e4441d-b2f7-4f6ea9211aea\%40sessionmgr114\&vid=6

Kanter, M, Ochoa, E., Nassif, R., \& Chong, F. (2011). Meeting President Obama's 2020 college completion goal. Retrieved from http://www.ed.gov/news/speeches/meeting-presidentobamas-2020-college-completion-goal 
Kimball, E. \& Campbell, S. M. (2013) Advising strategies to support student learning success: Linking theory and philosophy with intentional practice. In J. K. Drake, P. Jordan, \& M. A. Miller (Eds.), Academic advising approaches: Strategies that teach students to make the most of college (pp. 3-16). San Francisco, CA: Jossey-Bass.

King, M. C. (2008). Organization of academic advising services. In Gordon, Habley, Grites, and Associates (Eds.), Academic advising: A comprehensive handbook ( $2^{\text {nd }}$ ed.) (pp. 242-252). San Francisco, CA: Jossey-Bass.

Kolenovic, Z., Linderman, D., \& Karp, M. M. (2013). Improving student outcomes via comprehensive supports: Three-year outcomes From CUNY's accelerated study in associate programs (ASAP). Community College Review, 41(4), 271-291.

doi:10.1177/0091552113503709

King, M. C. (2005). Developmental academic advising. Retrieved from NACADA Clearinghouse of Academic Advising Resources Retrieved from http://www.nacada.ksu.edu/Clearinghouse/AdvisingIssues/dev_adv.htm

Kuh, G. D. (2008). Advising for student success. In Gordon, V. N., Habley, W. R., Grites, T. J. \& Associates, Academic advising a comprehensive handbook (2nd ed.) (pp.68-84). San Francisco, CA: Jossey-Bass.

Kuh, G. D., Kinzie, J., Schuh, J.H., Whitt, E. J., \& Associates (2010). Student success in college: Creating conditions that matter. San Francisco, CA: JosseyBass.

Light, R. J. (2001). Making the most of college: Students speak their minds. Cambridge, MA: Harvard University Press.

Lucas, C. (2006). American higher education: A history. ( $2^{\text {nd }}$ ed). New York: Palgrave 
MacMillan.

Martin, J. (2002). Organizational culture: Mapping the terrain. Thousand Oaks, CA: Sage.

Maxwell, J. A. (2009). Designing a qualitative study. In L. Bickman \& D. J. Rog (Eds.). The Sage handbook of applied social science research methods ( $2^{\text {nd }}$ ed.) (pp. 214-253). Thousand Oaks, CA: Sage.

Maykut, P., \& Morehouse, R. (1994). Beginning qualitative research: A philosophic and practical guide. Bristol, PA: Falmer Press.

McArthur, R. (2005). Faculty-based advising: An important factor in community college retention. Community College Review, 32, 1-19. http://web.ebscohost.com/ehost/detail?vid=20\&hid=110\&sid=96bd0bfb-a1c1-4004-af1eeb4690178119\%40sessionmgr113\&bdata=JnNpdGU9ZWhvc3QtbGl2ZQ\%3d\%3d\#db=f $\underline{5 h \& A N=17355902}$

Melander, E. R. (2005). Advising as educating: A framework for organizing advising systems. NACADA Journal, 25, 84-91 www.nacada.ksu.edu/clearinghouse/.../learningoutcomes.htm

Merriam, S. B. (2009). Qualitative research: A guide to design and implementation. San Francisco, CA: Jossey Bass.

Miville, M. L. \& Sedlacek, W. E. (1995). An assessment of centralized versus faculty advising in a college of engineering. NACADA Journal, 15 (2), 20-25. Retrieved from http://www.nacada.ksu.edu/Journal/Volume-Fifteen-Issue-1-2.htm

National Center for Educational Resources (2016). The condition of education 2016: Undergraduate retention and graduation rates. Retrieved from http://nces.ed.gov/

Nitecki, E. M. (2011). The power of the program: How the academic program can improve 
community college student success. Community College Review, 39 (2), 98-120. doi: $10.1177 / 009155211140-4926$.

Noel-Levitz. (2009). 2009 National research report: Academic advising highly important to students. Retrieved from https://www.noellevitz.com/documents/shared/Papers_and_Research/2009/AcademicAdv isingHighlyImportant09.pdf

Noel-Levitz. (2014). ACT National Collegiate Retention and Persistence to Degree Rates. Retrieved from https://www.noellevitz.com/papers-research-higher-education/student-retention-whitepapers-and-trend-reports/act-collegiate-retention-persistence-rates

Nutt, C. (2013). From the Executive Director: Higher education focuses on college completionacademic advising at the center of University efforts. Academic Advising Today, (36)1. Retrieved from http://www.nacada.ksu.edu/Resources/Academic-Advising-Today/ViewArticles/From-the-Executive-Director-Higher-Education-Focuses-on-CollegeCompletion-\%E2\%80\%93-Academic-Advising-at-the-Center-of-University-Efforts.aspx

Obama, Barack President Remarks by the President on higher education. Office of the Press Secretary April 24, 2009 Retrieved from http://www.whitehouse.gov/the_press_office/Remarks-by-the-President-on-Higher$\underline{\text { Education/ }}$

O’Keeffe, P. (2013). A sense of belonging: Improving student retention. College Student Journal, 47(4), 605-613. Retrieved from http://wvu.summon.serialssolutions.com.www.libproxy.wvu.edu/search?s.q=College\%20 retention $\% 20$ initiatives $\% 20$ meeting $\% 20$ the $\% 20$ needs $\% 20$ of $\% 20$ millennial $\% 20$ freshman 
\%20students.\#!/search?ho=t\&q=A\%20sense $\% 20$ of $\% 20$ belonging:\%20Improving\%20stu $\underline{\text { dent } \% 20 \text { retention\&l=en }}$

Oswald, A. J., Proto, E., \& Sgroi, D. (2014). Happiness and productivity. Unpublished manuscript. Department of Economics, University of Warwick, UK, and IZA Boon, Germany.

Pardee, C. F. (2004).Organizational structures for advising. NACADA Clearinghouse of Academic Advising Resources. Retrieved from http://www.nacada.ksu.edu/Resources/Clearinghouse/View$\underline{\text { Articles/Organizational-Models-for-Advising.aspx }}$

Pascarella, E. T. \& Terenzini, P. T. (1991). How college affects students: Findings from twenty years of research. San Francisco, CA: Jossey-Bass.

Pascarella, E. T. \& Terenzini, P. T. (2005). How college affects students volume 2: A third decade of research. San Francisco, CA: Jossey-Bass.

Patrick, J., Furlow, J. W., \& Donovan, S. (1988) Using a comprehensive academic intervention program in the retention of high-risk students. NACADA Journal 8(1), 29-34. doi 10.12930/0271-9517-8.1.29

Patton, M. Q. (2015). Qualitative research \& evaluation methods $\left(4^{\text {th }}\right.$ ed.). Thousand Oaks, CA: Sage.

Pizzolato, J. E. (2008). Advisor, teacher, partner: Using the learning partnerships model to reshape academic advising. About Campus, March-April, 18-25. doi: 10.1002/abc.243

Pryor, J. H., DeAngelo, L., Palucki-Blake, L., Hurtado, S., \& Tran, S. (2011). The American 
freshman: National norms fall 2011 Cooperative Institutional Research Program. 1-78

Retrieved from Higher Education Research Institute at UCLA website:

www.heri.ucla.edu/research-piblications.php

Robbins, S., Allen, J., Casillas, A., Akamigbo, A., Saltonstall, M., Campbell, R.,...Gore, P. (2009). Associations of resource and service utilization, risk levels, and college outcomes. Research in Higher Education, 50(1), 101-18. Retrieved from www.scholar.google.com

Ryan, C. C. (1992). Advising as teaching. NACADA Journal, 12(1), 4-8. Retrieved from http://nacadajournal.org/doi/pdf/10.12930/0271-9517-12.1.4

Sams, W. P., Brown, L. S., Hussey, R. B., \& Leonard, M. J. (2003). The development, implementation, and assessment of a systematic academic advising program for exploratory first-year students. NACADA Journal 23(1 \& 2), 75-85. Retrieved from doi: http://dx.doi.org/10.12930/0271-9517-23.1-2.75

Schein, E. H. (2010). Organizational culture and leadership ( ${ }^{\text {th }}$ ed.). San Francisco, CA: Jossey-Bass.

Self, C. (2008). Advising delivery: Professional advisors, counselors, and other staff. In Gordon, Habley, Grites, and Associates (Eds.), Academic advising: A comprehensive handbook ( $2^{\text {nd }}$ ed.) (pp. 267-278). San Francisco, CA: Jossey-Bass.

Self, C. (2013). Implications of advising personnel of undergraduates 2011 National Survey. NACADA Clearinghouse of Academic Advising Resources. http://www.nacada.ksu.edu/Resources/Clearinghouse/View-Articles/Implications-ofadvising-personnel-of-undergraduates-2011-National-Survey.aspx

Smith, J. S. (2007). Using data to inform decisions: Intrusive faculty advising at a community 
college. Community College Journal of Research \& Practice, 31, 813-831.

http://web.ebscohost.com.www.libproxy.wvu.edu/ehost/pdfviewer/pdfviewer?vid=24\&hi $\underline{\mathrm{d}=9 \& \text { sid=fe5efdba-e5f6-4b3e-bd78-e5609d5a660c\%40sessionmgr10 }}$

Stake, R. E. (2010). Qualitative research: Studying how things work. New York, NY: Guilford.

Thelin, J. R., \& Hirschy, A. S. (2009). College students and the curriculum: The fantastic voyage of higher education, 1636 to the present. NACADA Journal, 29 (2), 9-17. http://www.nacada.ksu.edu/Resources/Clearinghouse/View-Articles/Implications-ofadvising-personnel-of-undergraduates-2011-NationalSurvey.aspx\#sthash.vYvvftWA.dpuf

Tinto, V. (1987). Leaving college. Chicago, IL: University of Chicago Press.

Tinto, V. (1993). Leaving college: Rethinking the causes and cures of student attrition ( $2^{\text {nd }}$ ed). Chicago: Chicago Press.

Tinto, V. (2006). Taking student retention seriously. Maricopa Center for Learning and Instruction, Division of academic and Student Affairs, 1-8. Retrieved from http://www.mcli.dist.maricopa.edu/fsd/c2006/docs/takingretentionseriously.pdf

Titley, R. W., \& Titley, B. S. (1982). Academic advising: The neglected dimension in designs for undergraduate education. Teaching of Psychology, 9, 45-49. Retrieved from http://web.ebscohost.com/ehost/pdfviewer/pdfviewer?hid=113\&sid=57e691f5-89e4441d-b2f7-4f6ea9211aea\%40sessionmgr114\&vid=8

Tontodonato, P. (2006). Goals, expectations, and satisfaction of criminal justice majors: Implications for faculty, students, and programs. Journal of Criminal Justice Education, 17, 162-180.

http://web.ebscohost.com.www.libproxy.wvu.edu/ehost/detail?vid=3\&hid=6\&sid=fe5efd 
$\underline{\text { ba-e } 5 f 6-4 b 3 e-b d 78-}$

e5609d5a660c\%40sessionmgr10\&bdata=JnNpdGU9ZWhvc3QtbGl2ZQ\%3d\%3d\#db=a9 $\underline{\mathrm{h} \& \mathrm{AN}=19761889}$

Trotter, E. \& Roberts, C. A. (2006). Enhancing the early student experience. Higher Education Research \& Development, 25 (4), 371-386. DOI 10.1080/07294360600947368.

Truschel, J. (2008). Does the use of appreciative advising work? Learning Assistance Review, 13 (2), 7-16. Retrieved from http://web.ebscohost.com.www.libproxy.wvu.edu/ehost/results?vid=2\&hid=108\&sid=54 $\underline{\text { a1671f-757b-4710-ba02- }}$ e47701a8a68d\%40sessionmgr112\&bquery=(Does+AND+the+AND+use+AND+of+AN $\underline{\text { D+appreciative+AND+advising+AND+work)\&bdata=JmRiPWVyaWMmdHlwZT0wJn }}$ NpdGU9ZWhvc3QtbGl2ZQ\%3d\%3d

Turner, P. \& Thompson, E. (2014). College retention initiatives meeting the needs of millennial freshman students. College Student Journal, 48(1), 94-104. Retrieved from http://wvu.summon.serialssolutions.com.www.libproxy.wvu.edu/search?s.q=College\%20 retention $\% 20$ initiatives $\% 20$ meeting $\% 20$ the $\% 20$ needs $\% 20$ of $\% 20$ millennial $\% 20$ freshman \%20students.\#!/search?q=College\%20retention\%20initiatives\%20meeting\%20the\%20ne eds $\% 20 \mathrm{of} \% 20$ millennial $\% 20$ freshman $\% 20$ students.

U.S. Department of Education: Institute of Education Sciences: National Center for Educational Statistics (2014). Retrieved from http://nces.ed.gov/programs/coe/indicator_cva.asp Varney, J. (2007). Intrusive advising. The NACADA Clearinghouse of Academic Advising Resources, 30 (3), Retrieved from: http://www.nacada.ksu.edu/aat/nw30_3.htm\#10 Varney, J. (2012, September). Proactive (Intrusive) Advising! Academic Advising Today, 35(3). 
Retrieved from https://www.nacada.ksu.edu/Resources/Academic-Advising$\underline{\text { Today/View-Articles/Intrusive-Advising.aspx }}$

Varney, J. (2013). Proactive advising. In Drake, J. K., Jordan, P., \& Miller, M. A. (Eds.), Academic advising approaches: Strategies that teach students to make the most of college (pp. 137-152). San Francisco, CA: Jossey-Bass.

Wallace, S. (2011). Implications for faculty advising. NACADA Clearinghouse of Academic Advising Resources Retrieved from http://www.nacada.ksu.edu/Resources/Clearinghouse/View-Articles/Implications-forfaculty-advising-2011-National-Survey.aspx

Wirth, R. M. \& Padilla, R. V. (2008). College student success: A qualitative modeling approach. Community College Journal of Research and Practice, 32, 688-711. DOI: $10.1080 / 10668920701380942$.

Yarbrough, D. (2002). The engagement model for effective academic advising with undergraduate college students and student organizations. Journal of Humanistic Counseling, Education, and Development, 41, 61-68. http://web.ebscohost.com/ehost/detail?vid=22\&hid=110\&sid=96bd0bfb-a1c1-4004-af1eeb4690178119\%40sessionmgr113\&bdata=JnNpdGU9ZWhvc3QtbGl2ZQ\%3d\%3d\#db=f $\underline{5 h \& A N=6766258}$

Yin, R. K. (2014). Case study research: Design and methods ( $5^{\text {th }}$ ed.). Thousand Oaks, CA: Sage.

Yin, R. K. (2016). Qualitative research from start to finish ( $2^{\text {nd }}$ ed.). New York, NY: Guilford. Youngmi, K. \& Sherraden, M. (2014). What shapes assessment of ability to pay for children's 
college education? Journal of Consumer Affairs, 48(3), 486-514. doi:

10.1111/joca.12049 


\section{Appendix A}

\section{Interview Questions for Students for first Research Question}

Demographic information related to ethnicity, age, educational background, and occupation is collected for each participant.

Key: $\mathrm{E} / \mathrm{B}=$ Experience and behaviors, $\mathrm{O} / \mathrm{V}=$ opinion and values, $\mathrm{F}=$ feelings, $\mathrm{K}=$ knowledge

1. Research Question1: What are the strategies the CAAP uses with the aim of increasing retention rates?

E/B Could you walk me through a typical advising experience?

$\mathrm{O} / \mathrm{V} \quad$ What is your opinion of the academic advising program?

E/B What types of advising services are available to you?

$\mathrm{O} / \mathrm{V}$ In what ways do you value the academic advising program?

F How do you feel about receiving advising services?

$\mathrm{O} / \mathrm{V}$ In your opinion, what can be done to improve the existing academic advising program?

$\mathrm{O} / \mathrm{V} \quad$ How has academic advising had a valuable impact on your educational experience?

$\mathrm{O} / \mathrm{V}$ In your opinion, what can be done to improve the existing academic advising program?

$\mathrm{K} \quad$ Based on your knowledge, in what ways has the academic advising program been beneficial to other students and the institution?

E/B In what ways has academic advising you with staying in school and persisting to graduation? 


\section{Appendix B \\ Interview Questions for Students for second Research Question}

Demographic information related to ethnicity, age, educational background, and occupation is collected for each participant.

Key: $\mathrm{E} / \mathrm{B}=$ Experience and behaviors, $\mathrm{O} / \mathrm{V}=$ opinion and values, $\mathrm{F}=$ feelings, $\mathrm{K}=$ knowledge

Research Question 2: What are the ways in which the institution has embedded the CAAP into its institutional culture?

Schein's Level 1: Artifacts - Visible and feelable structures and processes

Observed behavior

\section{Questions:}

$\mathrm{K} \quad$ How would you know academic advising services are available?

E/B How would go about accessing academic advising services?

Schein's Level 2: Espoused Beliefs and Values - Ideals, goals, values, aspirations;

Ideologies; and Rationalizations

\section{Questions:}

$\mathrm{O} / \mathrm{V}$ what would students say if they were talking about academic advising amongst themselves?

Schein's Level 3: Basic Underlying Assumptions - Unconscious, taken-for-granted beliefs and values

\section{Questions:}

$\mathrm{O} / \mathrm{V} \quad$ How is the academic advising program valued at you institution?

F How do you feel about academic advising as a requirement? 


\section{Appendix C}

Interview Questions for Academic Advisors (professional, faculty, and administrators) for first Research Question

Demographic information related to ethnicity, age, educational background, and occupation is collected for each participant.

Key: $\mathrm{E} / \mathrm{B}=$ Experience and behaviors, $\mathrm{O} / \mathrm{V}=$ opinion and values, $\mathrm{F}=$ feelings, $\mathrm{K}=$ knowledge

1. Research Question 1: What are the strategies the CAAP uses with the aim of increasing retention rates?

E/B What is a typical day like as an academic advising?

$\mathrm{K} \quad$ What types of advising services do you offer?

$\mathrm{K} \quad$ Which advising styles do you use most often?

$\mathrm{O} / \mathrm{V}$ In your opinion, how is the academic advising program valued?

F How do you feel about academic advising at your institution?

$\mathrm{O} / \mathrm{V} \quad$ In your opinion, how are the advising services useful?

F In what ways do you feel the advising services provided by this institution are worthwhile?

$\mathrm{O} / \mathrm{V}$ In your opinion, what can be done to improve the existing academic advising program?

$\mathrm{K}$ Based on your knowledge, in what ways has the academic advising program been beneficial to the students and the institution?

E/B In what ways has academic advising assisted the student with persisting to graduation (retention)? 


\section{Appendix D}

Interview Questions for Academic Advisors (professional, faculty, and administrators) for Second Research Question

Demographic information related to ethnicity, age, educational background, and occupation is collected for each participant.

Key: $\mathrm{E} / \mathrm{B}=$ Experience and behaviors, $\mathrm{O} / \mathrm{V}=$ opinion and values, $\mathrm{F}=$ feelings, $\mathrm{K}=$ knowledge

Research Question 2: What are the ways in which the institution has embedded the CAAP into its institutional culture?

Schein's Level 1: Artifacts - Visible and feelable structures and processes Observed behavior

Questions:

$\mathrm{K} \quad$ How would a student become aware of academic advising services?

$\mathrm{O} / \mathrm{V}$ What is your opinion of the organizational placement of academic advising within the institution?

Schein's Level 2: Espoused Beliefs and Values - Ideals, goals, values, aspirations; Ideologies; and Rationalizations

Questions:

E/B How would you explain the presence of academic advising?

$\mathrm{O} / \mathrm{V}$ In what ways would you like to see faculty, staff, and administrators exhibit the importance of academic advising at the institution?

Schein's Level 3: Basic Underlying Assumptions - Unconscious, taken-for-granted beliefs and values

\section{Questions:}

$\mathrm{O} / \mathrm{V} \quad$ How is the academic advising program valued at you institution?

$\mathrm{O} / \mathrm{V} \quad$ What makes you think that academic advising is important to the majority? 


\section{Appendix E}

\section{Observation Protocol}

1. Time:

2. Location of advising activity:

3. Description of setting:

4. The activity, event, or non-event:

5. Participant information:

6. Meaning of what was observed from the perspectives of those observed:

Source: Patton, M. Q. (2015). Qualitative research \& evaluation methods (3 ${ }^{\text {rd }}$. ed.) (pp. 144-

145. Thousands Oaks, CA: Sage and Yin, R. K. (2010). Qualitative research from start to finish (p. 262). New York, NY: Guilford. 


\section{Appendix F \\ Informed Consent Script}

Initial Interview Statement:

"Good afternoon. Thank you for agreeing to participate in my study. The goal of my research is to examine the impact of a comprehensive academic advising program on student retention. I would like to record your experiences related to academic advising and student retention. The information gathered will be used for my doctoral dissertation.

I want to point out several things to you before we start:

1. Your participation is entirely voluntary and you do not have to respond to every item or question.

2. Although you previously consented to the interviews being taped, you may request that the recording be stopped at any time.

3. Your responses will remain anonymous and strict confidentiality will be maintained.

4. Any conclusions drawn or analyses made in the study will have no bearing on your Employment, subsequent performance evaluations, or status as a student.

5. You may request a copy of the summary report. The request must be in writing. You may E mail this request to: Heidi B. Samuels at: heidi.samuels@mail.wvu.edu. Thank you, again, for agreeing to participate in this study. 


\section{Appendix G}

\section{Informed Consent Statement of Understanding for Administrator}

\section{DATE:}

$\mathrm{I}$, give my permission for Heidi B. Samuels, doctoral student at West Virginia University, to use data from any interviews pertaining to this study. I understand that this data will be used in a descriptive case study about the impact of a comprehensive academic advising program on student retention. I understand that my name will not appear in the dissertation and that no one other than the researcher will know who participated in the study. I have been assured that my anonymity will be respected.

I also understand that any conclusions drawn or any analyses made in or through this study will have no bearing or effect on subsequent performance evaluations and /or employment. None of these conclusions or analyses will appear in my personnel file at any time.

Signed: Administrator

Signed: Researcher 


\section{Appendix $\mathbf{H}$}

\section{Informed Consent Statement of Understanding for Students}

\section{DATE:}

$\mathrm{I}$, give my permission for Heidi B. Samuels, doctoral student at West Virginia University, to use data from any interviews pertaining to this study. I understand that this data will be used in a descriptive case study about the impact of a comprehensive academic advising program on student retention. I understand that my name will not appear in the dissertation and that no one other than the researcher will know who participated in the study. I have been assured that my anonymity will be respected.

I also understand that any conclusions drawn or any analyses made in or through this study will have no bearing or effect on subsequent performance evaluations and /or employment. None of these conclusions or analyses will appear in my personnel file at any time.

Signed: Student

Signed: Researcher 


\section{Appendix I}

\section{Informed Consent Statement of Understanding for Faculty Academic Advisors}

\section{DATE:}

$\mathrm{I}$, give my permission for Heidi B. Samuels, doctoral student at West Virginia University, to use data from any interviews pertaining to this study. I understand that this data will be used in a descriptive case study about the impact of a comprehensive academic advising program on student retention. I understand that my name will not appear in the dissertation and that no one other than the researcher will know who participated in the study. I have been assured that my anonymity will be respected.

I also understand that any conclusions drawn or any analyses made in or through this study will have no bearing or effect on subsequent performance evaluations and /or employment. None of these conclusions or analyses will appear in my personnel file at any time.

Signed: Faculty Member

Signed: Researcher 


\section{Appendix J}

\section{Informed Consent Statement of Understanding for Professional Advising Staff}

DATE:

$\mathrm{I}$, give my permission for Heidi B. Samuels, doctoral student at West Virginia University, to use data from any interviews pertaining to this study. I understand that this data will be used in a descriptive case study about the impact of a comprehensive academic advising program on student retention. I understand that my name will not appear in the dissertation and that no one other than the researcher will know who participated in the study. I have been assured that my anonymity will be respected.

I also understand that any conclusions drawn or any analyses made in or through this study will have no bearing or effect on subsequent performance evaluations and /or employment. None of these conclusions or analyses will appear in my personnel file at any time.

Signed: Professional Advising Staff

Signed: Researcher 


\title{
Appendix K
}

\section{Interview Cover Letter}

\author{
West Virginia University \\ College of Education and Human Services \\ 355 Oakland Drive \\ P. O. Box 6122 \\ Morgantown, WV 26506-6122 \\ Dear Faculty Member,
}

My name is Heidi Samuels and I am requesting your assistance. I am a student in the Educational Leadership Doctoral Program at West Virginia University. I am currently working on my dissertation with a research emphasis on student retention through comprehensive academic advising programs. The completion of this project is the final step in obtaining my Doctor of Education in Educational Leadership.

This is a qualitative case study where by data will be collected from students, faculty advisors, and administrators. I will be conducting on site interviews and observations at your school. I would like to interview you. Your selection was based on your multiple years of experience with academic advising at your institution. I have attached copies of the interview and observation protocols.

I have taken steps to ensure that the rights, dignity, welfare and privacy of all research participants are protected in my study. The interviews will be taped using an audio recording, stored in a secure area (a locked file cabinet at my personal residence) that only I can access, and I will physically destroy the audio tape upon completion of my dissertation. All individual responses will be kept confidential. Participation in this study is completely voluntary. There will be no penalty for anyone choosing not to participate. During the interview, you do not have to 
answer all of the questions and may quit at any time. Please understand that that any conclusions drawn or analyses made in the study will have no bearing on your employment or subsequent performance evaluations.

To ensure all procedures are followed, the West Virginia University Institutional Review Board (IRB) has acknowledgment of this study on file. I will serve as the Principal Investigator under the direct supervision of Dr. Erin McHenry-Sorber from WVU for this project. Dr. Sorber may be reached at 304-293-2017 or ecmchenrysorber@mail.wvu.edu.

If you have any questions about this project, please contact me at my home phone number. (304-813-1524). In addition, upon completion of this project, I will be glad to send you a copy of the summary report per your request.

Sincerely,

Heidi B. Samuels

Erin McHenry-Sorber, Ph.D.

heidi.samuels@mail.wvu.edu 